\title{
The Isolation and Identification of a-Glucosidase and Lipase Inhibitors from Samoan Plant Extracts
}

\author{
BY \\ Julian Wong Soon
}

\begin{abstract}
A thesis
submitted to the Victoria University of Wellington in fulfilment of the requirements for the degree of Master of Biomedical Science
\end{abstract}

Victoria University of Wellington 


\section{Abstract}

There is a growth in the problems relating to diabetes and obesity within the Pacific region. A recent study found that nearly $20 \%$ of the Samoan population suffer from type 2 diabetes. The same study found that rates of obesity are correspondingly high, at 53\% of the male population and almost $77 \%$ of the female population. Healthcare costs are high, and so this study was initiated to focus specifically on an economical, available and socially acceptable way of introducing anti-diabetic and anti-obesity treatments. Inspired by ethnobotanical interests relating to the unknown potential of plants within the Pacific Island region, a set of five Samoan plants were selected for evaluation of their potential to provide leads for anti-diabetic or anti-obesity treatments. The work presented here was carried out in collaboration with the Scientific Research Organisation of Samoa (SROS) which collected plant samples and provided the extracts used for the present study.

This study focused on the biological activity of the five selected Samoan plant extracts; Myristica fatua, Barringtonia samoensis, Barringtonia asiatica, Annona muricata and Neisosperma oppositifolia against pancreatic lipase and $\alpha$-glucosidase enzymes. The enzyme bioassays were optimised and used to validate and identify potential antidiabetic and anti-obesity treatments from compounds isolated and identified from the samples using LC-MS/MS and NMR spectroscopy.

Two main fractions were carried forward for further fractionation and in vitro bioassay screening; one against lipase and the other against $\alpha$-glucosidase. The known compound threo-dihydroguaiaretic acid was identified and isolated from Myristica fatua having the most potent lipase inhibition whereas a mixture of compounds containing alkaloids and the compound nirathin was obtained from Neisosperma oppositifolia in a fraction that exhibited the highest $\alpha$-glucosidase inhibition. The kinetic modelling of both fractions were used to identify threo-dihydroguaiaretic acid having a mixed inhibition and the compound mixture inhibiting $\alpha$-glucosidase competitively. 


\title{
Acknowledgements
}

\author{
"Motives reveal why we do what we do, \\ which is actually more important to God \\ than what we're doing.” Joyce Meyer
}

Throughout the course of my Masters study, God has always been the primary motivation and has enabled me to endure. He made it possible for me to work with people who have helped and shared their knowledge. I honour Him with all I am and the works of my hands.

Firstly, I'd like to thank my supervisor A. Prof Paul Teesdale-Spittle for being understandable and giving so much of his time. You're an overall amazing person Paul, and you have really helped me improve myself in and out of the lab. I truly appreciate you for you who you are and teaching me about critical thinking. I will always remember and take with me the advice.

Secondly, I also wish to acknowledge the assistance of Dr. Rob Keyzers from the School of Chemical and Physical Sciences. Thank you for giving guidance and mainly helping me with MS data. It played a huge role in the output of my research and my interest in using LC-MS. Your enthusiasm on natural products was always obvious and refreshing to see.

To my colleague and friend Dr. Kenji Sakamoto-san from the Scientific Research Organisation of Samoa and Japan International Cooperation Agency, thank you for the great support. Three years ago we initiated this project which encouraged me to continue in a Master's degree for the sake of scientific development in Samoa. It was a start of an epic journey. Dōmo arigatōgozaimasu.

My appreciation also extends out to PhD students Ethan Wooly and Amira Brackovic from School of Chemical and Physical Sciences. Thank you Ethan for running the NMR spectra and the introduction in using HP20 column. For all the TLC work and also looking out for me in the Chemistry lab, thank you Amira. You were both always helpful with the Chemistry side of my project. 
I would also like to thank all my fellow post-graduate students from the School of Biological Sciences for all their help especially with working in the cell culture lab. Particularly Leticia Castro, Vimal Patel, Richard Little, and Rose Gordon. It was obviously something new to work with but you directed me to the right track. Thank you for assisting with that part of my research.

Thank you also to my friends who have undoubtedly shown so much support towards me, from New Zealand and abroad. It made it bearable when I had a good laugh while there was so much stress and chaos in my mind. You all provided comfort and sanity moments to help me through.

I would like to especially thank my family. Being away from home is always a huge challenge but those phone calls kept me fighting. Thank you mum for your prayers. You've always been my hero and encouraged for me to finish well. Dad, you are the most hardworking person I know, and I look up to you for motivational strength. My oldest sister Agnes who would go far and wide for me. Thank you for being my second mother and closest friend. Your constant messaging meant the world to me and also for visiting me while I was here. For my extended family, you have all played a vital part in this journey. I appreciate each and every one of you. To my boyfriend Tomáš Kudera, my source of calmness and serenity. Thank you for your patience and always walking alongside me despite the distance. I love you and I thank God for you.

Finally, I would like to thank the Chief Executive Officer, Afioga Dr. Seuseu Tauai, Assistant Chief Executive Officer, Dr. Samani Tupufia and management of the Scientific Research Organisation of Samoa for awarding me the Victoria University scholarship and financially supporting me. Also to all the staff members who I have been working with, thank you for keeping in contact and providing the extracts needed for this research.

Thank you, fa'afetai tele lava. Vi'ia le Ali'i. 


\section{Table of Contents}

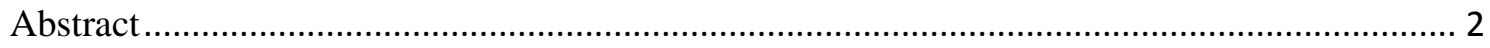

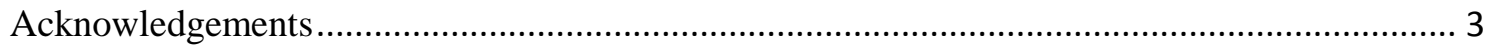

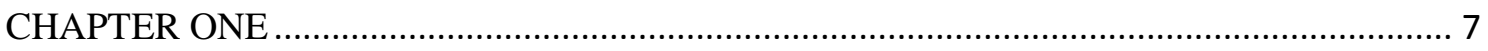

1.1 NATURAL PRODUCTS IN DRUG DISCOVERY ………......................................... 7

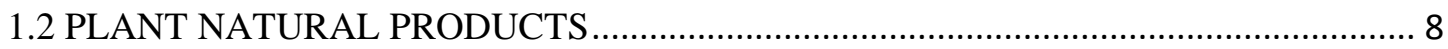

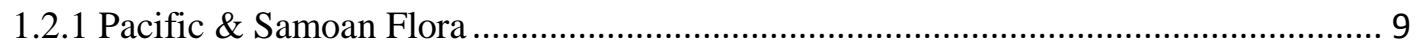

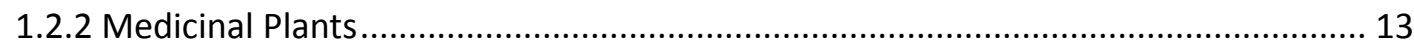

1.3 BIOACTIVE NATURAL PRODUCTS CLASSIFICATION ................................... 14

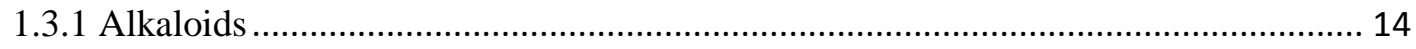

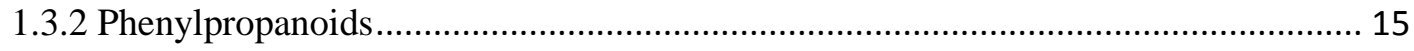

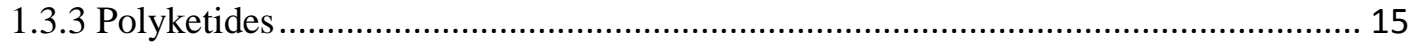

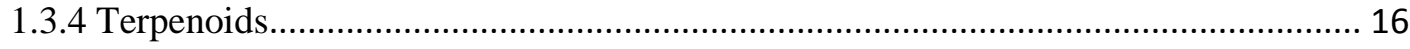

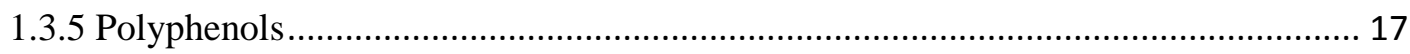

1.4 ISOLATION OF NATURAL PRODUCTS ……….................................................... 17

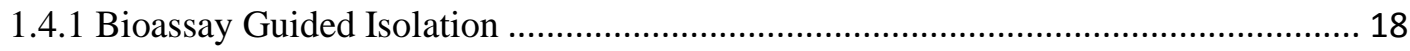

1.4.2 Spectroscopy-Guided Isolation Using LC-MS and NMR..................................... 20

1.4.3 Global Natural Products Social Molecular Networking (GNPS).............................. 22

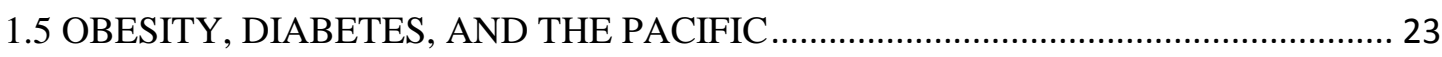

1.5.1 Drug targets for treatment of diabetes and obesity ................................................... 25

1.5.2 $\alpha$-Glucosidase as an antidiabetic enzyme target...................................................... 26

1.5.3 Lipase as an anti-obesity enzyme target................................................................. 28

1.5.4 Other mechanisms of antidiabetic agents............................................................... 29

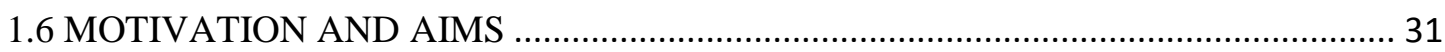

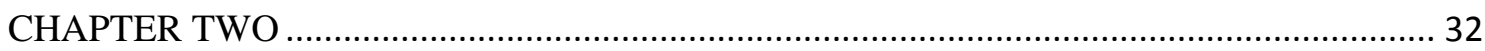

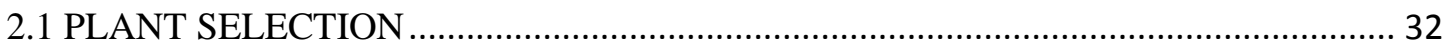

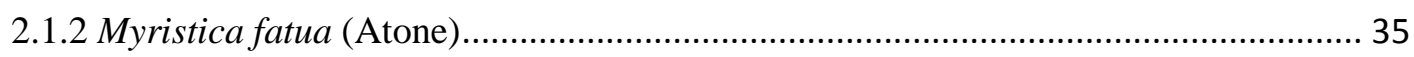

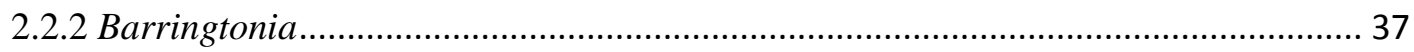

2.3.2 Neisosperma oppositifolia (Fao) .......................................................................... 41

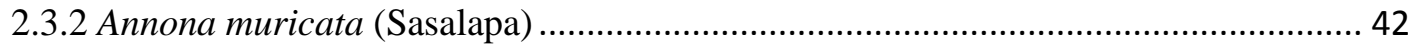

2.3 INTRODUCTION TO $\alpha$-GLUCOSIDASE AND LIPASE BIOASSAYS ........................ 45

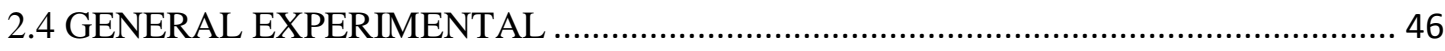

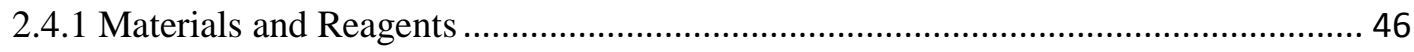

2.4.2 Sample collection and extract preparation ............................................................. 47

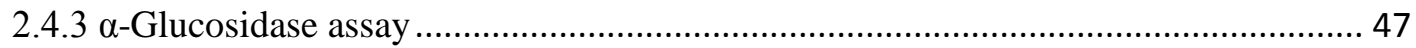




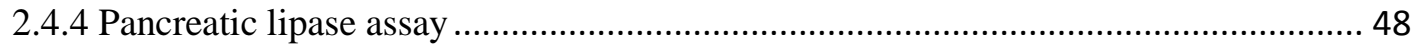

2.4.5 Cyclic Loading and Backloading ............................................................................. 49

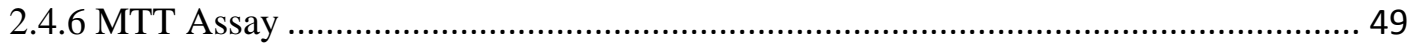

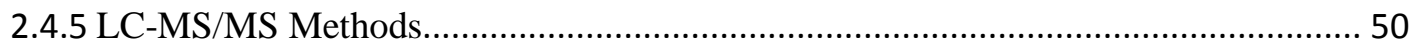

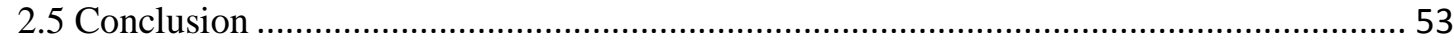

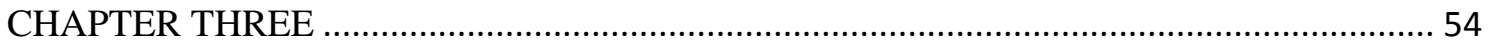

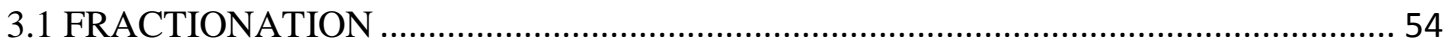

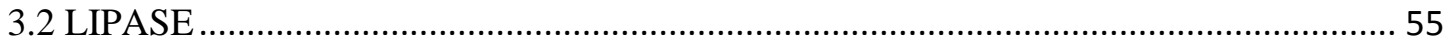

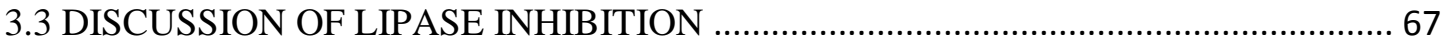

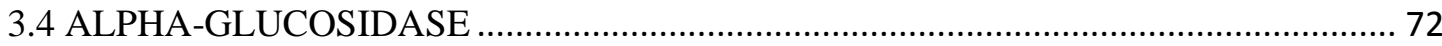

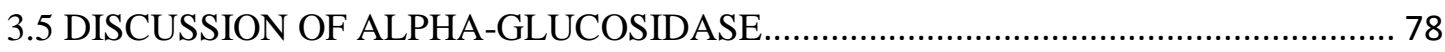

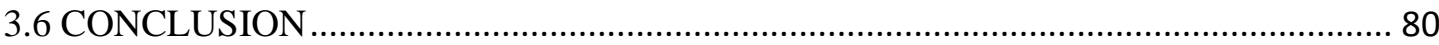

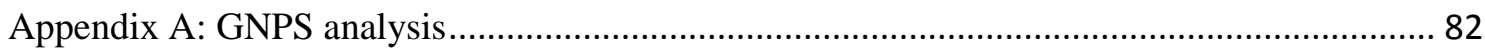

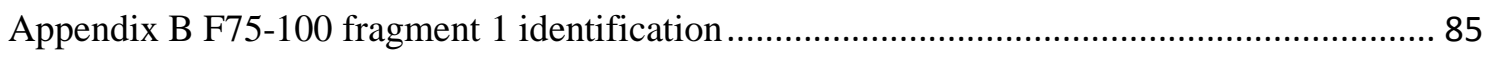

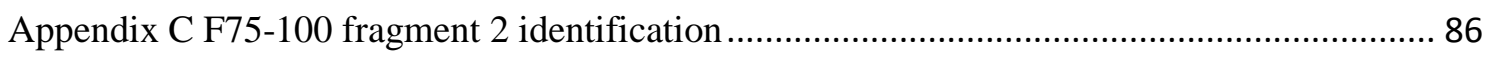

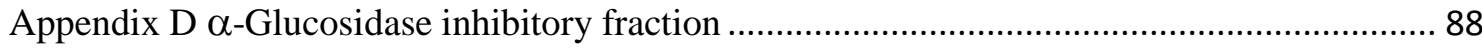

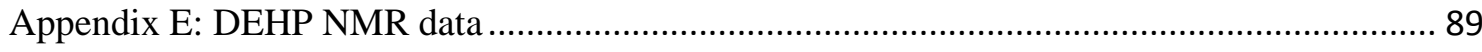

Appendix G NMR spectrum of isolated threo-dihydroguaiaretic acid ......................................... 94

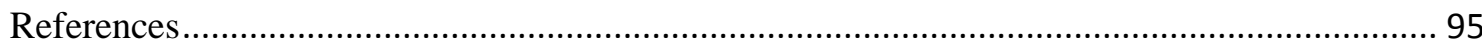




\section{CHAPTER ONE}

\subsection{NATURAL PRODUCTS IN DRUG DISCOVERY}

Natural products are compounds that are produced by living organisms (Ouyang, et al., 2014). They have provided the most successful input into drug discovery (Newman \& Cragg, 2016), showing enhanced structural diversity compared to standard combinatorial chemistry. (Dias, et al., 2012). Ancient records from China, India, ancient Egypt and Mesopotamia show the extended use of plant natural products for the development of medicine (Newman, et al., 2003). There is substantial interest in discovering new natural products or naturally derived drugs since the early isolated compounds marking the 'Golden Age of Antibiotics', such as penicillin (Ganewatta, et al., 2014). Penicillin, a natural product derived from the fungus Penicillium notatum, was discovered and isolated by Fleming in 1929 (Mann, 1994) who was later awarded a Nobel Prize in 1945 in Physiology and Medicine leading to a commercialization of synthetic penicillins and revolutionizing drug discovery research (Dias, et al., 2012).

Natural products research continues to explore the use of novel lead structures as templates for development of new medicines particularly for therapeutic areas such as anti-cancer, anti-hypertensive, anti-infective, immune-suppressive, and agents for neurological diseases (Lahlou, 2013). It still plays an important role in drug development. Between 1981 and 2008, a study of the sources of drugs showed that $63 \%$ of new drugs are classified as naturally derived compounds (Dias, et al., 2012). Naturally derived compounds include those that are natural products, derivatives of natural products, synthetic compounds based on a natural product pharmacophore or synthetic compounds that show competitive inhibition of a natural product substrate (Harvey A. , 2008). Natural products are not often used as drugs in their directly isolated form; they often serve as lead compounds resulting in the development of analogues with optimised pharmacological properties (Newman \& Cragg, 2012)Natural product chemistry can therefore be considered the first step in the journey to finding new, naturally-derived drugs for clinical use. 


\subsection{PLANT NATURAL PRODUCTS}

The world relied heavily on plants in the search for remedies for several centuries (Kong, et al., 2003). Before the "Synthetic Era" in early 1900s, 80\% of all medicines were obtained from leaves, roots and barks which built the foundation for many treatments used today (James, et al., 2007).The earliest record pertaining to medicinal uses of plants is an old Sumerian clay tablet (2600 B.C.) consisting of remedies for various diseases (Kong, et al., 2003). This early work contained 12 recipes for drug preparation and recorded uses for over 250 plants (Petrovska, 2012). In around 2500 BC, the Chinese book about roots and grasses called “Pen T'Sao," written by Emperor Shen Nung presents 365 drug treatments from medicinal plants (Petrovska, 2012). The Greek scholar Pedanius Dioscorides (c 40 - 90 A.D.), considered the "father of western medicine”, compiled the "De Material Medica” which further documents around 600 medicinal plants with their medicinal applications (Byung-Wook, et al., 2013). The historical records of herbal medicine show that initial plant medicines were made into forms such as tinctures, teas, powders, poultices, and other herbal formulations, (Balick \& Cox, 1997) and that such uses date back millennia.

Before the realization that pharmacologically active compounds present in medicinal plants are responsible for their efficacy, the “doctrine of signatures” was often used to identify plants for treating diseases. For example, goldenrod with a yellow hue was used to cure jaundice, red-coloured herbs were used to treat blood diseases, liverworts were used for liver diseases, pileworts for haemorrhoids, and toothworts for toothache (Ramawat \& Merillon, 2008). It was not until the nineteenth century that scientists successfully isolated active components from various medicinal plants (Byung-Wook, et al., 2013). A major breakthrough in natural products discovery occurred in 1806 when the German scientist Friedrich Sertüner isolated morphine from the opium poppy (Papaver somniferum). In particular, the early $19^{\text {th }}$ century was a golden period with the isolation of alkaloids from poppy (1806), ipecacuanha (1817), strychnos (1817), cinchona (1820) and pomegranate (1878). Along with this isolation of alkaloids came the discovery of other active phytochemicals such as tannins, saponins, etheric oils, and vitamins which were also present (Sheikha, 2017). 
Since these findings, other purified plant compounds have been isolated and developed into useful treatments with the use of improved methods: synthetic chemistry and biotechnology (Petrovska, 2012). For example, the antihypertensive agent, reserpine, isolated from Rauwolfia serpentine used in Ayurvedic medicine for the treatment of snakebite and other ailments (Kapoor, 1990); ephedrine, from Ephedra sinica, a traditional Chinese medicine for the synthesis of anti-asthma agents, salbutamol and salmetrol (Buss \& Waigh, 1995) and the well-known vinca alkaloids, vinblastine and vincristine, isolated from Catharanthus roseus (Gueritte \& Fahy, 2005; Roussi, et al., 2012) used for chemotherapeutic treatment (Hlimes, Kersey, Heller-Bettinger, \& Samson, 1976). Moreover, there has been the identification of insulin-supporting activity observed in plants such as Sarcopoterium Spinosum (Smirin, et al., 2010), Nigella Sativa L (Benhaddou-Andaloussi, et al., 2008), Cichorium Intybus (Tousch, et al., 2008), and Momordica Charantia (Yibchok-anun, et al., 2006).

\subsubsection{Pacific \& Samoan Flora}

As the Earth underwent changes over millions of years, the plant species in each of its various environments began to also adapt for survival resulting in a diversity of plant groups (Amaranthus \& Simpson, 2011). This leads to an estimate of 391,000 vascular plant species known to science, 369,000 known flowering plants and 1,065,235 species names with the large numbers of species names accounted for by the fact that many plants have an average of 2.7 names per vascular plant (Royal Botanic Gardens Kew, 2016). As part of this evolutionary journey, geographical isolation can lead to unique evolutionary pressures, which in turn can give rise to equally unique natural products. These can be investigated by natural product chemists seeking to develop improved medicines (Shakya, 2016; Gwynn \& Hylands, 2000)

Living in a region with abundant natural resources, the people of the Pacific have used their knowledge of its traditional plants for cures over hundreds of years (World Health Organisation, 1998). Carrying out natural product research using the extensive collection of plants within island nations such as Samoa will therefore be of great value, not only to Samoa and its neighbouring islands, but potentially across the world, and will build on the development of the cultural knowledge of native species. Most of the 
Pacific island regions however are facing environmental threats to endemic rainforests and hence the urgency of raising understanding of their importance and value within communities. Therefore, this has been the primary objective for government ministries in the natural resources sector.

The Pacific region is made up of 22 different island countries and territories having at least 7,500 islands with only about 500 being inhabited (Haberkorn, 2008). These islands nurture a beautiful diversity of cultural heritage and tradition across the Pacific Ocean. As there are two basic island types existing within the Pacific naming "high islands" and "low islands," there is a wide range of plant life throughout the area (Whistler A. , 1992). The high islands are known to have more variety in flora compared to the low islands, as they have restrictions resulting in flora that comprises mainly drought-resistant species such as coconuts and pandanus (Stanley, 1999). For example, the state of Hawaii, which is the largest Pacific island region, has about 1,392 taxa of which 1,158 are endemic to the state (United States Department of Agriculture, 2010).

Samoa remained isolated from the world until it was reached by a Dutch navigator in 1722 (Whistler A. , 2000). It's latitude and longitude is $13^{\circ} 35$ South and $172^{\circ} 20$ West with its capital Apia on the island of Upolu $13^{\circ} 58$ South and $172^{\circ} 0$ West. The Samoan archipelago lies within the South Pacific Ocean comprising of a chain of volcanic islands divided into two countries as illustrated in Figure 1: American Samoa, one of the American territories since 1900, and Samoa (Kendall, 2011). Samoa consists of two large islands of Upolu and Savai'i which account for 99\% of its total land area of 2934 $\mathrm{km}^{2}$, and eight small islets (Frederic, et al., 2009). Its landscape is known to be very fertile and rich in a variety of flora (Kendall, 2011). It has nearly 500 species of flowering plants and about 200 species of ferns, giving it a wider variety compared to any of the tropical Polynesian islands other than those in the Hawaiian archipelago (Whistler A. , Rainforest Trees of Samoa, 2004). 


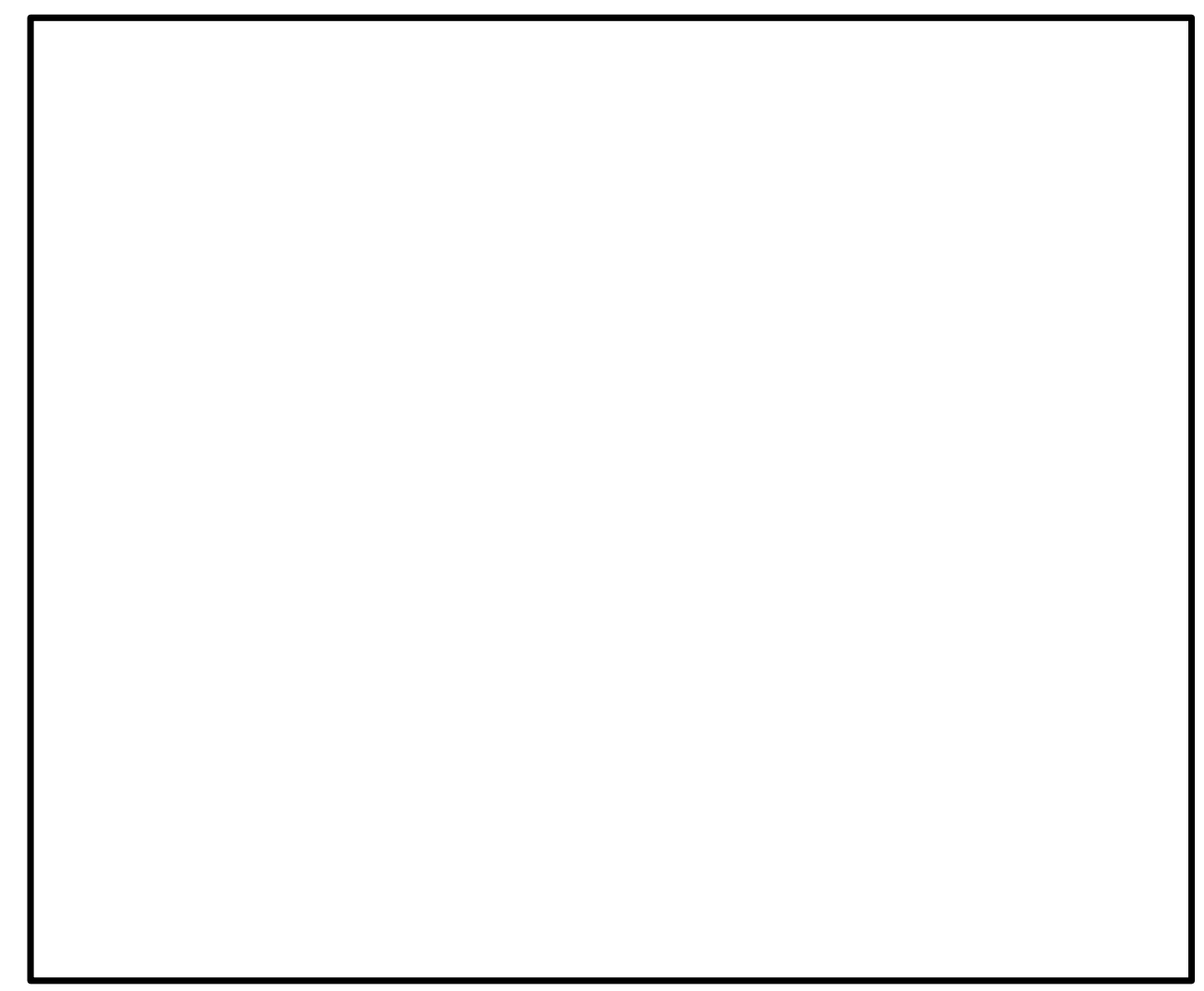

Figure 1 : Map showing the location of American Samoa and the independent islands of Western Samoa (officially known as 'Samoa') in the Pacific Ocean (Owen, 2014) https:/hubpages.com/travel/Odd-World-Time-Zones

Human exploitation of plant species in the Samoa archipelago has resulted in a devastating change to forests and has endangered most endemic species (Whistler A. , 2004). However, Samoa is known to have the second largest variety of native flora in tropical Polynesia (behind Hawai’i) and its largest variety of flowering plant lies within the orchid family Orchidaceae, with approximately 100 species (Cribb \& Whistler, 1996).

The importance of the Pacific region to the search for medicinal uses of plant species was recognised by European ethnobotanists (Whistler A. , 2000). The independent state of Samoa was no exception in the discovery route of the European travellers (Whistler A. , 1996). The discovery and use of plants for medical practices in ancient Polynesia depended on the medical problems that troubled the Polynesians and their beliefs in the causes of such diseases (Whistler A. , 1992). The infrequent occurrence of diseases across the region did not give them enough reason or interest in searching for 
new medicines (Von Kruzeshtern, 1968) until European travellers and missionaries arrived in the Pacific (Whistler A. , 1992).

The observations of those missionaries who served in the Pacific showed evidence towards very few uses of internal medicines, especially in Samoa (Health, 1840). This is due to there being comparatively few cases of serious illnesses and experiences of only minor cuts and wounds from hunting and inter-island warfare (Whistler A. , 1992). However, the migration of travellers to the islands caused a plague of epidemics which took many lives and in return initiated early medicinal practices (Morrison, 1935). The use of specific plants for treatment was later aided by exposure to the study of ethnobotany. The first proper record of Samoan plant species made in the 1800s (Whistler A. , 1992), although the earliest written record of herbal medicine within Polynesia came from a Spanish expedition that made landfall in Fatu Hiva in the Marquesas Islands in 1595 (Whistler A. , 1992). However, these records mainly consisted of uses of plants in the region for the purpose of healing cuts and wounds (Whistler A. , 1992). The more systematic botanical records of the Pacific flora have been made by botanists such as Yuncker in 1959 who wrote about Tongan flora; Smith 1979-1996 who has published a large comprehensive flora about Fiji (International Conservation, 2011), and Whistler in 2004 who published records on Samoan flora (Whistler A. , 2004). As a foreigner, Whistler spoke of his hope for more locals to take up the challenge in expanding his work on endemic Samoan plants with inspiration from his writings:

....a question has been posed indirectly to me several times - how can I, as a palagi (foreigner), write a book about Samoan plants? It is an unfortunate fact that virtually all the written botanical information about the Samoan flora is by foreign scientists rather than by local sources. Although I was not brought up in Samoa, and Samoan is my second language (allowing me to communicate as well as a four-year old Samoan child), I have some advantage in that I am a botanist, I like to write books, and I have a fascination for the flora. I hope that in some way the publication of Rainforest Trees of Samoa and the information it contains may be of interest to others who share my love of plants, and that it may serve to stimulate others who are awaiting the call, so that they may help preserve the trend towards the loss of plants that call Samoa their home." (Whistler A. , 2004) 


\subsubsection{Medicinal Plants}

The early historical use of plants in healing was primarily based on experiences and cultural beliefs (Petrovska, 2012). Traditional medicine can be defined as "the knowledge, skills and practices based on the theories, beliefs and experiences indigenous to different cultures, used in the maintenance of health and in the prevention, diagnosis, improvement or treatment of physical and mental illness” (WHO, 2014). The evolution of traditional practices has resurfaced as interest has grown in the potential for cultural practices to inform modern medicine (Tyler, 1999), with this interest being particularly apparent in Europe and North America (Hosseinzadeh, et al., 2015).

Although traditional medicines are well-established, the application of medicinal herbs continues to meet healthcare needs around the world (WHO, 2014). For example, 40\% of Chinese healthcare comes from traditional medicine and over $90 \%$ of Chinese general hospitals have units for traditional medicine (Sissi \& Iris, 2011). The use of herbs has been recognized to be profitable. For example the European market in 1994 was worth $£ 1.8$ billion (Shaw, 1998) and a survey in 1999 showed 28\% of Canadians were using more than three herbal medicine (Berger, 2001).

Building on the traditional uses of medicinal plant natural products (Dias, Urban, \& Roessner, 2012), modern research procedures provide better understanding of their chemical and biological effects (Harvey A. L., 2015). As pharmaceutical companies have reduced their investment in natural products (Beutler, 2010), ethnobotanists, chemists, and biologists have worked together to develop methods to isolate natural products that have drug-like chemical space (Henkel, et al., 1999). These endeavours have been supported by new approaches in supporting in vivo and in vitro studies to present a platform through which novel compounds can be assessed for drug development. 


\subsection{BIOACTIVE NATURAL PRODUCTS CLASSIFICATION}

Identification and isolation of natural products is not an easy task, especially for natural products that are present at very low concentrations. However, improvements in methodology, instrumentation, databases and software systems are progressively assisting this task.

There are more than 12,000 known natural products (Springob \& Kutchan, 2009). An excellent overview of the main classes of Natural Products by Springbob and Kutchan (2009) shows the inter-relationship between their functions and structures. They discussed the classification of secondary metabolites in plants into four main classes according to their biosynthetic origin: alkaloids, phenylpropanoids, polyketides, and terpenoids (Springob \& Kutchan, 2009).

\subsubsection{Alkaloids}

The alkaloids, typified by the natural product morphine, are a class of plant natural products that contain nitrogen, and are frequently basic in nature, although some are neutral or weakly acid compounds. They are produced by a large variety of organisms such as bacteria and animals but mostly by plants as secondary metabolites. They exhibit a diversity of pharmacological effects (Aniszewki, 2007) and have a long history in the development of natural remedies (Clarke, 1970). Whilst it is convenient to classify compounds into isolated categories, such as alkaloids, it is become increasingly obvious that the boundaries of these categories are not rigid. A number of nitrogencontaining natural products have similarities with the alkaloids (Giweli, et al., 2013; Savithramma, et al., 2011), and a number of compounds classified as alkaloids also fit additional categories. 


\subsubsection{Phenylpropanoids}

Benzoic acid derivatives and phenylpropanoid compounds can be provided by a biosynthetic route known as the shikimate pathway (Springob \& Kutchan, 2009). It was discovered as the route to the aromatic amino acids through the studies of Bernhard Davis and David Sprinson and colleagues which can be explained It in two parts: the shikimate pathway from phosphoenol pyruvate and erythrose-4-phosphate to chorismate, which is common to phenylalanine, tyrosine, and tryptophan biosynthesis, and the three specific terminal pathways that use chorismate as a substrate (Herrmann, 1995). As it is specifically occurring in plants and microorganisms, L-phenylalanine, Ltyrosine, and L-tryptophan are therefore essential for animals and have to be taken up with food. L-Phenylalanine, and in monocots also L-tyrosine, are the precursors of the phenylpropanoids comprising of cinnamic acid derivatives, lignin, lignans, phenylpropenes, and coumarins, which all share the basic C6 -C3 skeleton. Phenyl propanoids are aromatic compounds, often with a hydroxy group in the para position. If two or more hydroxy groups are present on the aromatic ring, the new phenolic function is usually positioned next to the first phenolic group (ortho position).

\subsubsection{Polyketides}

The polyketide natural products exhibit a range of functional and structural diversity, boasting a wealth of medicinally important activities, including antibiotic, anticancer, antifungal, antidiabetic, antiparasitic and immunosuppressive properties. They are known to be synthesized from two-carbon units derived from activated acetate in the form of acetyl-CoA and malonyl-CoA. Recent findings have shown their potential and use in antidiabetic treatment as relevancy to our study. Such findings include the identification of the aromatic polyketide NFAT-133, isolated from strains of Dactylosporangium and Streptomyces showed its efficacy to lower plasma glucose and insulin which is effective if used as an antidiabetic drug (Yang, et al., 2016). Also, the new discovery of two new polyketides, minimoidiones A and B from Preussia minimoides showed significant inhibition of yeast $\alpha$-glucosidase in search of type 2 diabetes treatment (Rangel-Grimaldo, et al., 2017). 


\subsubsection{Terpenoids}

The isoprenoids, or terpenoids make up the largest class of natural products in plants, comprising of over 40,000 different structures. They are derived from five-carbon isoprene units, and according to the number of isoprene molecules incorporated, they can be classified into hemiterpenes $\left(C_{5}\right)$, monoterpenes $\left(C_{10}\right)$, sesquiterpenes $\left(C_{15}\right)$, diterpenes $\left(\mathrm{C}_{20}\right)$, triterpenes $\left(\mathrm{C}_{30}\right)$, tetrapenes $\left(\mathrm{C}_{40}\right)$, and polyterpenes such as rubber (Dewick, 2002).

\subsubsection{Saponins}

As studies have made known that antidiabetic medicinal plants have significant presence of saponins (Osadebe, et al., 2010; Patel, et al., 2012; Gopiesh-khanna \& Kannabiran, 2008), the understanding of their adverse structure is of interest to recent investigation for antidiabetic treatment (Elekofehinti, 2015). Saponins are found mainly in angiosperms and are a class of secondary plant metabolites with diverse biological properties (Ellen, et al., 2007).

Previous studies have discovered that they are primarily found in the roots and rhizomes of various plants and their attachment to a steroid or triterpene gives them the diversity of their biological effects (Drug Discovery, 2007; Kitagawa, 2002; Heng, et al., 2006) foaming and emulsifying properties (Price, et al., 1987), pharmacological and medicinal properties (Attele, Wu, \& Yuan, 1999) haemolytic properties (Oda, et al., 2000; Sparg, et al., 2004) as well as antimicrobial, insecticidal, and molluscicidal activities (Sparg, et al., 2004). Saponins have found wide applications in beverages and confectionery, as well as in cosmetics (Price, et al., 1987; Petit, et al., 1995; Uematsu, et al., 2000) and pharmaceutical products (Sparg, et al., 2004). 


\subsubsection{Polyphenols}

Polyphenols are naturally occurring compounds which can be found in fruits and vegetables. They are generally involved in defence against UV radiation or aggression by pathogens (Kanti \& Syed, 2009). Polyphenolics are characterised by as possessing a number of phenol groups. They have affinity for proteins, primarily through hydrophobic interactions and hydrogen bonding. Of particular relevance to this study, many polyphenolics have been discovered to be active against pancreatic lipase including flavones, flavonols, tannins and chalcones. An interesting study by Sirichai (2010) and colleagues showed that grape seed extract (GSE) includes compounds with inhibitory activity against pancreatic lipase and lipoprotein lipase. As such, these compounds have potential to limit dietary fat absorption and the accumulation of fat in adipose tissue. Accordingly, GSE has been shown to decrease isoproterenol-stimulated lipolysis in 3T3-L1 adipocytes (Adisakwattana, et al., 2010).

\subsection{ISOLATION OF NATURAL PRODUCTS}

The application of plant-derived natural products to modern medicine requires collaborations between botanists, natural product chemists \& pharmacologists to identify and isolate specific, active constituents in plants (Odey, et al., 2012). It is critical for plant material to be prepared in such a way that the desirable therapeutic portions are retained and the inactive material eliminated (Walker, 2006). In the preparation of plants, the isolation of active components within plant tissues relies on the extraction technique to separate the soluble plant metabolites from the insoluble material to attain the desired therapeutical portions and eliminate unwanted material (Sukhde, et al., 2008). This extraction of compounds from their original biological sources (be they from plants, fungi, bacteria, or other sources) is a crucial and frequently underestimated step in qualitative analysis and identification of natural products (Sasidharan, et al., 2011). The difficulties associated with this step arise from the unknown chemistry of the as-yet unidentified natural product, coupled with interference of other compounds in the biological matrix. 
Various methods of extraction have been tested and found to be effective, with approaches including extraction with hot and cold solvents (Balunas \& Kinghorn, 2005; Handa, 2008), ultrasound-assisted extraction (Dhanani, et al., 2017), and supercritical fluid extraction (Azwanida, 2015). The industrial processing of medicinal and aromatic plants are observed to generally follow these extraction methods, but have also developed techniques such as hydro-distillation (water distillation, steam distillation, water and steam distillation), hydrolytic maceration followed by distillation, expression and enfleurage (cold fat extraction) for extraction purposes (Sukhde, et al., 2008). Such extraction processes will enrich for bioactive components, however they rarely deliver pure compounds. Further purification through chromatographic methods are valuable at the laboratory scale for the final purification steps.

Prior to extraction, plant samples are generally pre-washed, dried and subjected to grinding to obtain a homogenous sample. This processing improves the extraction and increases the contact of sample surface with the solvent. Solvents are used to separate small molecule natural products from insoluble, structural plant matter (Sasidharan, et al., 2011). This system largely depends on the specific nature of the bioactive compound being targeted and hence different solvent systems are available to extract the bioactive compounds by using polar solvents such as methanol, ethanol or less polar ones such as ethyl acetate (Cos et al., 2006).

In this work, natural products are to be isolated from plant species native to Samoa. For the purpose of this research, the purification processes used to identify plant bioactive compounds of interest are methanolic extraction followed by hydrophobic chromatography coupled to bioassay guided isolation, assisted by mass spectrometry (MS) and nuclear magnetic resonance (NMR) spectroscopy. A discussion of the advantages and disadvantages of these techniques follows.

\subsubsection{Bioassay Guided Isolation}

A bioassay is any in vitro or in vivo system used to detect the biological activity of an extract or a pure substance (Colegate \& Molyneux, 2008) which is used widely for identifying bioactive compounds and potential leads from natural products (Strömstedt, et al., 2014). In this way, fractions showing bioactivity are identified and thus ensuring 
that active compounds are the target of isolation. This application can also allow for a combination of an in vivo or in vitro model, for example rat paw oedema with studies on the effect of inflammatory enzymes and mediators, providing more information on the activity of isolated compounds supporting the medicinal use of certain plants for inflammatory treatment (Strömstedt, et al., 2014).

Enzyme-based assays are used to identify compounds in a fraction that interact with a drug target, usually a specific enzyme or receptor protein. Although there is a huge advantage of obtaining a single pure compound with a known target and potential mechanism of specific activity, it also has disadvantages. Amongst these are the potential for antagonistic or synergistic effects of compounds in the early stages of fractionation, where each fraction can contain multiple bioactives (Katiyar, et al., 2012). Care also has to be taken to determine whether the finally isolated structure is a natural product, or has been structurally modified as a result of reactions during the isolation process. Other disadvantages include the risk of failure to identify a highly potent bioactive that is present in low concentrations, as it can be masked by the presence of other less bioactive compounds present in higher concentrations (Byung-Wook, et al., 2013).

Following bioassay-guided isolation, cell survival evaluation can be carried out to test for toxicity of bioactives (Ekwall, et al., 1990). This is an excellent way to assess the effects of isolated substances on a cell system, which assists with the discovery of anticancer agents (Burger \& Fiebig, 2014) or to prevent progression of undesirable toxic compounds into further drug development (Colegate \& Molyneux, 2008).

With bioassay guided isolation, the re-discovery of known bioactives, or of compounds that show promiscuous activity against a wide array of targets can become a disadvantage. Compounds of this sort have been referred to as "Pan Assay Interfering Substances" or PAINS, a term that arose from the high-throughput screening world (Baell \& Holloway, 2010; Dutra, et al., 2016). To avoid spending time isolating abundant, widely known compounds or PAINS, it is advantageous to involve techniques such as mass spectrometry and nuclear magnetic resonance (NMR) spectroscopy which will give full or preliminary identification of key compounds in a mixture at an early stage of a bioactivity-guided isolation campaign (Huth, et al., 2005). 


\subsubsection{Spectroscopy-Guided Isolation Using LC-MS and NMR}

Liquid Chromatography Mass Spectroscopy (LC-MS) is widely used to detect compounds within a sample mixture (Bross-Walch, et al., 2005 ). The development of electrospray ionisation (ESI) permitted the concatenation of separation via liquid chromatography and MS, and the resultant LC-MS technique is now widely adopted for clinical, biochemical, and natural product isolation applications (Ho, et al., 2003). The separation capacity of the liquid chromatographic step of an LC-MS assay enhances the identification of components in a mixture using optimised conditions. It is therefore important to evaluate the impact of modifying mobile and stationary phases, as well as any mobile phase gradient used when developing a new assay (Xing, et al., 2007).

Amongst many types of stationary phase that can be used in LC-MS, reverse-phase and the normal-phase media are most commonly applied (Sasidharan, et al., 2011). The moving or 'mobile phase' will hold the more soluble components as the mixture is carried across the column packing material or 'stationary phase' which separates analytes (Wachsmuth, et al., 2013). Reverse-phase chromatography consists of a relatively hydrophobic stationary phase environment which allows for the hydrophobic molecules to adsorb onto it and thus hydrophilic molecules are eluted first (Aguilar, 2004). In contrast to reversed-phase chromatography, normal-phase chromatography has a more polar stationary phase and thus more hydrophobic molecules are eluted first (Rubinson, 2000). A key step in LC-MS assays is optimising the combination of mobile and stationary phases to achieve the most effective separation of constituents of a mixture of analytes.

The coupling of MS to chromatographic separation provides a highly sensitive and a more sensitive and powerful tool for identification of specific natural products compared to other known spectrometry methods (Bouslimani, et al., 2014). Further refinement can be introduced through use of tandem mass spectrometry (MS/MS), through which molecules can be identified not only through their molecular ions but also through characteristic fragment ions (Watson \& Sparkman, 2007). 
LC-MS/MS was used extensively in this study as it could simultaneously reveal the number of major constituents in an extract or sample fraction and provide information to assist in compound identification, (see 1.4.3 Global Natural Products Social Molecular Networking (GNPS) below). In operating mass spectrometry, the ions can be either positively or negatively charged atoms, groups of atoms, or molecules. However, as positive ions are produced in larger number than negative ions (Kang J. , 2012) all LC-MS/MS for this study was carried out using this ion source. LC-MS/MS systems can be used to very selectively detect and quantify targeted analytes for which the mass to charge ratios $(\mathrm{m} / \mathrm{z})$ of both parent and daughter ions are known by filtering for the parent ion in the first MS and detecting only the daughter ion. In other situations, where there is not a known target for detection, the instrument can be set to an automated mode where MS/MS analysis is done on any ions detected in the first MS that meet pre-set criteria. However, where matching of sample results to an MS/MS database is being used as a path for compound identification, it is not uncommon to follow automated LC-MS/MS with a targeted run for each specific species detected. The targeted run allows parameters such as collision energies to be more tightly controlled and optimised for database matching.

For many years, Nuclear Magnetic Resonance (NMR) has been one of the key tools for identifying the structure of novel compounds, such as natural products (Kennett \& Dan, 2007). NMR does not have the exquisite sensitivity of MS. It is thus rarely paired in tandem with liquid chromatography, making it less useful for compound mixtures, and it requires larger amounts of sample for identification purposes than does MS. This disadvantage is offset by the fact NMR is not destructive on the sample and the array of structural information it provides. The ease of use of NMR spectroscopy to probe the chemical environments of every proton and carbon atom in an organic molecule, as well as range of connectivity and structural elements through 2D NMR techniques make it a method of choice for the identification of newly isolated compounds. 


\subsubsection{Global Natural Products Social Molecular Networking (GNPS)}

The purification and isolation processes in this study were followed using LC-MS/MS. In this technique, samples are separated by liquid chromatography and each component is detected through the mass spectrometer. The total ion chromatogram (TIC) reveals the number of compounds in an extract. Compounds can be identified through MS/MS analysis. The MS/MS function results in fragments of a selected ion, and the masses of these fragments is characteristic of the parent ion, and these can be used to identify compounds if these selected ions and fragments can be matched to a suitable database of molecular structural information. In other cases, highly accurate determination of molecular mass can be used to determine a likely molecular formula and confirm molecular identity inferred from other techniques, such as NMR.

GNPS is an internationally available platform created solely for the purpose of sharing and curation of raw, processed or identified tandem mass spectrometry (MS/MS) data. This open access, data-driven network has been developed to allow the natural products community to facilitate identification and matching of compounds of interest present in natural product preparations.

It is an excellent approach built on buried information in MS/MS data sets from research papers and existing databases. The GNPS analysis infrastructure further enables online de-replication, automated molecular networking analysis, and crowdsourced MS/MS spectrum curation. Each data set added to the GNPS repository is automatically re-analysed in the next monthly cycle of continuous identification. Each of these tens of millions of spectra in GNPS data sets is matched to reference spectral libraries to annotate molecules and to discover putative analogues. The number of users reached 9,267 from 100 different countries from January 2014 to November 2015, analysing 42,486 analysis sessions, processing >93 million spectra as molecular networks from a quarter million LC-MS runs (Wang, et al., 2016).

The GNPS libraries, together with publically available libraries MassBank, ReSpect, and NIST (National Institute of Standards and Technology), work as the search and match engines within this global network. Its library of data gathered from the GNPS 
community has grown to include 2,224 MS/MS Spectra of 1,325 compounds from 55 worldwide contributors, which add to its 6,629 reference spectra for 4,243 compounds (Wang, et al., 2016).

For the assurance and accuracy of each output from GNPS, it offers several aspects for the user to utilise and make a decision on the reliability of the matched spectra. In a dereplication or data analysis workflow result, GNPS will normally display columns consisting of the raw spectra of the input MS/MS data-file, the matching spectra from the spectral libraries selected by the user in the workflow, a compound name, a cosine value showing how well the match are the input and library spectra ( 0 as being very unlikely and 1 as being the perfect match), shared peaks from both the input spectra file and the matching spectra, a parameter representing how accurate the match is (the $\mathrm{m} / \mathrm{z}$ error in ppm; the higher the value the more unlikely the match), mass difference between the data file input compound and the match, mass of compound found from within the libraries selected by user, and the ion mode used by GNPS compound contributor (either positive or negative).

\subsection{OBESITY, DIABETES, AND THE PACIFIC}

Obesity is a term given to an excessive amount of adipose tissue storing triacylglycerols, and generally arises from an imbalance in energy intake and energy usage (Sikaris, 2004). Obesity is not measured by a patient's weight alone but rather their Body Mass Index (BMI) (Sikaris, 2004). The World Health Organisation guidelines in 1985 have defined obesity >30.0 for men and >28.6 for women (WHO, Energy and protein requirements, 1985). As reported in statistics from the World Health Organisation, the global impact of obesity includes approximately 2.8 million deaths annually, and 35.8 million disability adjusted life years lost (World Health Organisation, 2016). It is said to be the leading cause of major diseases such as hypertension, coronary heart disease and ischemic stroke (Siewe-Ling, et al., 2014). Of particular importance to this study, the increase rate of obesity globally has become one of the main contributing factors to type 2 diabetes (Cheng-Dong, et al., 2010). The risk 
of diabetes increases by 9\% for each kg gained in self-reported weight (Ford, et al., 1997) and generally starts to increase at a BMI of 22 (Colditz \& Willett, 1990) and is 40 times higher at a BMI over 35 (Hu, et al., 2001; Must, et al., 1999). Diabetes mellitus has affected $2.5-7 \%$ of the total world population (Gurudeeban, et al., 2012) and is highest amongst adults in the Pacific region. For example, the rate is $47 \%$ in American Samoa compared with 13\% in USA mainland (World Health Organisation, 2010). There has been an observed dramatic change in the lifestyle of society worldwide which has played its part in causing unhealthy habits (Sirichai, et al., 2012), which is exacerbated by the difficulties facing small island regions in obtaining affordable medication (World Health Organisation, 2010). A recent overview of the increase of diabetes and obesity in Samoa illustrates the growth in this area. Based on eight surveys from 1978 to 2013, Lin and co-workers showed that the incidence of type 2 diabetes has risen from $1.2 \%$ to $19.6 \%$ in men and $2.2 \%$ to $19.5 \%$ in women. A similar rise was found for obesity, increasing from $27.7 \%$ to $53.1 \%$ in men and from $44.4 \%$ to $76.7 \%$ in women (Lin, et al., 2016).

The rising number of diabetic patients in the Pacific region has caused great concern within local health organizations as "Many amputations are done in Pacific hospitals due to diabetes” according to one Fiji-based spokesperson to the Inter Press Service Agency (March 9, 2017). Local chiefs across the Pacific Islands have encouraged healthier lifestyles and diet in their communities. However external political and social factors have a great impact in this issue especially in small island nations (Foliaki \& Pearce, 2003). Hence, there is a continuous struggle to implement ways to improve on the health state of many Pacific Islands. These problems could be alleviated if local communities were to seek for and establish effective ways of utilising the abundant resources provided for by ethnobotanical studies. 


\subsubsection{Drug targets for treatment of diabetes and obesity}

Diabetes is a metabolic disorder in which there is excess amount of glucose in the blood. This can occur because of the inability of the body to create sufficient of the hormone insulin to appropriately regulate glucose concentrations, or through the development of insulin resistance (American Diabetes Association, 2008). One clear symptom of this failure to produce or respond to insulin is postprandial hyperglycemia. There is no current cure for type 1 diabetes, although it can be managed through insulin injections and diet management (WHO, Global Report on Diabetes, 2016). Type 2 diabetes can be controlled through weight loss and exercise, often supported by pharmacological intervention. It is type 2 diabetes therefore, that has been the focus of those trying to discover new pharmacological approaches to control postprandial hyperglycemia (Puls, et al., 1977).

Diabetes increases the risk of developing various metabolic disorders, including hyperlipidemia, liver-kidney dysfunctions and hypertension (Liu, et al., 2011). One of the therapeutic approaches used to control diabetes and decrease its complications is to retard the absorption of glucose through the inhibition of carbohydrate-hydrolyzing enzymes (such as $\alpha$-glucosidase, $\alpha$-amylase, maltase), and of lipids through inhibition of lipase activity in the intestine (Hamden, et al., 2010; Abel-Mawla, et al., 2011; Hamden, et al., 2011). Enzyme inhibitors; namely molecules having the ability to prevent a reaction being carried forward by enzymes, can carry out inhibition reversibly or irreversibly (Sharma, 2012).

As the global problems of diabetes and obesity increase substantially with the wave of modernised lifestyle, substantial research effort has been directed at developing antiobesity medications. However, some medications have been found to have serious side effects, and therefore had to be withdrawn from the market (Kang \& Park, 2012). For example, the appetite-suppressant drug rimonabant, which functions through regulation of appetitive behaviour, was commercially available in 56 countries since 2006 although it was never approved by the Food and Drug Administration (FDA) (Christensen, et al., 2007). However, rimonabant was suspended by European Medicines Agency (EMA) in 2008 due to associated risks including anxiety, sleep disorders, psychiatric side effects, and depression. 


\subsection{2 $\alpha$-Glucosidase as an antidiabetic enzyme target}

Alpha-glucosidase is produced by intestinal cells and breaks glycosidic bonds in oligosaccharides eventually yielding glucose (Li, et al., 2009). The excess glucose level will result from the production of monosaccharides from the reaction by $\alpha$-glucosidase if insulin is not used appropriately by the body (Soumya \& Srilatha, 2011). Glucose is the main component of starch and is also one of the saccharide subunits of sucrose. Targeting $\alpha$-glucosidase is therefore considered to be an effective approach for treating at least type 2 diabetes (Seo, et al., 2007; Selvaraj G., 2012) and researchers have looked into the possible control of postprandial hyperglycemia by inhibition of both $\alpha-$ glucosidase and $\alpha$-amylase (Sirichai, et al., 2010). This will delay the digestion of carbohydrates to absorbable monosaccharide (Sirichai, et al., 2010) and hence decrease postprandial blood glucose levels from the inhibition of the catalytic activity (Dwek, et al., 2002; Braun, et al., 1995).

In controlling the reaction catalysed by $\alpha$-glucosidase, possible treatment of numerous metabolic disorders and diseases involved in the breakdown of complex carbohydrates to be absorbed by the human body can be developed (Gurudeeban, et al., 2012). The alteration and balancing of the amount of carbohydrates in the system is thus controlled in part by this specific reaction chemistry (Natasha, et al., 2012).

Different phenolic compounds such as flavonoids and anthocyanins have positive effects on diabetes (Nelson-Dooley, et al., 2005). For example, anthocyanins from Ipomoea batatas and Pharbitis nil are effective inhibitors of intestinal $\alpha$-glucosidase (Matsui, et al., 2001) which can reduce glycemia after starch-rich meals. Inhibitory effects of anthocyanins depend on their structure, as their potency as acylated anthocyanins are more effective $\alpha$-glucosidase inhibitors than non-acylated derivatives (Bedekar, et al., 2010). The use of isolated phytochemicals for the treatment of diabetes has been recently reviewed (Firdous, 2014). Two notable examples of this have focused on the inhibition of $\alpha$ - glucosidase. In the first, the in vitro screening of the bulbs of Eleutherine Americana from Yogyakarta, Indonesia yielded three naphthalene compounds: eleutherol, eleutherinoside A and eleuthoside B with $\mathrm{IC}_{50}$ values of $>1.00$ $\mathrm{mM}, 0.50 \mathrm{mM}$ and $>1.00 \mathrm{mM}$ respectively against $\alpha$-glucosidase. However, this study 
concluded that their inhibitory activity was low compared to commercially available glucosidase inhibitors such as acarbose (Tomohiro, et al., 2011). In the second example, Jing and colleagues (2013) isolated two new iridoid glycosides; Ningposide I and Ningposide II along with twelve known iridoid and phenylpropanoid glycosides from the roots of Scrophularia ningpoensis (Hemsi). They obtained the lowest $\mathrm{IC}_{50}$ values of $0.37 \pm 0.01 \mathrm{mM}$ from the compounds isolated in their study using acarbose as the positive control (Hua, et al., 2013).

A phenolic natural product extract called pycnogenol, rich in procyanidins, that has antidiabetic properties can be extracted from the bark of the French maritime pine (Pinus pinaster Aiton, Pinaceae)(Bedekar, et al., 2010). The antidiabetic properties of this water extract are due to its ability to hinder digestive enzyme activity, especially against $\alpha$-glucosidase (Schafer \& Hogger, 2007). From this compound mixture, only $(+)$-catechin and procyanidins are able to inhibit $\alpha$-glucosidase. A dosage of $100 \mathrm{mg} / \mathrm{day}$ for 3 months of pycnogenol in addition to conventional treatment with oral antidiabetic drugs reduced blood glucose levels and improved endothelial function in patients with type 2 diabetes. The reduction in glycemia was dose dependent without increasing insulin secretion (Liu, et al., 2004a; Liu, et al., 2004b).

Other natural origin products having antidiabetic effects are acarbose and miglitol (Jose, et al., 2015). The most widely used digestive enzyme inhibitor for type 2 diabetes is acarbose (from Actinoplanes sp.) that acts on $\alpha$-glucosidase, $\alpha$-amylase, and sucrase, but without insulinotropic properties (Bedekar, et al., 2010; Wehmeier U. , 2003; Wehmeier \& Piepersberg, 2004). Miglitol is a second-generation $\alpha$-glucosidase inhibitor structurally similar to glucose which is derived from the 1-deoxynojirimycin approved by the U.S. FDA in 1996 as an additional therapy to diet alone therapy in patients with type 2 diabetes (Brian, 2007). Voglibose is synthesized from valiolamine, isolated from Streptomyces hydroscopicus subsp. limoneus fermented broth having competitive inhibition against glucoamylase, sucrase, and isomaltase but without activity against $\alpha$ amylases (Matsuo, et al., 1992). It reduces plasma glucose levels and insulin in a dosedependent manner (Bedekar, et al., 2010; Chen, et al., 2006).

As agents which target $\alpha$-glucosidase include extracts from plants, a focus on herbal drug standardization and an in-depth study of sample preparation is crucial to ensure quality safety, and results reproducibility. In tackling this objective, Chawla and co- 
workers (2013) proposed a model in clinical studies, and suggested further studies to guarantee effective herbal drug standardization methodology, as well as a regulatory standard guide for future research.

\subsubsection{Lipase as an anti-obesity enzyme target}

Pancreatic lipase (PL) is said to be the most important enzyme secreted by specific body organs for the digestion of dietary triacylglycerol (Moreno, et al., 2003) and therefore a target enzyme in anti-obesity drug treatment. Another reported enzyme lipoprotein lipase (LPL) is an enzyme responsible for the hydrolysis of triacylglycerol from plasma lipoproteins, mainly chylomicrons and very low-density lipoproteins, and its activity is known to be influenced by nutritional and hormonal status and by environmental conditions. It is a factor that contributes to the development of obesity (Halpern \& Mancini, 2003; Je'quier, 2002).

Inspired by the clinical success of the lipase inhibitor orlistat (Drew, et al., 2007), a number studies have investigated the use of plant natural products and extracts as lipase inhibitors. The review of studies of medicinal plants and their pancreatic lipase (PL) inhibitory activities by Seyedan (2015) and colleagues recorded 1,105 medicinal plants been used for in vitro lipase assay screening. From this screen, 115 medicinal plants showed potential to inhibit PL (Seyedan, et al., 2015). This review also noted the part of the plant from which the bioactive was isolated, where this was recorded in the source publication. In total, PL inhibition was found in 6 different bark solvent extracts, 10 roots extracts, 13 whole fruits, 35 leaf extracts, 5 flowers and the rest from whole plants, seeds and aerial parts (Seyedan, et al., 2015). This distribution of bioactives illustrates the ability to isolate beneficial components from parts of plants that can be renewably harvested (such as leaves, fruit and flowers) or from waste material left over from other uses. The lowest $\mathrm{IC}_{50}$ reported in the summary of medicinal PL-inhibiting plants was $0.05 \pm 0.01 \mu \mathrm{g} / \mathrm{mL}$ from aqueous leaf extract of Bingko biloba (L.) (Adisakwattana, Intrawangso, Hemrid, Chanathong, \& Makynen, 2012), while Aleurites moluccana (L.), Archidendron jiringa (Jack), Averrhoa carambola (L.), and Cynometra caulifrora (L.) showed an impressive 100\% PL inhibition (Ad, et al., 2013). 
Many newly discovered natural products with potential for treatment of obesity could be considered lead compounds for drug development. The most promising of these natural PL inhibitors are going through preclinical investigations; unfortunately none have yet reached clinical stages. One challenge in this phase of study is finding the link between in vitro and in vivo studies, hence more research is needed specifically in this area (Seyedan, et al., 2015).

\subsubsection{Other mechanisms of antidiabetic agents}

Whilst there are clinical successes from inhibiting lipase and $\alpha$-glucosidase, natural products have been shown to have potential benefits in treatment of diabetes and obesity through other approaches. The first medicinal plant described with a clear antidiabetic effect was Galega officinalis (L.) (Fabaceae), which has been prescribed since the Middle Ages to treat diabetes mellitus. From this plant, also called goat's rue, French lilac, or Italian fitch, a guanidine derivative, galegine, was isolated. This compound, whose chemical structure is quite similar to the antidiabetic drug metformin, is responsible for the lowering of blood glucose produced by the plant extract (Bedekar, et al., 2010; Perla \& Jayanty, 2013).

Research by Tabatababaei-Malazy and colleagues discussed five different effects on insulin secretion based on published, in vitro studies. These are; 1. Suppression of oxidative stress; 2. Insulin secretion by insulin-like activity; 3. Increasing viability and proliferation of $\beta$-cells; 4 . Alterations to the ATP/ADP ratio and intracellular $\mathrm{Ca}^{2+}$ concentration; and 5. Inhibition of UCP2 (a mitochondrial carrier protein) (TabatabaeiMalazy, et al., 2012).

A number of plants reviewed in the Tabatabaei-Malazy study showed more than one active component, all of which suppressed oxidative stress (Tabatabaei-Malazy, et al., 2012). This suggested a combined synergistic action involving the improvement of oxidative metabolism. There has been a vast record of antioxidants such as American ginseng (Lin, et al., 2008), Commiphora cukul (Lv, et al., 2008), germinated fenugreek (Dixit, et al., 2008), Rhizoma coptidis (Kim, et al., 2007), and Curcuma longa 
(Meghana, Sanjeev, \& Ramesh, 2007), Pueraria lobata (Xiong, et al., 2006) present in medicinal anti-diabetic plants.

An association has been shown between oxidative stress and occurrence of several diseases, such as cardiovascular, diabetes, and metabolic syndrome (Ballinger, 2005; Muchova J. , 1999; Muchova, et al., 1999). Oxidative stress is a phenomenon associated with the action of free radicals and reactive metabolites in the organism (Abdollahi, et al., 2004). Most antioxidants, be they in the form of endogenous enzymes (e.g. SOD, CAT, GPx) or natural products, protect cells from damage induced by free radicals such as the superoxide anion radical or NO (Durackova, 2008). When NO is produced by catalytic action of iNOS, it can cause a damage to proteins, lipids and DNA either directly or after reaction with superoxide (Knott \& Bossy-Wetzel, 2009). An increased production of free radicals has a central role in development of the complications of diabetes (Rahimi, et al., 2005).

Other mechanisms have direct effects on insulin secretion (Bataille, 2002; Maechler, 2003) include regulation of the ATP/ADP ratio and intracellular $\mathrm{Ca}^{2+}$ concentration (Affourtit \& Brand, 2006; Ashcroft \& Rorsman, 2004). Natural products that influence these include: Angelica hirsutiflora (Leu, et al., 2009), Stevia rebaudiana Bertoni (Abudula, et al., 2008; Abudula, et al., 2004), Korean red ginseng (Kim \& Kim, 2008), Asparagus racemosus (Hannan, et al., Insulin secretory actions of extracts of Asparagus racemosus root in perfused pancreas, isolated islets and clonal pancreatic beta-cells, 2007), Ocium sanctum (Hannan, et al., 2006), and Gardenia jasminoides Ellis (Zhang, et al., 2006).

Studies have shown that increased UCP2 expression in islets can lead to $\beta$-cell dysfunction and development of type 2 diabetes mellitus. Thus, a deficiency of UCP2 can prevent this dysfunction. This mitochondrial protein has been recorded to have negative effects on glucose-stimulated insulin secretion (Chan, et al., 2001). Compounds extracted from several medicinal plants, such as Gardenia jasminoides Ellis (Zhang, et al., 2006) markedly suppress UCP2. 


\subsection{MOTIVATION AND AIMS}

Whilst Whistler's focus was on the plants themselves, his inspirational writing also provides motivation for the evaluation of the uses of Samoan plans. Inspired by this, the Scientific Research Organisation of Samoa (SROS) initiated a project to evaluate the uses of various plant species found on the Samoan archipelago, which includes their application to pressing health challenges such as obesity and diabetes. The use of natural medicines for obesity and diabetes across Asia and India based on knowledge of traditional medicine from plant extracts provided further motivation for the study (Manisha, et al., 2007). Discovery of new lead compounds or natural medicines for obesity and diabetes from an endemic Pacific plant would be of great value, and initiate of a journey towards dealing with the increase of these disorders using locally available resources within the Polynesian region.

This project aims to isolate components from Samoan plant extracts that have ability to inhibit lipase and $\alpha$-glucosidase activities, which are proven targets in the treatment of obesity and diabetes respectively. In achieving this aim, crude Samoan plant extracts were selected for fractionation which will be assessed by monitoring their inhibition of target enzymes and components will be mass specified.

This study concentrated on the following objectives as guidelines towards succeeding its aim.

- Identification of plants with bioactive compounds.

- Develop and optimise bioassay for $\alpha$-glucosidase and lipase enzyme inhibition.

- Initial fractionation of plant extracts used in screening of inhibition against target enzymes to identify specific fractions with promising activity.

- Sub-fractionation of selected fractions and purification to homogeneity.

- Identification of active compounds by using LC-MS/MS and NMR techniques.

- Obtain $\mathrm{IC}_{50}$ values for each active fraction or isolated compound against its target enzyme.

- Analysis of kinetics to confirm selectivity and potential for further development by assessing inhibition against the non-target enzyme

- Evaluation of the impact of active components on cell survival. 


\section{CHAPTER TWO}

The aim of this project is to isolate components from Samoan plant extracts that have ability to inhibit lipase and $\alpha$-glucosidase enzymes. The first steps in achieving this aim are to identify which Samoan plants will be used in the study and to establish the bioassays in a format suitable for screening extracts. Work to meet these objectives is presented in this chapter.

\subsection{PLANT SELECTION}

Four sites were chosen for collection of plant material by Scientific Research Organisation of Samoa (SROS) and Executive Consultant from the Japan International Cooperation Agency (JICA) Dr. Kenji Sakamoto-san. Plant samples were mainly collected from the Vailima Botanical Garden (Figure 2), although a small number of other species were collected from rainforests at Togitogiga falls, Afulilo dam, Vailele coastal reef, and around the SROS compound, shown on the map of the main island of Upolu labelled in Samoa (Figure 2). These locations were specifically chosen due to the different plant species found in the various sites. A total of 215 plants were sampled, transported, prepared, and extracted in methanol in the Environment \& Renewable Energy Division laboratory in SROS. The five plants selected were based on their abundance on the main island of the independent state of Samoa, uses as traditional medicine on a global scale and also preliminary results obtained from $\alpha$-glucosidase and lipase activity carried out by colleagues from the Environment and Renewable Energy Division of SROS. Upon discussion between both parties, SROS and consultant Dr. Sakamoto-san selected Neiososperma oppositifolium, Myristica fatua, Barringtonia samoensis, Annona muricata, and Barringtonia asiatica from the plant species collected for the investigation in this study. 
Figure 2: Vailima Botanical Garden (Ifieleele Plantation, 2014)

http://www.ifieleele.com/

Figure 3 : Sample sites

The identification and names for Samoan plants originated mainly from works carried out in the $19^{\text {th }}-20^{\text {th }}$ centuries from Reinecke (1896,), Pratt (1911), Setchell (1924), Christophersen (1935, 1938), and Yuncker (1945) (Whistler A. , A Study of the Rare Plants of American Samoa, 1998). As Samoa's flora mainly consists of angiosperms, the selected plant species are all in this plant group. Angiosperms, the seed-producing vascular flowering plants, are found in almost every habitat; from the forests and 
grasslands to the sea margins and desserts (The Angiosperm Phylogeny Group, 2016). They are known to be the most diverse extant plant group on the planet with at least 260,000 living species classified in 453 families (Pamela \& Douglas, 2004). The selected plants all have characteristics of dicotyledons: plants with two cotyledons associated with their seed (Robert, 1980), stem holding vascular bundles arranged in a ring structure (Willis \& McElwain, 2014) and flowering parts in fours, fives or multiples thereof (Robert, 1980).

Barringtonia samoensis and Barringtonia asiatica are both from the family Lecythidaceae. However all other selected plants are from different families, as shown in Table 1. All of the samples have been carefully evaluated according to previous records and their uses as traditional medicine throughout the Pacific region and also South East Asia. Species of the genus of Barringtonia are commonly found in South East Asian countries, however there are just a limited number of species present in Samoa.

Table 1: Plant Kingdom Classification

\begin{tabular}{|c|c|c|c|}
\hline Species & Genus & Family & Order \\
\hline Myristica fatua (Atone) & Myristica & Myristicaeae & \\
\hline $\begin{array}{ll}\text { Annona muricata } \\
\text { (Sasalapa) }\end{array}$ & Annona & Annonaceae & Magnoliales \\
\hline $\begin{array}{l}\text { Neisosperma oppositifolia } \\
\text { (Fao) }\end{array}$ & Neisosperma & Apocynaceae & Gentionale \\
\hline $\begin{array}{l}\text { Barringtonia samoensis } \\
\text { (Falaga) }\end{array}$ & \multirow{2}{*}{ Barringtonia } & \multirow{2}{*}{ Lecythidaceae } & \multirow{2}{*}{ Ericales } \\
\hline $\begin{array}{l}\text { Barringtonia asiatica } \\
\text { (Futu) }\end{array}$ & & & \\
\hline
\end{tabular}




\subsubsection{Myristica fatua (Atone)}

The 'Wild Nutmeg' (Myristica fatua) is closely related to the species Myristica fragrans; an evergreen dioecious tree, known as the 'nutmeg' which is native to the Molucca islands of Indonesia and is also now cultivated in Grenada (Iyer, 2007). Myristica fragrans yields the spices nutmeg (endosperm) and mace (the reddish aril), which are highly coveted for their aromatic, culinary and medicinal properties. Constituents of nutmeg are found in several cosmetics and are used in traditional medical practice in Indonesia for the treatment of ailments ranging from nervous to digestive disorders (Van-Gils \& Cox, 1994). Although it is not in use in Western medical practice, there are reports which suggest nutmeg may have a number of useful properties, including value in the treatment of Helicobacter pylori infections (Mahady, et al., 2005), anti-proliferative effects (Lee, et al., 2006), anti-oxidant activity (Sen, et al., 2010), hepatoprotective effects (Morita, et al., 2003) and neuroprotective activity (Ban, et al., 2004). These effects reveal a wide scope for its application in the health sector.

Whilst Myristica fragrans is of very limited geographical distribution owing to its characteristic ecological requirements, the fruits of Myristica fatua (Samoan name: 'Atone), used in this study as shown in Figure 4 were collected from the Vailima Botanical garden. It is a plant known as the "food for pigeons" on the island as Samoans usually feed pigeons with the 'Atone fruit (Whistler A. , 2011), or to be precise the aril around the seed. Its branches are mainly utilised as firewood, house posts, and for making carved artefacts which are sold in local markets and at special tourist festivals (Whistler A. , 2000). It is found commonly in lowland to montane forest and is an indigenous nutmeg tree often dominant in the sub-canopy species. There are exactly three Myristica species found within the Samoan archipelago naming; 'Atone, 'Atone Palagi, and 'Atone 'Ulu; scientifically called, Myristica fatua, Myristica fragrans, and Myristica hypargyraea respectively (Whistler A. , 2004). Myristica fatua, however, is viewed as an underutilized crop in the Independent State of Samoa, being less desirable for cooking than Myristica fragrans. 
Other uses of Myristica since the Middle Ages have included stimulant, carminative, as well as treatments for intestinal catarrh and colic, to stimulate appetite, and it has a reputation as an emmenagogue and abortifacient (Min, et al., 2011). Its essential oil is known to possess analgesic and anti-inflammatory properties (Santos, et al., 1997; Olajide, et al., 1999) while research from known compounds isolated from the seeds of Myristica fragrans have been reported to possess strong platelet anti-aggregation activity (Venton, et al., 1991; Somani \& Singhai, 2008). Crude extracts of nutmeg have been reported to have anti Helicobacter pylori activity, inhibit tyrosine phosphatase 1B (Bhamarapravati, et al., 2006) and acetylcholine esterase (Cuong, et al., 2014) as well as having an anti-diarrheal activity (Grover, et al., 2002).

Using solvent extractions and mass spectrometry, Rani and colleagues (2014) established that the seeds of Myristica fragrans contain a wide variety of natural products, including alkaloids, flavonoids, phenolics, phlobatannins quinones and terpenoids.

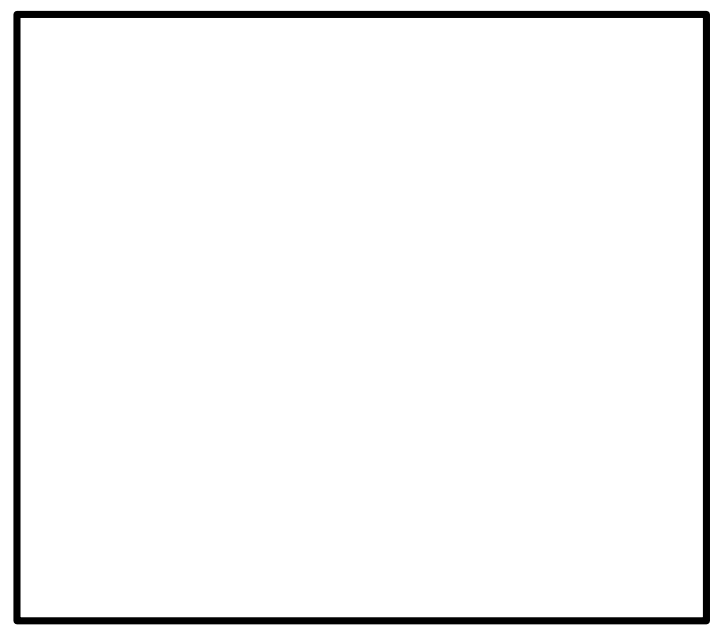

Figure 4: Myristica fragrans fruit (Herbalife, 2015)

It is distinguishable with its medium size, watery red sap, and described by Whistler to have "leathery leaves golden-green beneath; small axillary, unisexual flowers; and large, tan-coloured, ellipsoid drupe containing a large seed surrounded by a red aril.” (Whistler A. , 2004). There are no medicinal uses recorded across the Pacific region for Myristica fatua but members of the family of Myristica have been used extensively for medicinal purposes in South India (Renu, et al., 2016).

As mentioned in previous studies, there is a great interest in the application of the species of Myristica in the health sector from evidence supporting their benefits in 
medicine. However, although much work has been undertaken on the nutmeg seed and its aril there has been limited research on isolation and bioactivity of compounds from the soft parts of their fruits.

\subsubsection{Barringtonia}

Barringtonia, a genus within the family of Lethydiceae consists of 69 recognised species (Prance, 2012) and is distributed mainly in the Malesian and Pacific regions but also in South East Asia and Australia. Within the Pacific, Barringtonia is known to be most abundant in the New Guinea having several of its species. The three most widespread species, Barringtonia acutangula, Barringtonia asiatica, and Barringtonia racemosa are found near rivers, lakes and other inundated areas.

The fruit and bark of many species are used for fish poisons which is a common practise in the Pacific region due to the presence of saponins (Musman, 2010; Mills, et al., 2005). Although the majority of species contain saponins, there are three species with edible seeds most commonly known as cutnuts: Barringtonia novae-hiberniae, Barringtonia procera and Barringtonia edulis (Prance, 2012). The two species known to extend from the Pacific to East Africa are Barringtonia asiatica and Barringtonia racemosa. Only two species of Barringtonia are found in Samoa, Barringtonia asiatica and Barringtonia samoensis (Prance, 2012).

There have been several studies carried out on the bioactivity of the species Barringtonia asiatica and Barringtonia acutangula mainly found in India due to their recognized use in folklore medicine within the region for treatment of wounds, cuts and burns (Sumalatha, et al., 2011). Barringtonia acutangula known as the "Indian Oak" or "Samutraphalam tree" is shown in Figure 5. It has been reported to be used for treatment of diabetes across the peninsula of India. It also has other traditional medicine purposes such as many ailments including treatments for hemolytic disease (various diseases of blood), abdominal colic, lumbar pain, syphilis, blennorrhoea, fever and malaria (Maninderjit, et al., 2013). 


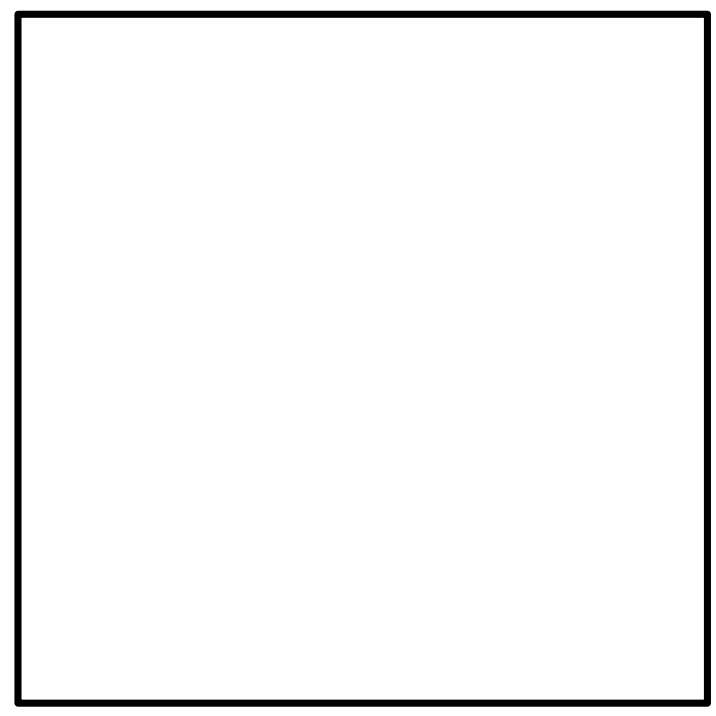

Figure 5: Barringtonia acutangula (World of Flowering Plants, 2017)

The leaves of Barringtonia acutangula were reported to possess steroidal compounds such as barringtogenic acid, tangulic and acutangulic acids while the fruits yielded saponins based on barringtogenol B, C and D (Wealth of India Division, 2000). The leaf extract was screened for in vitro antibacterial potential in petroleum ether, ethyl acetate and ethanol against Pseudomonas aeruginosa, Klebsiella pneumonia, Salmonella typhi and Salmonella paratyphi by Padmavathi and colleagues (Padmavathi, et al., 2012). The use of extracts of Barringtonia acutangula as antioxidants has been studied. An orally delivered aqueous ethanolic extract of Barringtonia acutangula Linn root revealed that levels of the hepatic antioxidant enzymes specifically catalase, glutathione peroxidase and superoxide dismutase are significantly decreased in streptozotocininduced diabetic rats with a high degree of lipid peroxidation at both test doses (250 $\mathrm{mg} / \mathrm{kg}$ and $500 \mathrm{mg} / \mathrm{kg}$ ) (Babre, et al., 2010). Also a methanolic extract of the leaves of Barringtonia acutangula showed promising potential in in vitro antioxidant assays assessing radical scavenging and reducing power activity (Kathirvel \& Sujatha, 2012). Studies from Malaysia focused mainly on Barringtonia racemosa in the hunt for proof of their anti-oxidant and anti-inflammatory bioactivity as measured by inhibition of nitric oxide production. Exploration of the non-polar fractions of extracts of the leaves of Barringtonia racemosa showed high nitric oxide inhibitory and antioxidant activity (Behbahaniet al., 2007). The results from this study shows that the chloroform extract of Barringtonia racemosa had the highest activity, followed by the hexane extract and ethanol extract using the ferric thiocyanate method. 
One study showed the presence of a major antioxidant, lycopene. It is a known compound in a range of fresh fruits and vegetables that protects organisms against damage from free radicals and singlet oxygen reactive species (Behbahani, et al., 2007). The fruit and seeds of Barringtonia racemosa are used to treat asthma, cough, abscess, ulcer, and diarrhoea in the region of Malaysia in which this study was carried out (Amran, et al., 2016). A study with mice showed lycopene having excellent antiinflammatory/antioxidant properties (Zhao, et al., 2003). Other studies showed the presence of phenolic, and flavonoid compounds which may contribute to the antioxidant and cytotoxic activity of the species (Amran, et al., 2016).

There has been interest in the use of the bark of Barringtonia asiatica which was analysed by Sumalantha (2011) and colleagues. They concluded that treating wounds with the powdered extract from the bark of Barringtonia asiatica has the ability to accelerate the healing process. The results also suggest that treatment with an alcoholic extract of Barringtonia asiatica may have a beneficial influence on the various phases of wound healing like epithelialization, collagen synthesis, and wound contraction, resulting in faster healing. The wound healing potential of the Barringtonia asiatica extract may be as a result of the presence of a mixture of constituents including flavonoids and tannins (Sumalatha, et al., 2011).

There is a record of activity from Baringtonia species in studies directly relevant to diabetes and obesity. A study by Gowri and colleagues (2007) isolated and identified the major compound bartogenic acid from Barringtonia racemosa seeds (Gowri, et al., 2007) having inhibition against $\alpha$-glucosidase. Other studies carried out specifically targeting anti-diabetic activity of another close related species, Barringtonia acutangula supported their extend use in traditional medicine. A previous study reported antidiabetic activity from ethanolic root extracts of the species on streptozotocin-induced diabetic rats (Babre, et al., 2010) while others specified how its aqueous leaf extracts relieved diabetic symptoms, including reductions in blood glucose and triglycerides, in the same animal model (Gregory, et al., 2014). Barringtonia acutangula extracts have also been assessed for their hypoglycemic activity. Aqueous, methanol and chloroform extracts of Barringtonia acutangula fruit were evaluated for hypoglycemic effects in rats subjected to the oral glucose tolerance test and in streptozotocin-induced hyperglycemic rats. The aqueous extract of Barringtonia acutangula whole fruit at a 
dose of $400 \mathrm{mg} / \mathrm{kg}$ b.w/p.o showed significant antihyperglycemic action (Khatib \& Patil, 2011). In another study, oral treatments with a crude aqueous ethanolic extract from roots of Barringtonia acutangula at 250 and $500 \mathrm{mg} / \mathrm{kg}$ b.w/p.o were found to reduce the blood glucose levels, significantly in both normal and glucose fed hyperglycemic rats (Babre, et al., 2010).

\subsubsection{Barringtonia asiatica (Futu)}

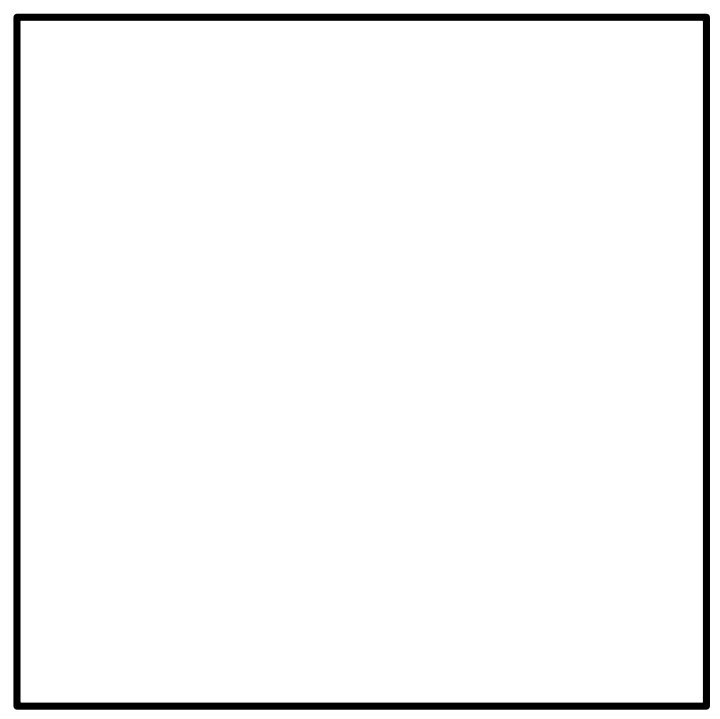

Figure 6: Barringtonia asiatica (Higher Plants \& Ferns of National Park of American Samoa)

Barringtonia asiatica, collected from the Vailima Botanical garden is known for its traditional use for treatment of skin sores (Whistler A. , 2000). In traditional Samoan medicine, its fruit or bark is also used to treat yaws, the seed to treat ringworm and the bark is used in treating tuberculosis. In the Solomon Islands and Samoa, it is used to stun fish (Gorre, Bhikku, Nagulu, \& Rani, 1984) and the wood is sometimes used to make parts of canoes (Whistler A. , 2000). These activities are likely to arise from the phytochemicals found in the extracts of Barringtonia asiatica, which include alkaloids, flavonoids, carbohydrates, glycosides, tannins, terpeniods, and phenols (Gorre, et al., 1984), however no specific compounds isolated from this plant have been reported. 
Whilst there is promising research on the use of extracts of Barringtonia acutangula for control of diabetes, there is comparatively little work done in this area with Barringtonia asiatica and Barringtonia samoensis. Although bartogenic acid isolated from Barringtonia racemosa has been shown to inhibit $\alpha$-glucosidase, there are no records of assessment of isolated compounds from the species chosen for this study (Barringtonia asiatica and Barringtonia samoensis) on the activity of pancreatic lipase and $\alpha$-glucosidase.

\subsubsection{Neisosperma oppositifolia (Fao)}

Neisosperma oppositifolia, (Samoan name: Fao) is a medium-sized indigenous tree uncommon in littoral forest, but locally common on the Aleipata Islands (Whistler A. , 2000). The Aleipata Islands consists of four small islands (totalling about $1.7 \mathrm{~km}^{2}$ ) located off the eastern coast of the main island of Upolu, Western Samoa (Whistler A. , 1984). Whistler states that there has been no recorded use for this particular plant in Western Samoa but it was used in a later study in Malaysia searching for new bioactive compounds with a particular interest in identifying indoles, indolines and bisindolines and developing new synthetic methodology for their construction (Kartini, et al., 2010). The richness of the variety of flora in Malaysia gives it great opportunity for discovery of new bioactive compounds. Thus, PhD graduate and author Kartini Ahmad from University of Malaya, focused on the study of alkaloids from the bark of Neisosperma oppositifolia and Kopsia singapurensis.

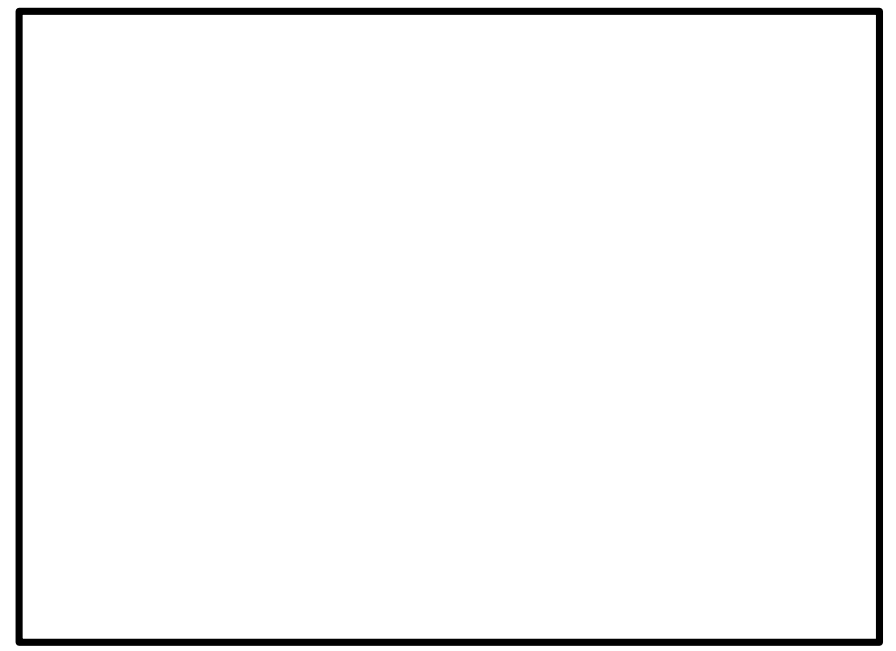

Figure 7: Neisosperma oppositifolia (Discover Cousin Island National Reserve) 
The genus Neisosperma which was later classified into the same genus as Ochrosia (David \& Jean-Francois, 2011) has 43 accepted species (The Plant List, 2010). The species collected in this study, Neisosperma oppotifolia, is closely related to the one found in Malaysia. The plant usually grows to a maximum height of $15 \mathrm{~m}$, produces five-petalled white flowers, and the fruits are elliptical and come in pairs. Its bark is used mainly for treatment of diabetes in Malaysia (Kartini, 2009), its stem for firewood, a mixture of 3 green and 3 yellow leaves in coconut kernel and water have been used to provide a therapeutic bath for treating sores from arthritis and its fragrant flowers are used for perfumes and deodorant (Kartini, 2009).

The selection of Neisosperma oppotifolia for this study was based on its traditional use to treat diabetes in Malaysia. As there is absence of studies attributing this activity to particular compounds or biomolecular targets, it was considered to be an important part of our objectives.

\subsubsection{Annona muricata (Sasalapa)}

Annona muricata (Figure 8) is given the Samoan name Sasalapa and producing a fruit that is known as soursop. It was introduced in the Pacific as a fruit tree over a century ago. It grows to heights of 5-9 m with low branches (Love \& Paull, 2011) with alternating leaves, and 3-merous flowers, sepals and fleshy petals, and greenish in colour (Morton, 1987). Its fruit has a heart or oval shape and can range in size range up to about $30 \mathrm{~cm}$ in length (Love \& Paull, 2011). The mesocarp is a somewhat fibrous juicy sweet-sour flesh surrounding several large smooth black seeds. The fruit is usually available all year round (World Health Organisation , 1998).

Folk medicine from parts of Africa and South America have extensively used the leaves of Annona muricata for anticancer, anticonvulsant, anti-arthritic, antiparasitic, antimalarial, hepatoprotective and antidiabetic activities (Soheil, et al., 2015). 


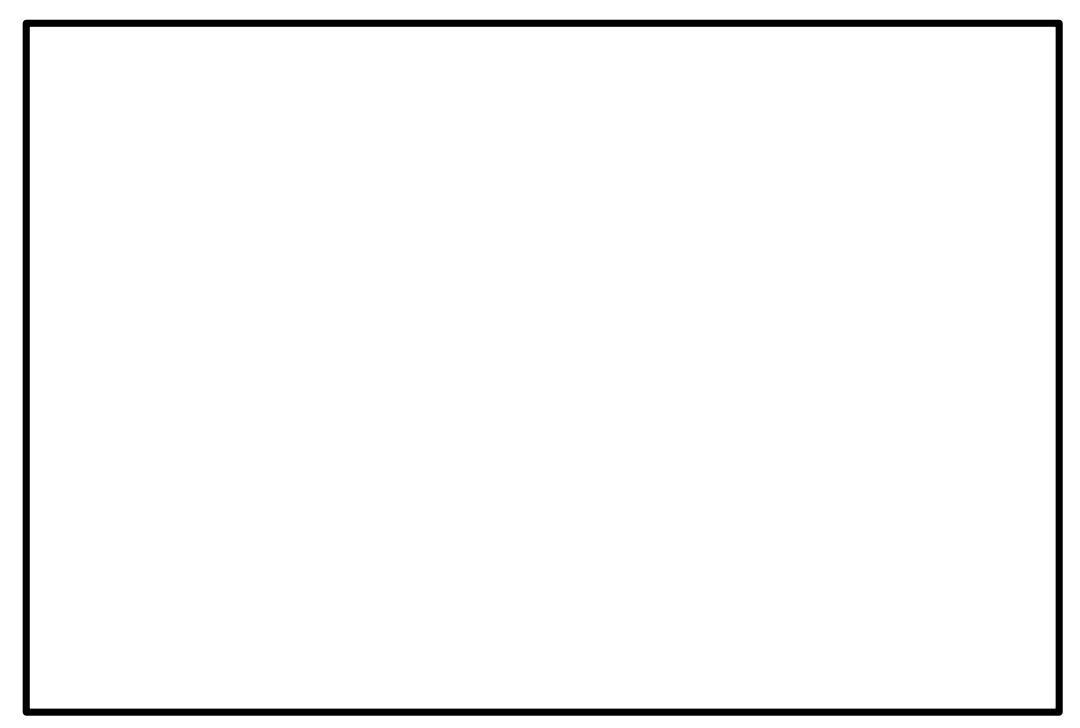

Figure 8: Annona muricata (HandPicked, 2017)

There has been extensive research on different parts of Annona muricata showing the presence of numerous compounds, including alkaloids (Leboeuf, et al., 1980; Yang, et al., 2015), megastigmanes (MGs) (Matsushige, et al., 2012) flavonol triglycosides (FTGs) (Nawwar, et al., 2012), phenolics (Jiménez, et al., 2014), cyclopeptides and essential oils (Pélissier, et al., 1994; Kossouoh, et al., 2007). However, Annona species, including Annona muricata, have been shown to be a generally rich source of annonaceous acetogenin compounds (AGEs) (Rupprecht, et al., 1990).

There have been in vivo studies carried out on the dose-related effects of methanolic extracts of the leaves and bark of Annona muricata on blood glucose concentration in rats (Soheil, et al., 2015). Research by Adeyemi and colleagues (2009) reported that daily intraperitoneal injection of the methanol extract of Annona muricata leaves (100 $\mathrm{mg} / \mathrm{kg}$ ) to streptozotocin-induced diabetic Wistar rats for a fortnight significantly lowered blood glucose concentration from 21.64 to $4.22 \mathrm{mM}$ (Adeyemi, et al., 2009). The same extract dose was also reported to significantly decrease the serum total cholesterol, low-density lipoprotein, triglyceride and very low-density lipoprotein cholesterol (Adeyemi, et al., 2008).

Based on the ethnopharmacological application of Annona muricata leaves against diabetes in Cameroon, another similar study examined the effect of aqueous extract of the leaves on streptozotocin-induced diabetes in rats and reported the same promising 
antidiabetic activities. The reported antioxidant and hypolipidemic potentials and protective effects for pancreatic $\beta$-cells explained the activity of the extract (Florence, et al., 2014). The study of its tissue characteristics showed that the leaf extract caused the regeneration of $\beta$-cells in the pancreas islets (Adeyemi, et al., 2006). The ethanolic extract of stem bark also demonstrated promising antidiabetic and hypolipidemic activities against alloxan- induced diabetic rats. The rats treatment from the extract was taken at 150 and $300 \mathrm{mg} / \mathrm{kg}$ for 14 days showing decrease in the blood glucose level and was associated with a reduction in cholesterol and triglyceride levels (Ahalya, et al., 2014).

Although there has been great work on the various parts of Annona muricata, a link between the antidiabetic and related activities and known isolated compounds has not yet been established. Sehoil and colleagues have shown that compounds isolated from Annona muricata have anti-cancer abilities (Soheil, et al., 2015). However, further research is needed to expand on the usage of its leaves, roots and barks for antiinflammatory, hypoglycemic, sedative, smooth muscle relaxant, hypotensive and antispasmodic effects (Mishra, et al., 2013).

The practical use of Annona muricata as an antidiabetic remedy gave reason for the selection of its leaves to be studied. Besides the fact of its great abundance in Samoa, this research will also aim to support and encourage the use and safeguarding of the plant species within the region.

The five chosen plant species from an initial selection of 215 plants were therefore evaluated in the current research. These plants were selected on their ability to be readily sampled and re-sampled, having sufficient abundance to be considered for later commercial use if required, and come from genera for which there is a literature record of producing natural products with interesting bioactivities, frequently appropriate to diabetes and obesity research. 


\subsection{INTRODUCTION TO $\alpha$-GLUCOSIDASE AND LIPASE BIOASSAYS}

The assays used in this study were based on literature precedence, but required optimisation. The experimental protocols finally adopted are reported in sections 2.4 .3 and 2.4.4. The $\alpha$-glucosidase bioassay was adapted from the method by Collins and colleagues (Collins, et al., 1997). The reported methods for in vitro screening of inhibiting activity from plant extracts on $\alpha$-glucosidase mainly use the readily available yeast enzyme in combination with the artificial substrate 4-nitrophenyl $\alpha$-Dglucopyranose. Hydrolysis of this substrate, catalysed by the $\alpha$-glucosidase enzyme produces 4-nitrophenol which can be readily detected through its intense yellow colour in basic conditions. The enzyme catalysed reaction is generally run at $\mathrm{pH} 6.8$ and $37{ }^{\circ} \mathrm{C}$ (Eertmans, et al., 2014). To achieve this, a phosphate buffer solution of pH 6.8 was used with concentration of $0.05 \mathrm{M}$, lying within the recorded range of buffer concentrations from $0.1 \mathrm{mM}$ (Zhang, et al., 2014) to 0.1 M (Mohiuddin, et al., 2016). The enzyme and substrate were incubated together for 10 minutes which was observed to give reliable and repetitive absorbance values in a 96 well microtitre plate format.

Similarly, screens for lipase inhibitory activity are generally carried out using a model enzyme and artificial substrate. In this case, the chosen enzyme is porcine pancreatic lipase and the substrate for the lipase bioassay is 4-nitrophenyl palmitate, again at a $\mathrm{pH}$ of 6.8 and at $37^{\circ} \mathrm{C}$. These have been previously reported to be used in the screening of selected plant extracts (Kanwar, et al., 2005; Oliveira, et al., 2015). Several conditions were tested to obtain a well-mixed solution of 4-nitrophenyl palmitate as it has low solubility in the buffer solution especially at high concentrations. Use of sodium deoxycholate in phosphate buffer and sonication to solubilise 4-nitrophenyl palmitate have been reported (Mayordomo, et al., 2000; Oliveira, et al., 2015) and were used for dissolving low concentrations of 4-nitrophenyl palmitate investigated for optimisation in this study. Again, the action of the enzyme liberates 4-nitrophenol from the substrate. Production of the 4-nitrophenol product for $\alpha$-glucosidase and lipase reactions was quantified using a standard curve of a range of concentration for 4-nitrophenol in each experiment. 


\subsection{GENERAL EXPERIMENTAL}

\subsubsection{Materials and Reagents}

All plant extracts were collected and prepared by Environment and Renewable Energy division in SROS, Apia Samoa. Upon arrival, they were stored in a freezer at $-20{ }^{\circ} \mathrm{C}$ until required. Porcine pancreatic lipase, $\alpha$-glucosidase, 4-nitrophenyl $\alpha$-Dglucopyranose, and 4-nitrophenyl palmitate were purchased from Sigma Aldrich. Anhydrous sodium carbonate, sodium phosphate (monobasic), sodium phosphate (dibasic), sodium deoxycholate, and 4-nitrophenol purchased from Sigma Aldrich and were of 95\% purity or better. All solvents used were HPLC-grade purchased from Fisher Scientific.

Reverse-phase column chromatography using HP20 resin beads were provided by the School of Chemical and Physical Sciences supplied by Sigma Aldrich. Silica TLC plates were visualised UV light and stained with a ceric ammonium molybdate dip.

Passaged stock of HL 60 cells, sterile fetal bovine serum, sterile (3-(4, 5dimethylthiazolyl-2)-2,5-diphenyltetrazolium bromide) (MTT) from Sigma Aldrich, and MTT solubilizer for use in the cytotoxicity assay experiment.. An addition of $10 \mathrm{v} / \mathrm{v} \%$ of sterile Fetal Bovine Serum to a stock of cell culture RPMI 1640 media from Thermo Fisher was used and kept at $4{ }^{\circ} \mathrm{C}$ until required.

For cell culture, phosphate buffer saline (PBS) solution was prepared by dissolving 8.0 g $(0.137 \mathrm{~mol})$ sodium chloride, $0.2 \mathrm{~g}(0.16 \mathrm{~mol})$ potassium chloride, $1.44 \mathrm{~g}(0.101 \mathrm{~mol})$ sodium phosphate dibasic and $0.24 \mathrm{~g}(0.18 \mathrm{~mol})$ potassium phosphate diabasic in $1 \mathrm{~L}$ Mill-Q distilled water and the $\mathrm{pH}$ adjusted to 7.4 by adding appropriate volumes of hydrochloric acid (1 M) and sodium hydroxide (1 M).

MTT was weighed then transferred into a sterile hood, where it was dissolved to a concentration of $5 \mathrm{mg} / \mathrm{mL}$ by addition of sterile PBS, and filtered through a $0.22 \mu \mathrm{m}$ filter with the hood lights off because MTT is light sensitive. The solution was wrapped in aluminum foil and stored at $4{ }^{\circ} \mathrm{C}$. 
The MTT solubilizer was prepared by adding 50.0 g sodium dodecyl sulphate and 225.0 $\mathrm{mL}$ of dimethylformamide supplied by Sigma Aldrich to $500 \mathrm{~mL}$ of Milli-Q distilled water with $\mathrm{pH}$ adjusted to 4.5 using glacial acetic acid.

\subsubsection{Sample collection and extract preparation}

Plant samples were collected from selected sites stated in Section 2.1 and transported to the SROS compound where they were washed with distilled water and air dried at room temperature for at least $48 \mathrm{hrs}$. Each dried plant sample was ground, and $50 \mathrm{~g}$ of the powder was blended in $250 \mathrm{~mL}$ of methanol and placed in a shaker overnight. The crude methanolic extract was obtained after filtering the mixture and was further concentrated using rotary vacuum evaporator at $45{ }^{\circ} \mathrm{C}$ and initially stored at $-20{ }^{\circ} \mathrm{C}$ in disposable plastic centrifuge tubes until shipment analysis to the School of Biological Sciences, VUW in cold temperature for use in the first set of fractionation and bioassay analysis of this study. A second shipment of crude methanolic extract stored at $-20{ }^{\circ} \mathrm{C}$ in glass vials were used for repetition of isolation and bioassay analysis.

\subsection{3 $\alpha$-Glucosidase assay}

The assay was undertaken using a method adapted from Collins et al (Collins, et al., 1997). The reaction mixture for each well in a 96 well microtitre plate contained $40 \mu \mathrm{L}$ of a solution of yeast $\alpha$-glucosidase at a concentration of $0.1 \mathrm{mg} / \mathrm{mL}$ and either $3 \mu \mathrm{L}$ or $30 \mu \mathrm{L}$ of plant extract stock solution made at $10 \mathrm{mg} / \mathrm{mL}$, both made up in $50 \mathrm{mM}$ phosphate buffer at $\mathrm{pH}$ 6.8. Additional phosphate buffer was added to give a total volume of $240 \mu \mathrm{L}$ and pre-incubated at $3{ }^{\circ} \mathrm{C}$ for $15 \mathrm{~min}$. To each experimental well was added $60 \mu \mathrm{L}$ of a $20 \mathrm{mM}$ stock of 4-nitrophenyl $\alpha$-D-glucopyranoside substrate, also dissolved in $50 \mathrm{mM}$ phosphate buffer at $\mathrm{pH}$ 6.8. Positive and negative control wells containing either no plant extract or no enzyme were established. All samples were prepared in triplicate. The microtitre plate was incubated at $37^{\circ} \mathrm{C}$ for 10 min prior to addition of $100 \mu \mathrm{L}$ of a $1 \mathrm{M}$ solution of sodium carbonate. The absorbance at $410 \mathrm{~nm}$ was measured and the amount of 4-nitrophenol produced was determined by 
comparison to a standard curve, established over a concentration range of 0.04 to 200 $\mathrm{mM}$ 4-nitrophenol dissolved in $300 \mu \mathrm{L}$ of $500 \mathrm{mM}$ phosphate buffer at $\mathrm{pH}$ 6.8.

\subsubsection{Pancreatic lipase assay}

A procedure to monitor lipase activity was developed and modified according to the method used by Muhammad and colleagues (2013). The bioassay reaction total volume in each well on a 96-well microtitre plate contained either 3 or $30 \mu \mathrm{L}$ of extracts from a $10 \mathrm{mg} / \mathrm{mL}$ stock solution, incubated at $40^{\circ} \mathrm{C}$ with $70 \mu \mathrm{L}$ of $0.15 \mathrm{mg} / \mathrm{mL}$ porcine pancreatic lipase, both prepared in a $50 \mathrm{mM}$ phosphate buffer of $\mathrm{pH}$ 6.8. To each experimental well was added $180 \mu \mathrm{L}$ of $2.5 \mathrm{mM}$ 4-nitrophenyl palmitate, prepared by sonication at $40{ }^{\circ} \mathrm{C}$ for $10 \mathrm{~min}$ in a $50 \mathrm{mM}$ sodium deoxycholate solution made with 50 $\mathrm{mM}$ sodium buffer of $\mathrm{pH}$ 6.8. Positive and negative control wells containing either no plant extract or no enzyme were established. All samples were prepared in triplicate. The microtitre plate was incubated at $40{ }^{\circ} \mathrm{C}$ for $15 \mathrm{~min}$ prior to addition of $100 \mu \mathrm{L}$ of a 1 M solution of sodium carbonate. The absorbance was measured at $410 \mathrm{~nm}$ and the amount of 4-nitrophenol produced was calculated using the standard curve, established over the concentration range of 0.01 to $200 \mathrm{mM}$ 4-nitrophenol dissolved in $300 \mu \mathrm{mM}$ of $500 \mathrm{mM}$ sodium phosphate buffer at $\mathrm{pH}$ 6.8.

The percentage inhibition for both bioassays were computed as follows:

$$
\text { Inhibition rate }(\%)=\left\{1-\frac{(A b s S-A b s B)}{A b s C}\right\} \times 100
$$

where: Abs S = absorbance of the experimental sample

Abs B = absorbance of the blank

Abs $\mathrm{C}=$ absorbance of the negative control, containing enzyme and substrate but no inhibitor. 


\subsubsection{Cyclic Loading and Backloading}

An HP20 column containing 40 mL HP20 resin beads was prepared and equilibrated in methanol. Each extract was passed through the screen column with a flow rate of approximately $10 \mathrm{~mL} / \mathrm{min}$ under gravity. The eluent was diluted with $200 \mathrm{~mL}$ distilled water and passed back through the column. The collected eluent was then further diluted with $400 \mathrm{~mL}$ distilled water and again passed through the column. This progressive dilution and re-elution of the original extract is referred to as cyclic loading.

Following loading, the column was washed with $100 \mathrm{~mL}$ distilled water, which was discarded immediately. Fractions were eluted from the column by passing through 100 $\mathrm{mL}$ each of $30 \%$ then $75 \%$ acetone in distilled water and finally $100 \%$ acetone at flow rate of approximately $10 \mathrm{~mL} / \mathrm{min}$. The $100 \%$ acetone fraction was dried using a rotary vacuum evaporator and used for experimental analysis.

The acetone-water fractions were backloaded onto the HP20 column to remove water. The 75\% acetone fraction was diluted with $100 \mathrm{~mL}$ distilled water and passed through the backloading column at a slower flow rate of approximately $8 \mathrm{~mL} / \mathrm{min}$. The eluent was diluted with $200 \mathrm{~mL}$ of distilled water and passed through the backloading column at the same flow rate of $8 \mathrm{~mL} / \mathrm{min}$ and kept until after analysis was complete before discarding. The backloaded column was then eluted with $100 \mathrm{~mL}$ of acetone and dried under vacuum using a rotary evaporator at room temperature. Similar procedures were used to obtain the $30 \%$ acetone in distilled water fraction for each extract.

\subsubsection{MTT Assay}

Measurement of cell viability was tested using the yellow tetrazolium MTT (3-(4, 5dimethylthiazolyl-2)-2,5-diphenyltetrazolium bromide) assay protocol. In each well of the 96 microtitre wellplate, $50 \mu \mathrm{L}$ of already prepared sterile cell culture media with 10 v/v \% fetal bovine serum was added except for the first sample and blank wells. Cell culture media of volume $100 \mu \mathrm{L}$ was added to each blank well. To the first sample wells was added $100 \mu \mathrm{L}$ of the extract stock solution of $2 \mathrm{mg} / \mathrm{mL}$ concentration, prepared by dissolving $0.1 \mathrm{mg}$ extract in $10 \mu \mathrm{L}$ ethanol and $500 \mu \mathrm{L}$ total volume was made up with 
the sterile cell culture media. A two-fold serial dilution of the extract across the sample wells was carried out by taking $50 \mu \mathrm{L}$ from the first wells, adding and mixing into the next well and so forth until the last well and discarded. The extract was not added into the control and blank wells. The first control wells contained an equivalent $\mathrm{v} / \mathrm{v} \%$ of ethanol used for the extract. Hence, $10 \mu \mathrm{L}$ of ethanol was mixed with $490 \mu \mathrm{L}$ cell culture media and $100 \mu \mathrm{L}$ were added to the first control wells. Similarly, a two-fold serial dilution of the control wells was done by taking $50 \mu \mathrm{L}$ from first wells, added and mixed into the next until the last well and discarded. All samples, controls and blanks were carried out in triplicate.

To each well except for the blanks, a $50 \mu \mathrm{L}$ aliquot of $2 \times 10^{-5}$ cells/mL HL60 cells which were prepared and incubated two days prior to the experimental date was added and incubated at $37{ }^{\circ} \mathrm{C}$ for 72 hrs. The cells were counted using a hemocytometer and diluted as necessary to make the desired concentration as follows: The culture was centrifuged at $300 \times g$ for 4 min and resuspended in fresh media after discarding the supernatant. To $10 \mu \mathrm{L}$ cells, $10 \mu \mathrm{L}$ of trypan blue was added and mixed and $10 \mu \mathrm{L}$ of this mixture was placed into a hemocytometer. A 1:10 cell dilution was made to facilitate counting.

The already prepared MTT solution was added to each well at $20 \mu \mathrm{L}$ each and incubated for $2 \mathrm{~h}$ at $37^{\circ} \mathrm{C}$ wrapped in aluminium foil prior to the addition of $100 \mu \mathrm{L}$ of solubilizer to each well, wrapped again in aluminium foil and incubated overnight at $37^{\circ} \mathrm{C}$ in a non-sterile incubator and the absorbance was read at $570 \mathrm{~nm}$. The cell viability was plotted against the cell survival \% calculated from the controls against each concentration.

\subsubsection{LC-MS/MS Methods}

LC-MS analyses of selected fractions were assessed out using two different columns: LiChrospher $100 \mathrm{CN}$ (5 $\mu \mathrm{m}$ particle size) and C18 (5 $\mu \mathrm{m}$ particle size). After evaluation, the C18 column was chosen for all further analyses unless stated otherwise. Each sample was injected at volume of $0.2 \mu \mathrm{L}$ of concentration $0.1 \mathrm{mg} / \mathrm{mL}$ after running $1 \mu \mathrm{L}$ of a methanol solvent blank using the same method to be used for each sample. The LC-MS solvents used for optimising gradient and retrieving mass spectra for all samples in this study were; Solvent $\mathrm{A}-\mathrm{H}_{2} \mathrm{O}$ with $0.05 \%$ formic acid; Solvent B 
- Acetonitrile with $0.05 \%$ ammonium formate acid. Solvent gradients were used as described in the following tables (Tables 9, 10, and 11).

Table 2: Atone30-100 DEHP solvent gradient

\begin{tabular}{|l|l|l|l|}
\hline Time (min) & Solvent A\% & Solvent B\% & Flow (mL/min) \\
\hline 0 & 20 & 80 & 0.4 \\
\hline 10 & 80 & 20 & 0.4 \\
\hline 15 & 80 & 20 & 0.4 \\
\hline 16 & 20 & 80 & 0.4 \\
\hline 25 & 20 & 80 & 0.4 \\
\hline
\end{tabular}

The target mass spectrum was used to identify for existence of other compounds. Evidently, the extract was clean which was confirmed by NMR.

Table 3: Atone100-100 solvent gradient

\begin{tabular}{|l|l|l|l|}
\hline Time (min) & Solvent A\% & Solvent B\% & $\begin{array}{l}\text { Flow } \\
(\mathrm{mL} / \mathrm{min})\end{array}$ \\
\hline 0 & 20 & 80 & 0.4 \\
\hline 10 & 80 & 20 & 0.4 \\
\hline 15 & 80 & 20 & 0.4 \\
\hline 16 & 20 & 80 & 0.4 \\
\hline 25 & 20 & 80 & 0.4 \\
\hline
\end{tabular}

Similarly, the Atone100-100 fraction appeared clean using the CN column. As seen in the raw LC-MS mass spectra, it had a high TIC of $>8 \times 10^{7}$. The clean sample was analysed using the NMR. Spectra matched those for threo-dihydroguaiaretic acid from previous studies (Macías-Villamizar, 2016). 
All LC-MS analysis for Fao75-100 was carried out using a C18 column in Error! Reference source not found.:

Table 4: Fao75-100 solvent gradient

\begin{tabular}{|l|l|l|l|}
\hline Time (min) & Solvent A\% & Solvent B\% & Flow (mL/min) \\
\hline 0 & 10 & 90 & 0.4 \\
\hline 10 & 50 & 50 & 0.4 \\
\hline 12 & 50 & 50 & 0.4 \\
\hline 13 & 40 & 60 & 0.4 \\
\hline 16 & 30 & 70 & 0.4 \\
\hline 20 & 30 & 70 & 0.4 \\
\hline 25 & 10 & 90 & 0.4 \\
\hline
\end{tabular}

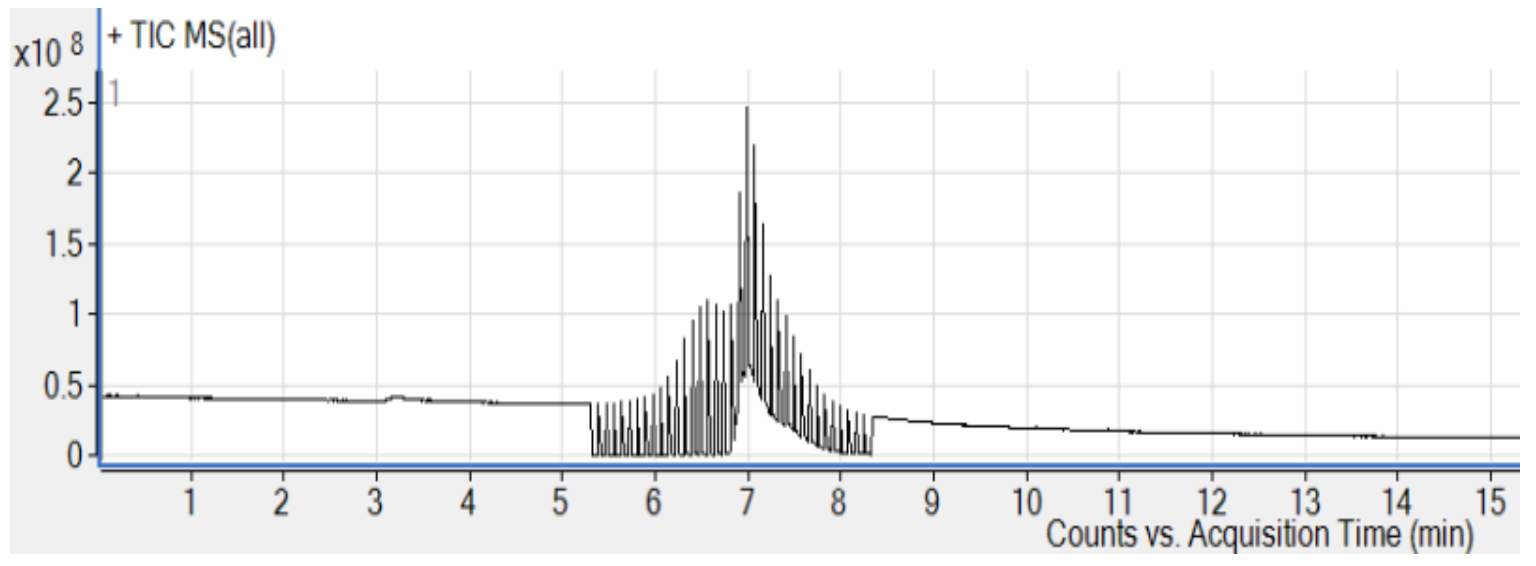

Figure 9: Target DEHP LC-MS/MS Fao30-100 


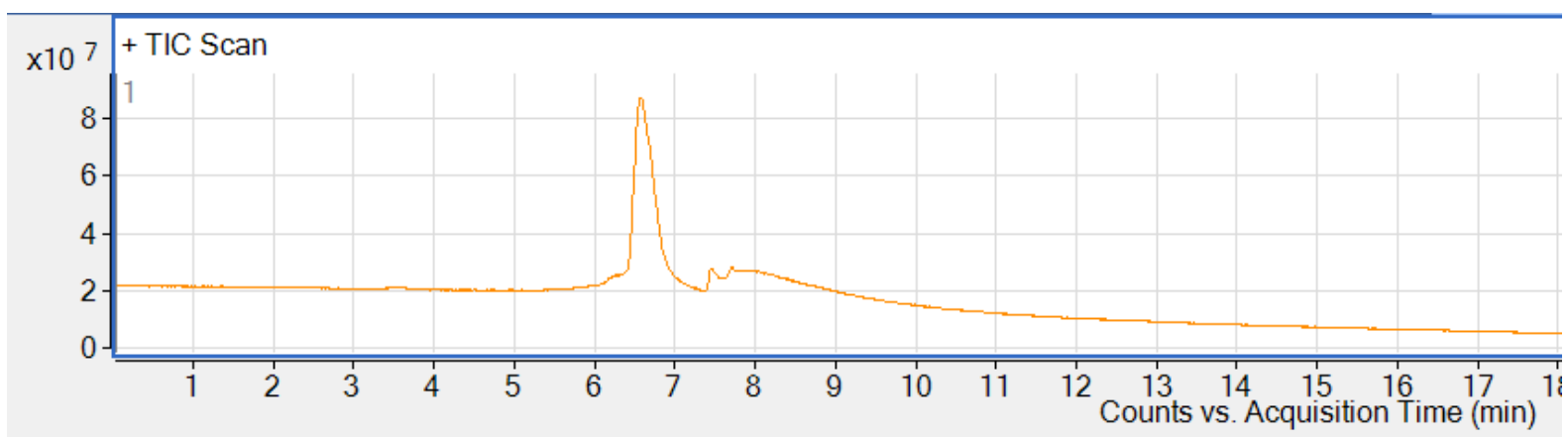

Figure 10: Atone100-100 LC-MS

As Fao75-100 appeared to a mixture of compounds, an auto-MS/MS was used to be able to find all the major compounds; there were at least 3. Each observed parent ion was then targeted using LC-MS for daughter ion spectra to be submit to GNPS database.

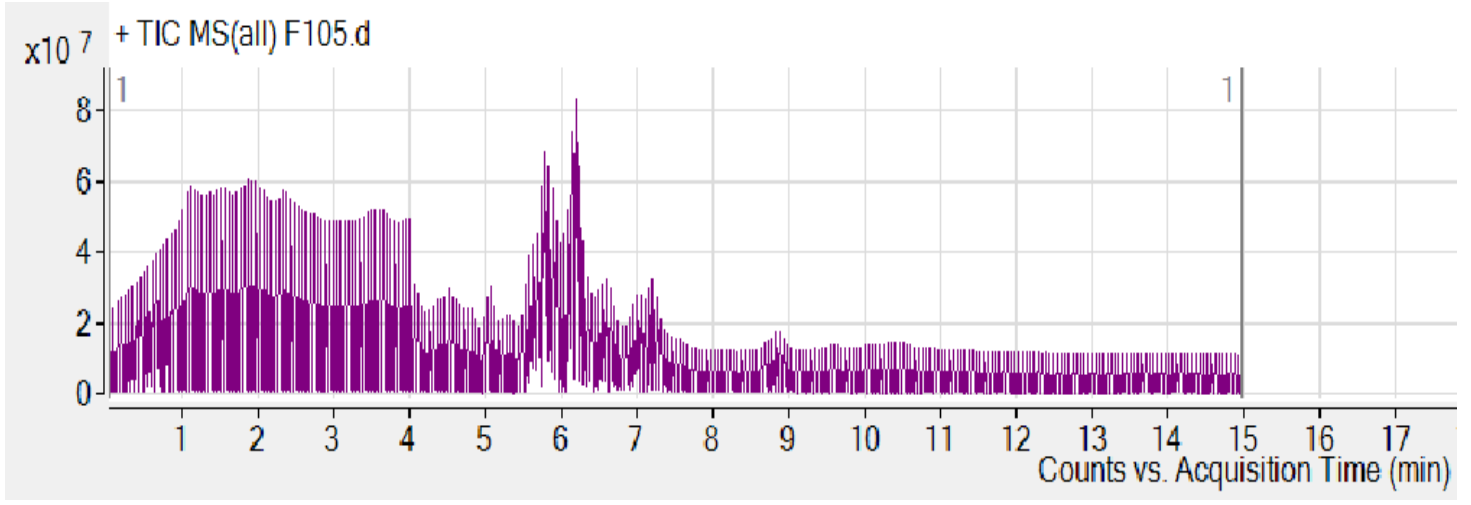

Figure 11: Fao75-100 Auto LC-MS/MS

\subsection{Conclusion}

This chapter contains the introduction to the methods and details on the formulation of the established step by step procedures for the thesis. The enzyme assays were run through a series of trials and optimised to set conditions for assay development used in screening the five chosen Samoan plant species. The application of bioassays in identifying of the bioactive compounds and results are presented in Chapter 3. 


\section{CHAPTER THREE}

The aim of this project is to isolate components from Samoan plant extracts that have ability to inhibit lipase and $\alpha$-glucosidase target enzymes. Having identified a set of five plants to evaluate, extracts of these plants had to be fractionated and evaluated for their potential to inhibit $\alpha$-glucosidase and lipase enzymes. This chapter reports the fractionation and enzyme inhibition of the extracts. Active fractions were subfractionated and the identity of active components determined by LC-MS/MS and NMR techniques. Enzyme kinetic data and the impact on cell metabolic activity, as determined by the MTT assay, were determined.

\subsection{FRACTIONATION}

The methanolic extract of each collected species was loaded onto HP20 resin using the cycling loading method as outlined in Section 2.4.5. Using sequentially water-rich loading solutions ensured that drug-like hydrophobic compounds are preferentially retained on the non-polar resin. Fractions were then eluted from the column using two acetone in water concentrations; 30\%, 75\% and finally 100\% acetone. To enable rapid evaporation with minimal loss of any volatile bioactives, the $30 \%$ and $75 \%$ acetone in water fractions were then re-loaded onto HP20 resin, which was flushed dry before elution with acetone. All three isolated fractions were then evaporated to dryness and subjected to in vitro bioassays, screen for their ability to inhibit porcine pancreatic lipase (PPL) and $\alpha$ - glucosidase (AG) at $1 \mathrm{mg} / \mathrm{mL}$ and $0.1 \mathrm{mg} / \mathrm{mL}$ concentrations.

Fractions with highest inhibition against either enzyme were further fractionated through the HP20 column and concentrations of acetone in water varied depending on the selected fraction of interest. The polar fraction ( $30 \%$ acetone in $\mathrm{H}_{2} \mathrm{O}$ ), was eluted from the column in sub-fractions to yield 20\%, 30\%, 40\%, 50\% \& $100 \%$ acetone in $\mathrm{H}_{2} \mathrm{O}$ while the non-polar fractions ( $75 \%$ and $100 \%$ acetone in $\mathrm{H}_{2} \mathrm{O}$ ) were eluted to give $40 \%, 50 \%, 60 \%, 70 \%$ and $100 \%$ acetone in water sub-fractions. This was considered as standard procedure for all the plant species of this study. 
A naming system for the fractions and sub-fractions was adopted for simplicity of data interpretation. For each plant, the Samoan name is used: Futu (Barringtonia asiatica), Falaga (Barringtonia samoensis), Sasalapa (Annona muricata), Atone (Myristica fatua), Fao (Neisosperma oppositifolia). The percentage of acetone in the initial fractions directly accompanies the plant name, for example Fao100 for the first 100\% acetone fraction of Neisosperma oppositifolia. The sub-fractions are indicated by a second number, representing the percentage of acetone in the sample. For example Futu30-70 denotes a sample of Barringtonia asiatica extract that came from the initial $30 \%$ acetone in water fraction and the $70 \%$ acetone in water sub-fraction.

\subsection{LIPASE}

The inhibition of PPL by the imported crude extracts had a range of $10.87 \%$ as shown in Table 5. The activity of Fao30 polar fraction of Neisosperma oppositifolia was most active at $87.7 \pm 079 \%$ at $1 \mathrm{mg} / \mathrm{mL}$ followed by Myristica fatua fractions. Atone30 and Atone75 having $51.1 \pm 0.25 \%(1 \mathrm{mg} / \mathrm{mL})$ and $48.6 \pm 0.03 \%(1 \mathrm{mg} / \mathrm{mL})$ respectively. The lower concentration in Myristica fatua fractions at $0.1 \mathrm{mg} / \mathrm{mL}$ showed inhibition of 24$31 \%$, equivalent to the Fao30 extract at the same low concentration. Fractions from Annona muricata and Barringtonia asiatica did not have high inhibition in comparison. 
Table 5: PPL inhibition by initial plant fractions. Inhibition is shown as a percentage of the activity, obtained in the absence of an inhibitor. The percentage of inhibition is shown at two concentrations for each fraction, 0.1 and $1.0 \mathrm{mg} / \mathrm{mL}$

\begin{tabular}{|c|c|c|c|c|}
\hline $\begin{array}{l}\text { Samoan } \\
\text { name }\end{array}$ & Scientific name & $\begin{array}{l}\text { Fraction } \\
\text { (\% acetone) }\end{array}$ & $\begin{array}{l}0.1 \\
\mathrm{mg} / \mathrm{mL}\end{array}$ & $1 \mathrm{mg} / \mathrm{mL}$ \\
\hline \multirow[t]{3}{*}{ Fao } & $\begin{array}{l}\text { Neisosperma } \\
\text { oppositifolium }\end{array}$ & 30 & $27.8 \pm 0.12$ & $87.7 \pm 0.79$ \\
\hline & & 75 & $20.9 \pm 0.06$ & $52.4 \pm 0.12$ \\
\hline & & 100 & $20.2 \pm 0.13$ & $49.8 \pm 0.24$ \\
\hline \multirow[t]{3}{*}{ Atone } & Myristica fatua & 30 & $24.1 \pm 0.24$ & $51.1 \pm 0.25$ \\
\hline & & 75 & $31.4 \pm 0.14$ & $48.6 \pm 0.03$ \\
\hline & & 100 & $30.2 \pm 0.01$ & $49.6 \pm 0.17$ \\
\hline \multirow[t]{3}{*}{ Falaga } & Barringtonia samoensis & 30 & $25.3 \pm 0.10$ & $27.1 \pm 0.12$ \\
\hline & & 75 & $26.4 \pm 0.25$ & $30.9 \pm 0.14$ \\
\hline & & 100 & $31.1 \pm 0.04$ & $47.6 \pm 0.2$ \\
\hline \multirow[t]{3}{*}{ Sasalapa } & Annona muricata & 30 & $22.2 \pm 0.14$ & $25.3 \pm 0.02$ \\
\hline & & 75 & $24.4 \pm 0.21$ & $29.3 \pm 0.17$ \\
\hline & & 100 & $17.8 \pm 0.06$ & $24.4 \pm 0.19$ \\
\hline \multirow[t]{3}{*}{ Futu } & Barringtonia asiatica & 30 & $12.2 \pm 0.09$ & $20.1 \pm 0.1$ \\
\hline & & 75 & $10.5 \pm 0.13$ & $27.3 \pm 0.16$ \\
\hline & & 100 & $20.3 \pm 0.04$ & $34.2 \pm 0.35$ \\
\hline
\end{tabular}


The PPL-inhibitory Fao30 was sub-fractionated. Surprisingly, the sub-fraction that showed the highest level of PPL activity was 100\% acetone sub fraction, Fao30-100, which gave $80.4 \pm 0.04 \%$ inhibition at $1 \mathrm{mg} / \mathrm{mL}$ as shown in Table 6 .

Table 6: Fao sub-fractionation PPL inhibition

\begin{tabular}{|c|c|c|c|c|c|}
\hline $\begin{array}{l}\text { Samoan } \\
\text { name }\end{array}$ & $\begin{array}{l}\text { Scientific } \\
\text { name }\end{array}$ & $\begin{array}{l}\text { Fraction } \\
\text { (\% acetone) }\end{array}$ & $\begin{array}{l}\text { Sub-fraction } \\
\text { (\% acetone) }\end{array}$ & $0.1 \mathrm{mg} / \mathrm{mL}$ & $1 \mathrm{mg} / \mathrm{mL}$ \\
\hline \multirow[t]{15}{*}{ Fao } & $\begin{array}{l}\text { Neisosperma } \\
\text { oppositifolium }\end{array}$ & 30 & 20 & $56 \pm 0.23$ & $57.6 \pm 0.32$ \\
\hline & & & 30 & $53.8 \pm 0.04$ & $58.7 \pm 0.28$ \\
\hline & & & 40 & $54 \pm 0.15$ & $73.3 \pm 0.01$ \\
\hline & & & 50 & $61.6 \pm 0.8$ & $67.6 \pm 0.12$ \\
\hline & & & 100 & $72 \pm 0.21$ & $80.4 \pm 0.04$ \\
\hline & & 75 & 40 & $12.4 \pm 0.14$ & $27.1 \pm 0.21$ \\
\hline & & & 50 & $24.6 \pm 0.01$ & $32.1 \pm 0.05$ \\
\hline & & & 60 & $10.2 \pm 0.05$ & $15.4 \pm 0.10$ \\
\hline & & & 70 & $23.1 \pm 0.12$ & $31 \pm 0.14$ \\
\hline & & & 100 & $34.2 \pm 0.01$ & $54.5 \pm 0.10$ \\
\hline & & 100 & 40 & $32.1 \pm 0.14$ & $46.2 \pm 0.2$ \\
\hline & & & 50 & $24.5 \pm 0.02$ & $35.3 \pm 0.14$ \\
\hline & & & 60 & $15.2 \pm 0.13$ & $30.8 \pm 0.11$ \\
\hline & & & 70 & $40.3 \pm 0.13$ & $45.3 \pm 0.24$ \\
\hline & & & 100 & $54.2 \pm 0.16$ & $56.2 \pm 0.1$ \\
\hline
\end{tabular}

This active sub-fraction was analysed using TLC. As shown in Figure 12 there was a clear major compound in the fraction which was purified to homogeneity using a small pipette silica column using hexane:ethyl acetate elutions at 3:1, 9:1, and finally 20:1. 


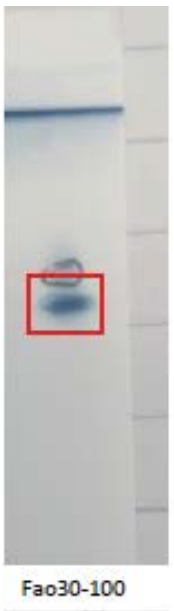

Figure 12: Fao30-100 TLC in 9:1 hexane:ethyl acetate

The purified major active component was in the 20:1 fraction, and identified by NMR spectroscopy. Although this compound exhibited an impressive $98 \pm 0.03 \%$ inhibition of PPL at $1 \mathrm{mg} / \mathrm{mL}$, the NMR screening of this particular compound identified it as a plasticiser named di(2-ethylhexyl) phthalate (DEHP). The NMR spectrum of the isolated compound is shown in Figure 13.

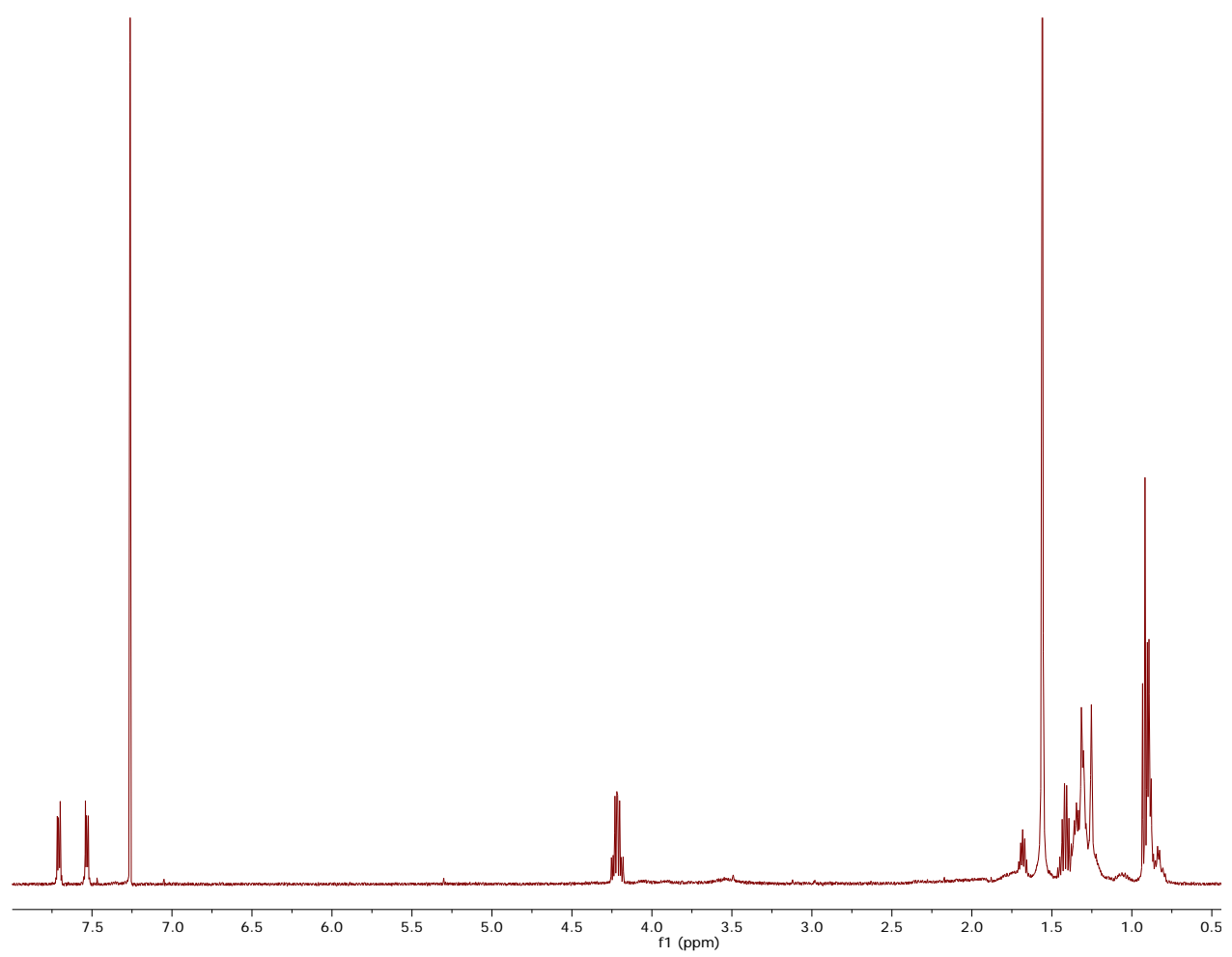

Figure 13: DEHP NMR ${ }^{1} \mathrm{H}$ spectrum (500 MHz, CDCl3) - Fao30-100 
TLC analysis was used to compare the Fao30-100 these fractions from the next highest inhibition in the Atone30 and Fao75 fractions. As suspected, TLC analysis indicated that these PPL-inhibiting extracts contained a very similar or identical compound. In order to avoid continued work on what might prove to be an artefact of isolation, earlystage analysis by NMR and MS was carried out, revealing that both samples contained the plasticiser DEHP. Investigation revealed that this had been introduced as a result of an error in setting up the original extracts by the laboratory team in Samoa. Due care had been taken to only use glassware when handling the extract during fractionation. Fractions were subsequently prepared again in Samoa without use of plasticware. Inhibition of PPL by phthalates such as DEHP has been previously noted. So, although the isolation of DEHP was disappointing, it served to validate the activity-guided isolation protocol being followed.

Nonetheless, Atone100 was only marginally less active than the DEHP-containing fraction, exhibiting $49.6 \pm 0.51 \%$ inhibition of PPL at $1 \mathrm{mg} / \mathrm{mL}$. This was selected for further fractionation, having first confirmed it was free of contaminating DEHP plasticiser. Sub-fractionation, as described above, led to increases in inhibitory activity, as the active component was purified away from inactive compounds. The Atone100100 sub-fraction showed $84.5 \pm 2.65 \%(1 \mathrm{mg} / \mathrm{mL})$ and $60.5 \pm 2.16 \%(0.1 \mathrm{mg} / \mathrm{mL})$ inhibition of PPL as illustrated in Table 7. This was then analysed by NMR spectroscopy within the School of Chemical and Physical Sciences and preliminary compound identification completed by MS.

Table 7: Sub-fraction PPL inhibition percentages

\begin{tabular}{|l|l|l|l|l|l|}
\hline $\begin{array}{l}\text { Samoan } \\
\text { name }\end{array}$ & $\begin{array}{l}\text { Scientific } \\
\text { name }\end{array}$ & $\begin{array}{l}\text { Fraction } \\
\text { (\% acetone) }\end{array}$ & $\begin{array}{l}\text { Sub-fraction } \\
\text { (\% acetone) }\end{array}$ & $\mathbf{0 . 1} \mathbf{~ m g} / \mathbf{m L}$ & $\mathbf{1 ~} \mathbf{~ g} / \mathbf{m L}$ \\
\hline Atone & Myristica fatua & 100 & 40 & $21 \pm 2.1$ & $34.1 \pm 0.2$ \\
\hline & & & 50 & $37.6 \pm 0.40$ & $45.3 \pm 0.49$ \\
\hline & & & 60 & $14.9 \pm 0.16$ & $20.06 \pm 0.80$ \\
\hline & & & 70 & $44.9 \pm 0.53$ & $52.5 \pm 0.65$ \\
\hline & & & 100 & $60.5 \pm 0.16$ & $84.5 \pm 0.65$ \\
\hline
\end{tabular}

The Atone100-100 fraction contained one major compound, as shown by NMR (Figure 14) which was identified as threo-dihydroguaiaretic acid (Figure 15). 


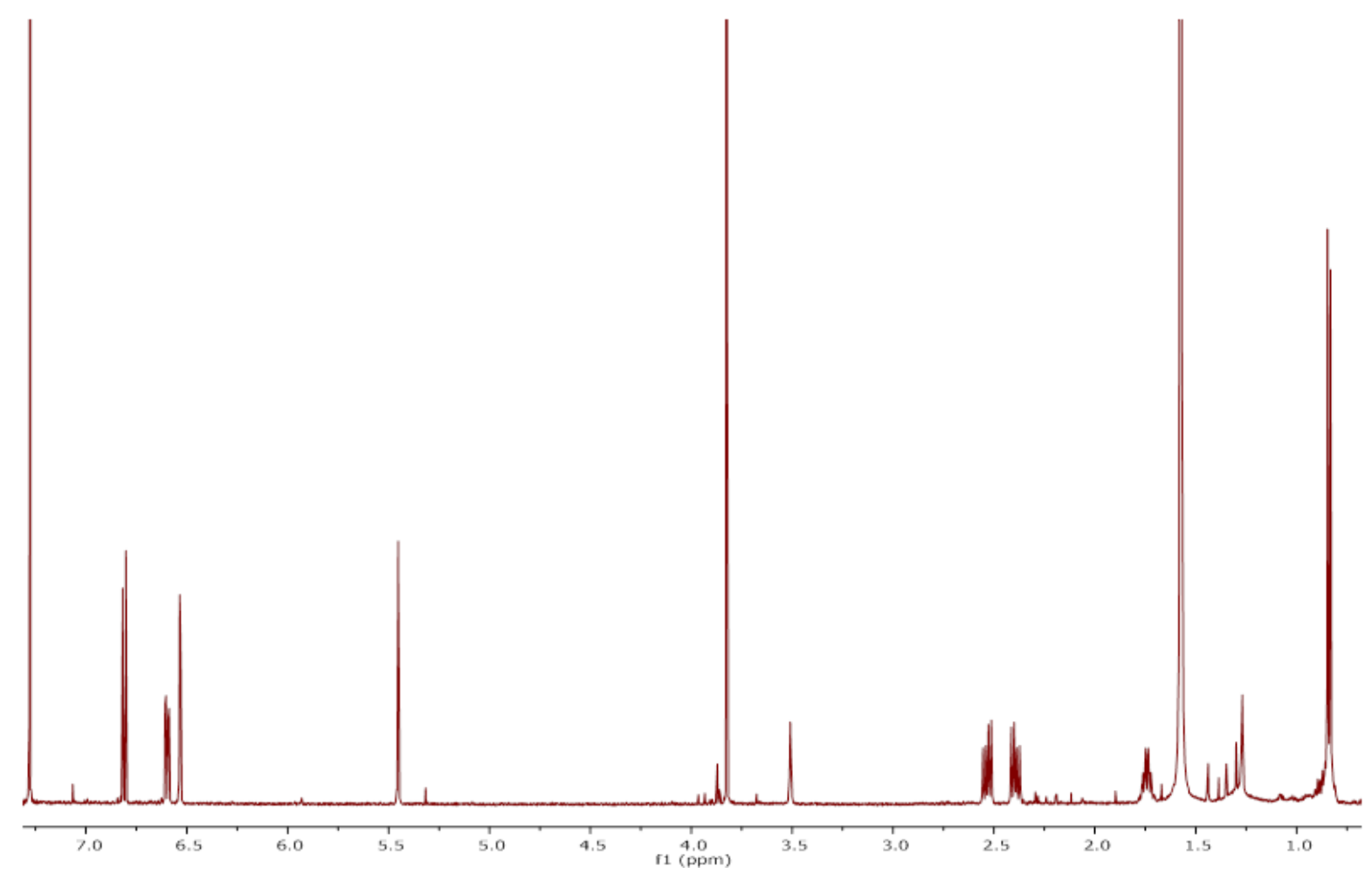

Figure 14: Atone 100-100 1H NMR (500 MHz, CDCI3)

The identity of the isolated product was confirmed by comparison to spectra of dihydroguaiaretic acid and three closely related compounds: meso-dihydroguaiaretic acid Figure 15, meso-monomethyldihydroguaiaretic acid (Figure 16) and Sauriol B in (Figure 17). These were used for identification of the structure from the extract using ${ }^{1} \mathrm{H},{ }^{13} \mathrm{C}$, COSY and HMBC NMR spectra. Threo-dihydroguaiaretic acid has been previously isolated from Myristica fragrans, a closely related species of the same genus showing its abundance in the family or Myristicaceae. 


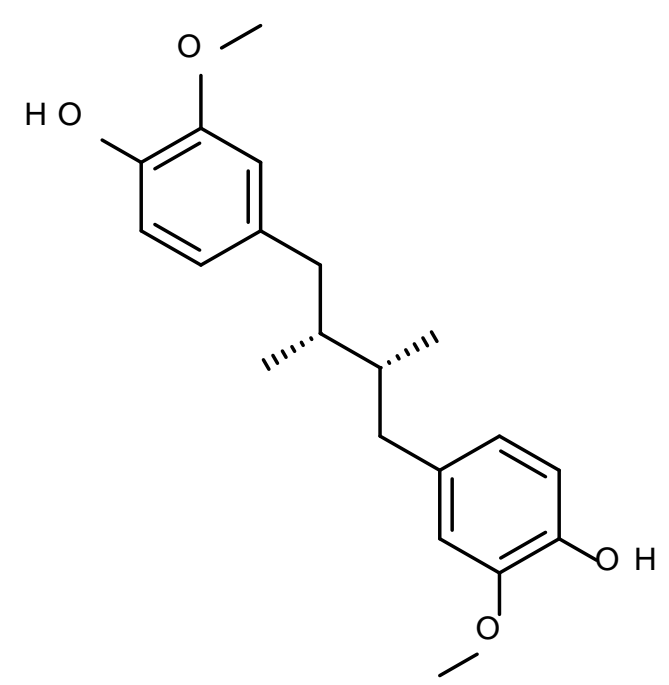

Figure 15: threo-dihydroguaiaretic acid

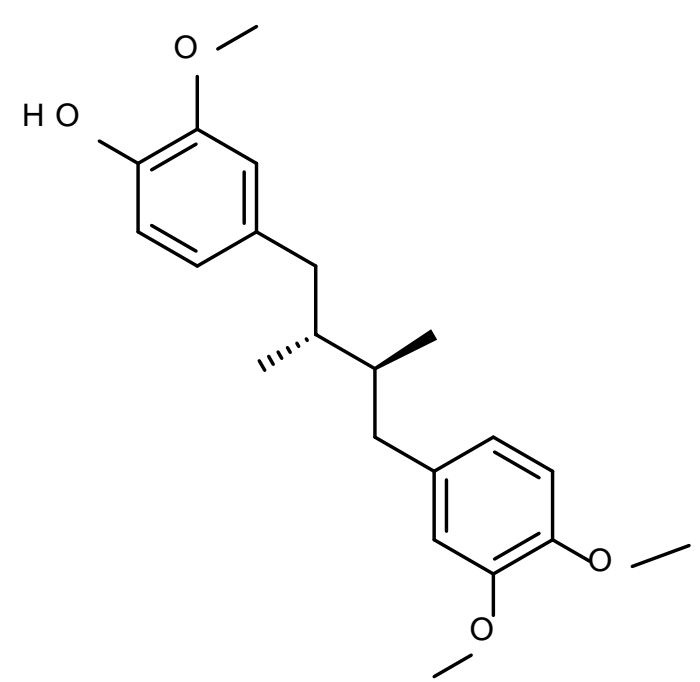

Figure 16: meso-

monomethyldihydroguaiaretic acid

The peak resonances of the Atone100-100 sub-fraction compared to that of mesomonomethyl dihydroguaiaretic acid showed substantial differences in intensities of resonances observed at $\delta 5.46\left({ }^{1} \mathrm{H}, \mathrm{s}, \mathrm{OH}\right)$ and $\delta 3.81(6 \mathrm{H}, \mathrm{s}, \mathrm{OMe})$, but were identical to the equivalent region of threo-dihydroguaiaretic acid. The spectra of the isolated Myristica fatua Atone100-100 sub-fraction was also compared to spectra of the plant metabolite sauriol B (Figure 17). The most significant differences were the NMR signals in sauriol B from its extra methoxy and phenolic groups compared to the spectrum of threo-dihydroguaiaretic acid.

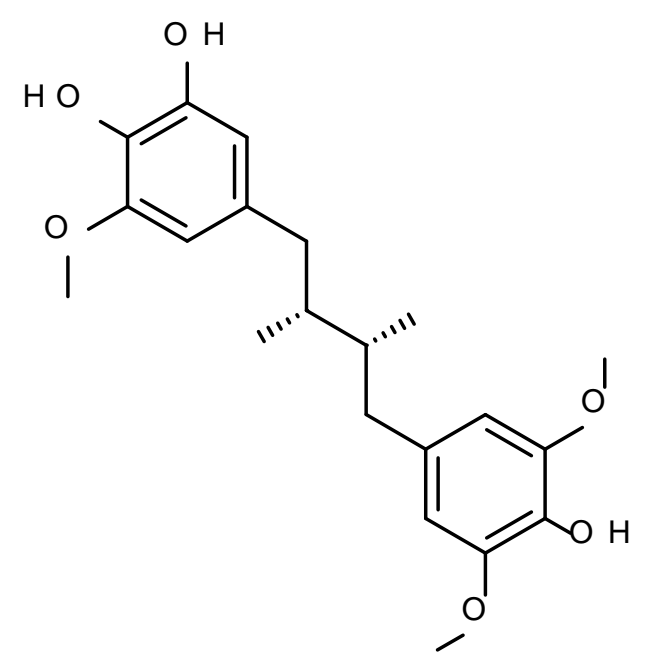

Figure 17: Sauriol B molecular structure 
Our obtained spectral data (see Figure 15) shows clearly the parent dihydroguaiaretic acid skeleton and matches exactly threo-dihydroguaiaretic acid with signals for $-\mathrm{OCH}_{3}$ and $-\mathrm{OH}$ resonances at $\delta 3.81$ and $\delta 5.43$ respectively confirming the presence of the two methoxy and phenolic groups on the aromatic moieties.

The threo-dihydroguaiaretic acid purified from the Atone100-100 subfraction was then further assayed against PPL. Its IC $_{50}$ value (concentration giving 50\% inhibition of PPL activity) was determined to be $0.05 \pm 0.03 \mathrm{mg} / \mathrm{mL}$ using the dose-response curve nonlinear regression as implemented in Prism. The data is shown graphically in Figure 15.

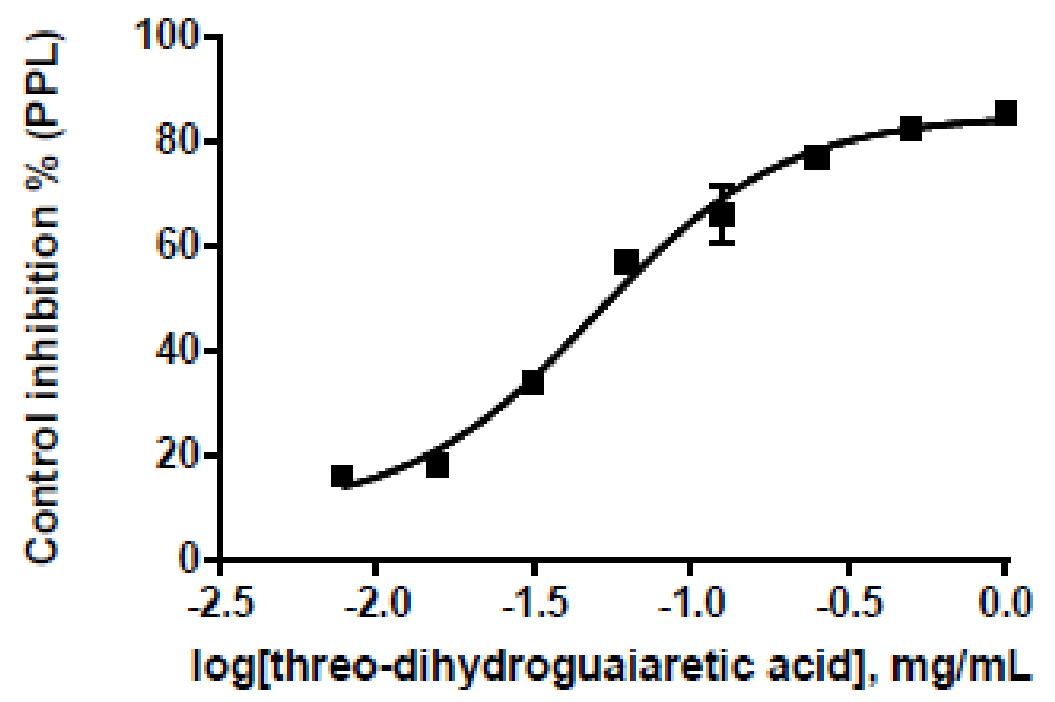

Figure 18: Control inhibition PPL\% across threo-dihydroguaiaretic acid conc. Points represent the average of triplicate measurements with error bars calculated from the standard error.

Previous studies have identified the $\mathrm{LD}_{50}$ of threo-dihydroguaiaretic acid to be 75 $\mathrm{mg} / \mathrm{kg}$ when administered IP in the mouse (Lambert et al., 2002). The impact on cellular metabolic activity of threo-dihydroguaiaretic acid purified from the Atone100-100 subfraction was assessed through an MTT assay using HL60 cells. This assay reveals cytostatic or cytotoxic effects of the fraction, and was carried out as a counter-screen to measure toxicity for comparison to the lipase inhibition activity. Growth inhibitory activity was noted for the fraction, with an $\mathrm{IC}_{50}$ of $0.098 \pm 0.034 \mathrm{mg} / \mathrm{mL}$ as illustrated in Figure 19. The observed cell viability at the highest inhibition concentration tested (1 
$\mathrm{mg} / \mathrm{mL}$ ) is $\sim 38 \%$. No impact on metabolic activity was found at or below $0.25 \mathrm{mg} / \mathrm{mL}$, and only a limited effect was observed up to a concentration of $0.5 \mathrm{mg} / \mathrm{mL}$.

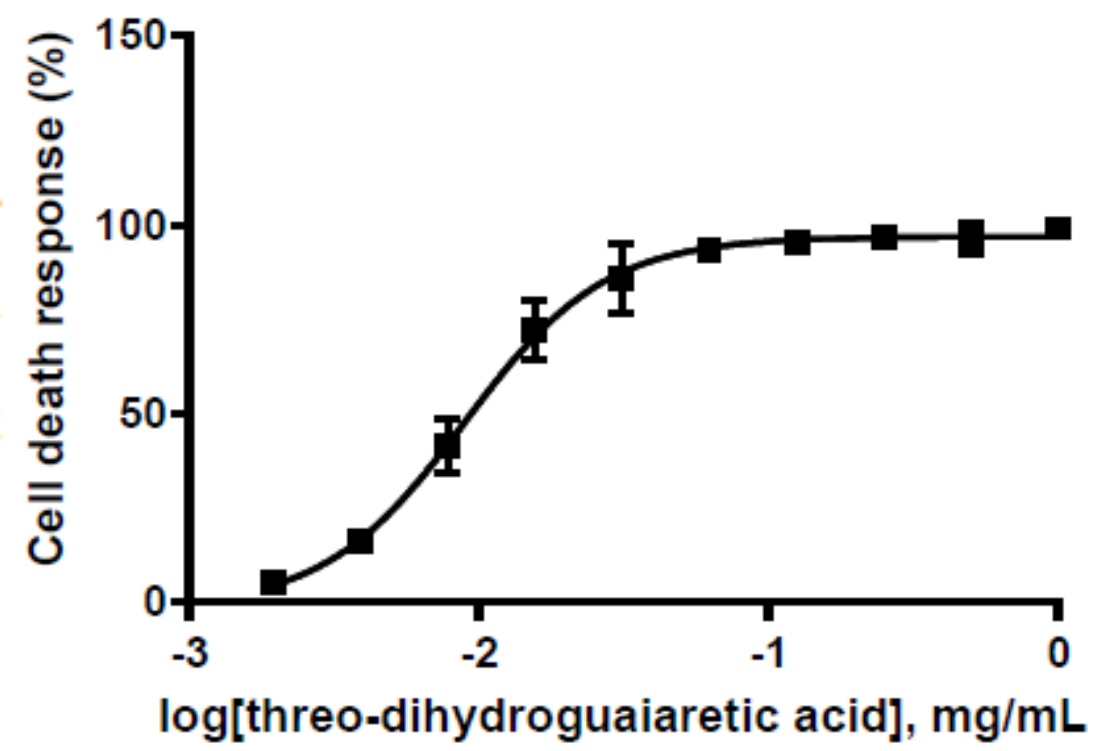

Figure 19: The impact of threo-dihydroguaiaretic acid on cell metabolic activity as measured by the MTT assay, reported as a cell death response (100 - \% control viability).

The mode of inhibition of threo-dihydroguaiaretic acid was determined by obtaining a Lineweaver-Burk plot (Figure 20). In addition to data collected without the inhibitor present, three concentrations of the compound were used: $0.05 \mathrm{mg} / \mathrm{mL}, 0.1 \mathrm{mg} / \mathrm{mL}$ and $1 \mathrm{mg} / \mathrm{mL}$ across a range of substrate concentrations: $0.01 \mathrm{mM}, 0.02 \mathrm{mM}, 0.05 \mathrm{mM}, 0.25$ $\mathrm{mM}$, and $2.5 \mathrm{mM}$ in the PPL bioassay. 


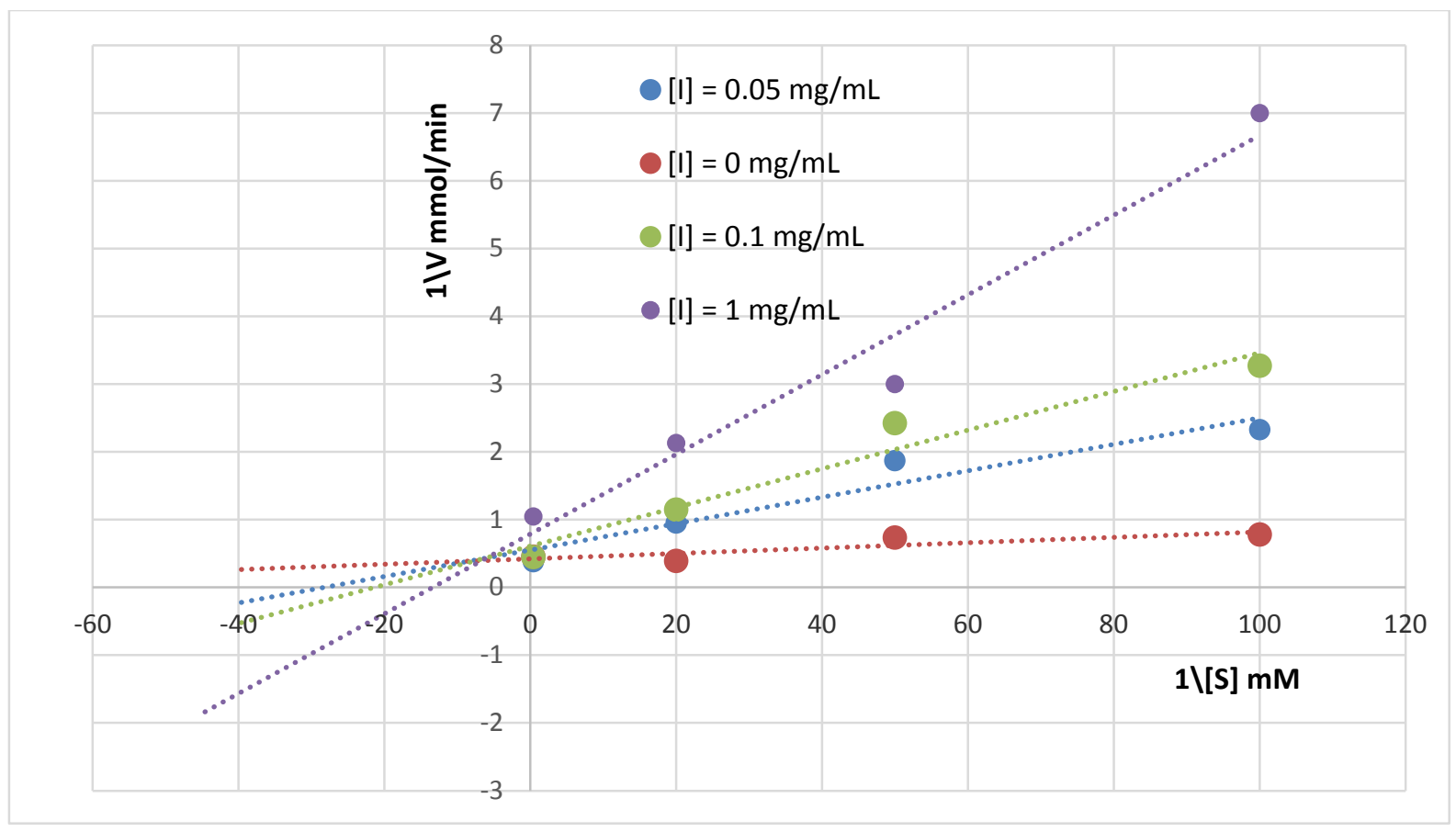

Figure 20: threo-dihydroguaiaretic Lineweaver-Burk plot

The Lineweaver-Burk plot showed a mixed inhibition of threo-dihydroguaiaretic acid and selective only towards PPL from running a side experiment to determine its activity against AG. The mixed inhibition model can be seen as the regression line for the three threo-dihydroguaiaretic acid concentrations and the non-inhibited data do not intercept at the $\mathrm{y}$-axis. The kinetic parameter Ki was further determined in the model using the Lineweaver-Burk plot gradient to plot against the threo-dihydroguaiaretic acid concentrations shown in Figure 21 to obtain a Dixon plot. The Ki and Ki' values for mixed inhibition according to our findings were $0.0196 \pm 0.0214 \mathrm{mg} / \mathrm{mL}$ and $2.41 \pm 1.427$ $\mathrm{mg} / \mathrm{mL}$ as calculated by Lucenz (Clark, 2004). These inhibitor dissociation constants relate to the interaction between inhibitor and enzyme (Ki) and inhibitor and enzymesubstrate (Michaelis) complex (Ki'). Under Cleland's nomenclature these are Kis and Kii respectively. For comparison, the clinically used lipase inhibitor orlistat was assayed under equivalent conditions. Its $\mathrm{IC}_{50}, \mathrm{Ki}$ and $\mathrm{Ki}$ ' values are shown in Table ㅇ. 
Table 8: PPL inhibition and MTT assays summary data

\begin{tabular}{|l|l|l|l|l|}
\hline Compound/drug & IC $_{50}(\mathrm{MTT})$ & $\mathrm{IC}_{50} \mathrm{PPL}$ & $\mathrm{Ki}$ & Ki' \\
\hline $\begin{array}{l}\text { Threo- } \\
\text { dihydroguaiaretic } \\
\text { acid }\end{array}$ & $\begin{array}{l}0.098 \mathrm{mg} / \mathrm{mL} \\
(297 \mu \mathrm{M})\end{array}$ & $\begin{array}{l}0.05 \mathrm{mg} / \mathrm{mL} \\
(151 \mu \mathrm{M})\end{array}$ & $\begin{array}{l}0.0196 \mathrm{mg} / \mathrm{mL} \\
(59.3 \mu \mathrm{M})\end{array}$ & $\begin{array}{l}2.41 \mathrm{mg} / \mathrm{mL} \\
(7293.75 \mu \mathrm{M})\end{array}$ \\
\hline Terameprocol & - & - & $\begin{array}{l}0.026 \pm 0.017 \\
\mathrm{mg} / \mathrm{mL} \\
(72.5 \mu \mathrm{M})\end{array}$ & - \\
\hline Orlistat & $\begin{array}{l}0.125 \mathrm{mg} / \mathrm{mL} \\
251.75 \mu \mathrm{M}\end{array}$ & $\begin{array}{l}0.015 \mathrm{mg} / \mathrm{mL} \\
30.26 \mu \mathrm{M}\end{array}$ & - & - \\
\hline
\end{tabular}

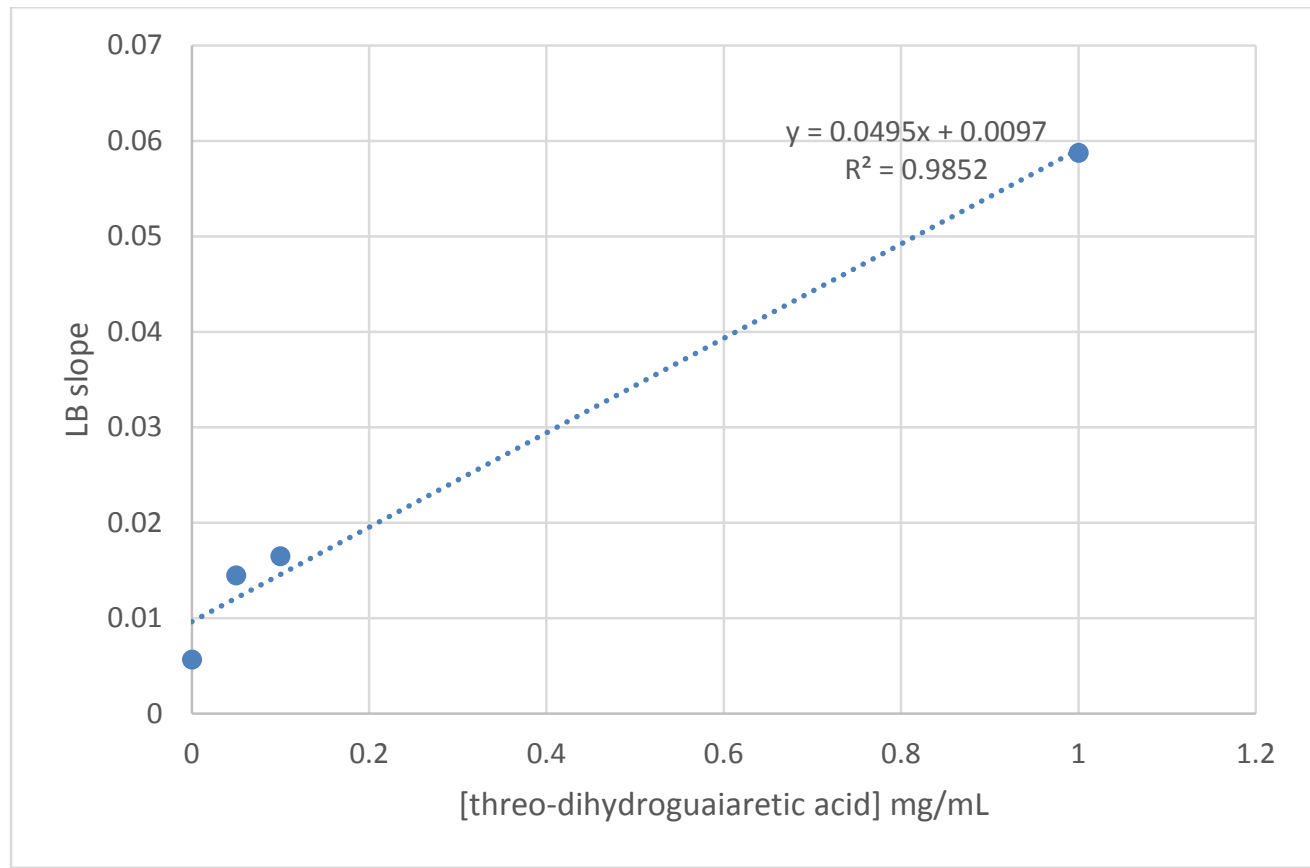

Figure 21: Dixon plot for the inhibition of PLL by threo-dihydroguaiaretic acid

Terameprocol is a commercially available compound having a close structure to threodihydroguaiaretic acid (Figure 22) and was assayed against the same concentration range of substrate to monitor its reaction and bioassay activity against PPL to determine whether this activity extends across this class of compounds. Its kinetic model is shown in Figure 23. It is not clear whether competitive or mixed inhibition models best fit the data. Analysis with Lucenz provided equivalent fit metrics for the two models, although on the basis of structural similarity to threo-dihydroguaiaretic acid and the unmodelled best fit lines of Figure 20, it is likely that terameprocol is a mixed inhibitor 
of PPL. The Ki values for either mode of inhibition was $0.026 \pm 0.017 \mathrm{mg} / \mathrm{mL}$ as determined using Lucenz (Clark, 2004). It is clear from comparison of the two Lineweaver-Burk plots and from the data shown in Table 5, termeprocol and threodihydroguaiaretic acid exhibit similar levels of inhibition of PPL.

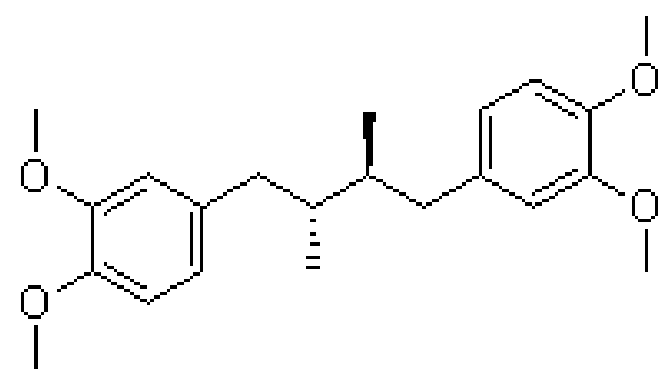

Figure 22: terameprocol molecular structure

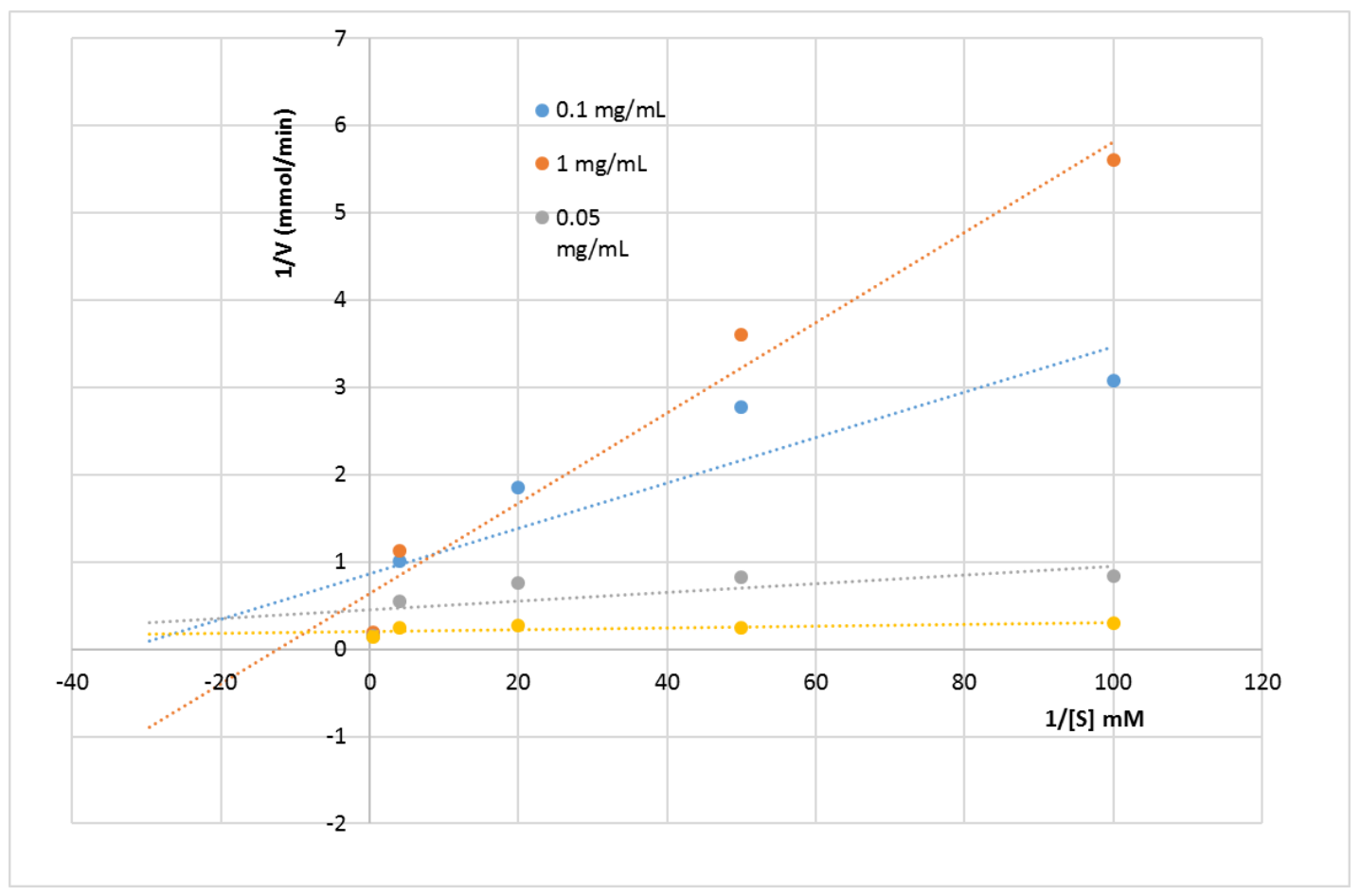

Figure 23: Terameprocol Lineweaver-Burk plot 


\subsection{DISCUSSION OF LIPASE INHIBITION}

A previous report on the crude ethanolic extract of Myristic fragrans by Siew-Li Ong using the mace of ripe mace fruit showed $20.23 \pm 0.25 \%$ inhibition at $0.1 \mathrm{mg} / \mathrm{mL}$ compared to the $49-51 \%$ inhibition in this study at $1 \mathrm{mg} / \mathrm{mL}$ and $10-49 \%$ at $0.1 \mathrm{mg} / \mathrm{mL}$ against PPL. However, the difference in activity compared to Myristica fatua used in this study may reflect different compounds existing in the extracts, or from a higher fractionation efficiency in this study using HP20 resin, compared to Ong's use of a crude ethanol extract. Our study also used the whole fruit extract mixture without separating the mace, pericarp and the seed. In the same study by Siew-Li Ong, inhibition from other parts of the ripe female pericarp of the fruit was $10.33 \pm 0.32 \%$. As their research suggested further work should be done to isolate the potential lipase inhibitor, this study shows the advantage of enhanced fractionation and additionally investigating closely related species to Myristica fragrans.

The inhibition obtained from Atone75 and Atone100 in this study is comparable to the outcome recorded by Dechakhamphu and Wongchum (2015) from their research on screening 28 traditional Thai medicinal plants for anti-lipase activity. Across their assayed extracts, at a concentration of $0.1 \mathrm{mg} / \mathrm{mL}, 12$ were inactive ( $<10 \%$ inhibition), 9 gave activities ranging from $10-70 \%$ inhibition, and 7 showed $>80 \%$ inhibition. Impressively, their extracts of four herbs, Memecylon edule Roxb., Garcinia vilersiana Pierre, Cryptolepis elegans Wall, and Phyllanthus chamaepeuce Ridl., strongly inhibited PPL by 90.97\%, 92.04\%, 94.64\% and 95.38\%, respectively compared to their recorded orlistat $\%$ of $>96 \%$. However, the compounds responsible for these high levels of inhibition were not isolated and characterised, nor is it known whether there is synergy between active components of the extracts.

Other studies carried out using mainly traditional plants (Roh \& Jung, 2012) on forty four plant extracts at concentration of $0.1 \mathrm{mg} / \mathrm{mL}$ as shown in Table 9 which was similar to the range of inhibition in our study, $10.5-31.4 \%$, and orlistat $>98 \%$ inhibition. Other studies on a few plant species have indicated inhibitory effects at various concentration of extracts $(0.1-5.0 \mathrm{mg} / \mathrm{mL})$ e.g. as those shown by llex paraguariensis at $3 \mathrm{mg} / \mathrm{mL}$ (Martins, et al., 2009), and of thirty seven traditional Chinese medicinal herbs at $0.2 \mathrm{mg} / \mathrm{mL}$ (Zheng, Duan, Gao, \& Ruan, 2010). There was also a wide variation in 
the lipase inhibition at various concentrations of the extracts tested, for example, at extract concentration of $0.2 \mathrm{mg} / \mathrm{mL}$ as shown in Table 9.

Table 9: PPL inhibition compared to orlistat + ve control previous study

\begin{tabular}{|l|l|l|l|}
\hline Author(s) of study & Extract(s) & Inhibition/range & $\begin{array}{l}\text { +ve control } \\
\text { activity (orlistat) }\end{array}$ \\
\hline Roh and Jung (2012) & 44 Plant extracts & $1.8-38.0 \%$ & $42.0 \%$ \\
\hline $\begin{array}{l}\text { Zheng and peers } \\
(2010)\end{array}$ & 37 Chinese herbs & $-11.0-74.7 \%$ & $93.5 \%$ \\
\hline $\begin{array}{l}\text { Dechakhamphu and } \\
\text { Wongchum (2015) }\end{array}$ & 28 Thai plants & $\begin{array}{l}10 \% \text { inhibition (12 } \\
\text { plants) } \\
10-70 \% \text { (9 plants) } \\
>80 \% \text { (7 plants) }\end{array}$ & $>96 \%$ \\
\hline
\end{tabular}

The inhibition range from our investigation at concentrations $1 \mathrm{mg} / \mathrm{mL}$ and $0.1 \mathrm{mg} / \mathrm{mL}$ are slightly higher than the works reported by Roh and Jung (2012), but lies within the range from Zheng and peers (2010) on Chinese medicinal herbs. As there has been some research on the closely related species, Myristica fragrans, a comparison to the fruit of Myristica fatua shows it to be more active.

There has been some research investigating the inhibition activity of dibenzylbutane lignans from the fruit extracts of Myristica fragrans against lipoxygenase with IC $_{50}$ value as low as $0.46 \pm 0.2 \mu \mathrm{M}$ from an isolated lignan demethyldihydroguaiaretic acid (DDGA, Figure 24) (Asgarpanah \& Kazemivash, 2012). DDGA is very closely related to the threo-dihydroguaiaretic acid studied here, with the difference only relating to the additional methyl substituent in threo-dihydroguaiaretic acid. 


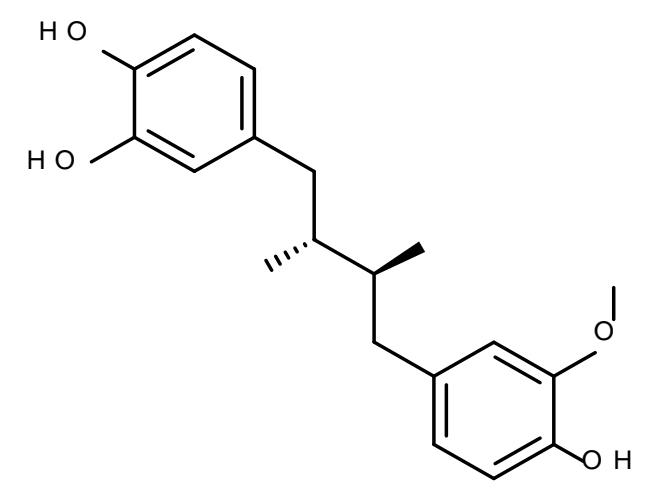

Figure 24: DDGA chemical structure

However, there has been no study being carried out in specific identification of compounds isolated from Myristica fragrans against lipase or $\alpha$-glucosidase. Lipoxygenase and lipase enzymes are both involved in lipid metabolism, however their chemistry differs. Lipoxygenase catalyzes the oxidation of polyunsaturated fatty acids to hydroperoxides whereas lipase is responsible for hydrolysis of triacylglycerol as explained in Section1.4.3. Therefore, this study compliments previous research in targeting inhibitors from nutmegs.

As presented in the kinetic modelling of the isolated compound against PPL, it exhibited a mixed inhibition mode. This mode of inhibition was also previously observed from a study by Shannon and peers (2017) on the activity of black tea theaflavins against PPL. They proposed on the basis of in silico modelling that there was a ligand binding site on PPL adjacent to the substrate binding site. This adjacent ligand binding site would provide characteristics of mixed inhibition, where the inhibitor has to be able to bind both free enzyme and enzyme-substrate complex. Their modelling suggested that the ligand binding site would accommodate the galloyl ester moiety Figure 25 of the theaflavin, (Shannon, Grove, Yennawar, \& Lambert, 2017) and so is likely to be able to accommodate the similar phenolic termini of threodihydroguaiaretic acid. 


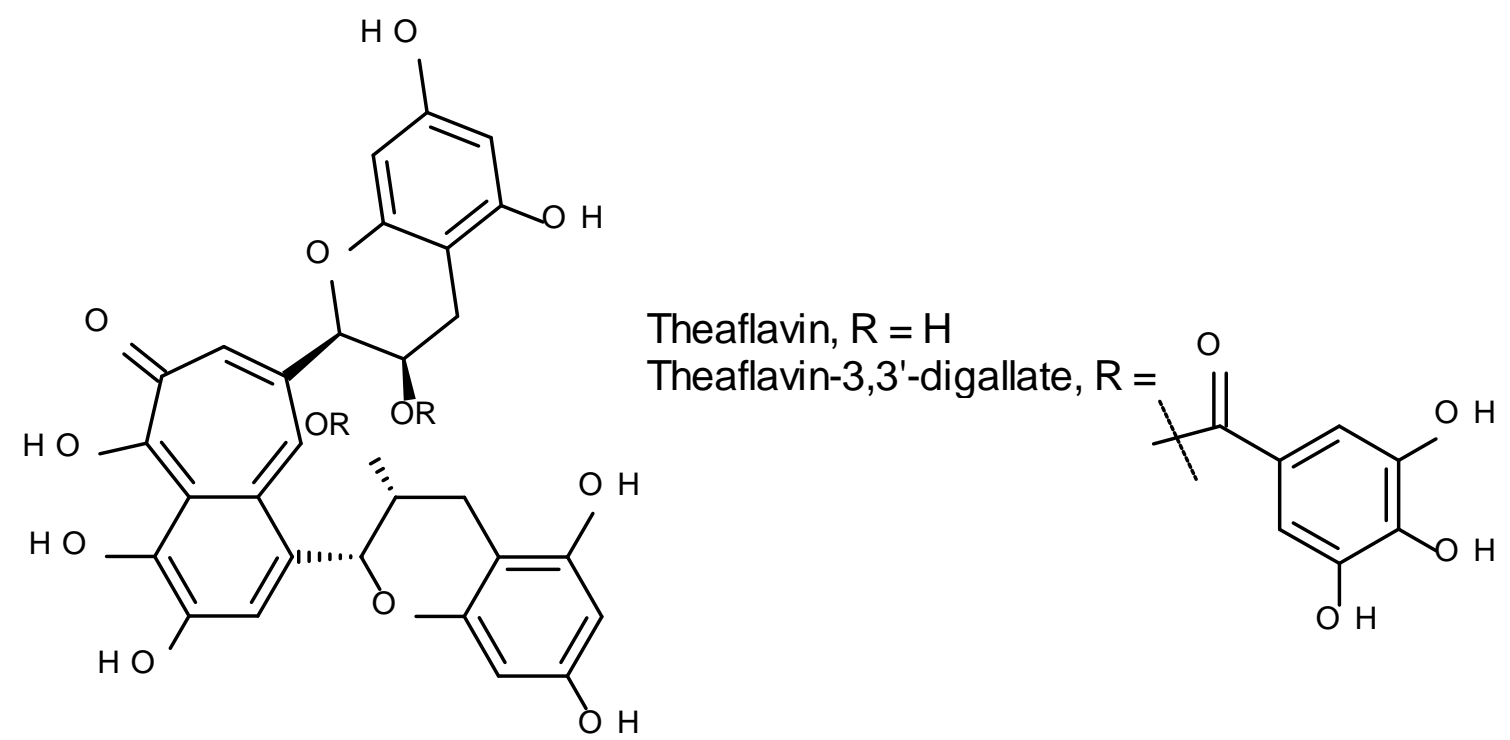

Figure 25: The structures of theaflavin and more potent mixed inhibitor PPL, theflavin-3,3'-digallate

Two studies have looked directly at the control of diabetes using extracts from Myristica fragrans. In the first of these, Somani and Singhai (2008) evaluated a petroleum ether extract of the seed of Myristica fragrans by monitoring the blood glucose of alloxan-induced diabetic rats. Ahmad and colleagues (2008) treated streptozotocin-induced diabetic rats with an ethanolic extract of Myristica fragrans. In both studies, they concluded that the Myristica fragrans extract possesses potential as an antidiabetic and highlighted the need for further studies to elucidate its mode of action. However, Somani and Singhai noted that an increase in the dose of the extract resulted in an increased body weight, which might be due to increased insulin secretion and better glycaemic control. From these past studies, it is evident that the extract of different parts of Myristica fragrans will yield bioactive compounds and thus give it potential in its bioactivity.

Terameprocol, a compound closely related to threo-dihydroguaiaretic acid, exhibits a similar level of PPL inhibition. This suggests that it may be possible to carry out a structure-activity relationship analysis on compounds of this class. However, whilst this study has shown that terameprocol and threo-dihydroguaiaretic acid inhibit PPL and previous work has shown demethyldihydroguaiaretic acid inhibits lipoxygenase (Asgarpanah \& Kazemivash, 2012), terameprocol has been shown to interact with DNA 
and impact on transcription of targets including surviving at concentrations (Sun et al., 2011), and this occurs below the Ki value determined here for PPL inhibition. Taken together, these compounds may exhibit characteristics of the PAINS discussed in section 1.3.1.

In summary, from the study presented it is clear that either the threo-dihydroguaiaretic acid or extracts of Myristica fatua that are rich in this compound may have potential to be developed to control obesity, and thereby diabetes. Whilst the $\mathrm{IC}_{50}$ values from the PPL inhibition and MTT assays are similar, it is concerning that the value from the MTT assay is the lower of the two. Set against this, the use of extracts of related species of plant suggest that toxicity in not likely to be limiting, however the care will need to be taken in any further development of this compound given the $\mathrm{LD}_{50}$ of threodihydroguaiaretic acid of $75 \mathrm{mg} / \mathrm{kg}$ when administered IP in the mouse (Lambert et al., 2002). Further note of caution is that the closely related compounds DDGA and terameprocol inhibits lipoxygenase and transcription respectively, and do so at concentrations below the $\mathrm{IC}_{50}$ value of $151 \mu \mathrm{M}$ found here for the inhibition of PPL by threo-dihydroguaiaretic acid. The ability of either a Myristica fragrans extract or isolated threo-dihydroguaiaretic acid to inhibit a wider range of lipid-processing enzymes and other targets needs to be considered in any future developments. 


\subsection{ALPHA-GLUCOSIDASE}

The results obtained from the preliminary screening of extracts in this study against AG showed low activity $<40 \%$ except for high acetone in water fractions from Neisosperma oppositifolia shown in

Table 10. Fao75 showed the highest inhibition $(78.9 \pm 1.18 \%$ at $1 \mathrm{mg} / \mathrm{mL})$. Thus this fraction was further partitioned and sub-fractions analysed for AG inhibition. A high level of AG inhibition was also noted in the $100 \%$ acetone fraction, as shown in

Table 10. TLC analysis was undertaken to evaluate the purity of the fractions obtained and to compare fractions to reveal possible common components.

\section{Table 10: AG inhibition percentages}

\begin{tabular}{|c|c|c|c|c|}
\hline Samoan name & Scientific name & Fraction (\%) & $\begin{array}{l}0.1 \\
\mathrm{mg} / \mathrm{mL}\end{array}$ & $1 \mathrm{mg} / \mathrm{mL}$ \\
\hline \multirow[t]{3}{*}{ Fao } & $\begin{array}{l}\text { Neisosperma } \\
\text { oppositifolium }\end{array}$ & 30 & $27.8 \pm 0.12$ & $47 \pm 0.24$ \\
\hline & & 75 & $79.5 \pm 0.31$ & $78.9 \pm 1.18$ \\
\hline & & 100 & $81.1 \pm 0.20$ & $78.4 \pm 0.13$ \\
\hline \multirow[t]{3}{*}{ Atone } & Myristica fatua & 30 & $37 \pm 0.14$ & $48 \pm 0.06$ \\
\hline & & 75 & $31 \pm 0.10$ & $47 \pm 0.07$ \\
\hline & & 100 & $42 \pm 0.11$ & $48 \pm 0.11$ \\
\hline \multirow[t]{3}{*}{ Falaga } & Barringtonia samoensis & 30 & $27.6 \pm 0.11$ & $24.3 \pm 0.23$ \\
\hline & & 75 & $20 \pm 0.25$ & $26.2 \pm 0.48$ \\
\hline & & 100 & $17.6 \pm 0.87$ & $17.6 \pm 0.98$ \\
\hline \multirow[t]{3}{*}{ Sasalapa } & Annona muricata & 30 & $26.7 \pm 0.36$ & $33.7 \pm 0.21$ \\
\hline & & 75 & $14.3 \pm 0.21$ & $17.5 \pm 0.33$ \\
\hline & & 100 & $32.4 \pm 0.91$ & $41.5 \pm 0.30$ \\
\hline \multirow[t]{2}{*}{ Futu } & Barringtonia asiatica & 30 & $22.7 \pm 0.14$ & $38.2 \pm 0.71$ \\
\hline & & 75 & $18.2 \pm 0.72$ & $39.5 \pm 5.68$ \\
\hline
\end{tabular}




\begin{tabular}{|l|l|l|l|l|}
\hline & & 100 & $38.2 \pm 0.73$ & $41.3 \pm 0.21$ \\
\hline
\end{tabular}

Sub-fractions for Fao75-100 showed the highest activity at $81.2 \pm 1.39(1 \mathrm{mg} / \mathrm{mL})$ and $69.7 \pm 0.06(0.1 \mathrm{mg} / \mathrm{mL})$ shown in

Table 11 . The sub-fractions of $100 \%$ acetone fraction was also noted to have high inhibition.

\section{Table 11: Fao75-100 AG inhibition}

\begin{tabular}{|c|c|c|c|c|c|}
\hline $\begin{array}{l}\text { Samoan } \\
\text { name }\end{array}$ & Scientific name & $\begin{array}{l}\text { Fraction } \\
\text { (\% acetone) }\end{array}$ & $\begin{array}{l}\text { Sub- } \\
\text { fraction } \\
\text { (\% acetone) }\end{array}$ & $0.1 \mathrm{mg} / \mathrm{mL}$ & $1 \mathrm{mg} / \mathrm{mL}$ \\
\hline \multirow[t]{15}{*}{ Fao } & $\begin{array}{l}\text { Neisosperma } \\
\text { oppositifolium }\end{array}$ & 30 & 20 & $2.1 \pm 0.12$ & $7.2 \pm 0.02$ \\
\hline & & & 30 & $2.4 \pm 0.03$ & $12.5 \pm 0.28$ \\
\hline & & & 40 & $13.6 \pm 0.15$ & $33.4 \pm 0.04$ \\
\hline & & & 50 & $16.4 \pm 0.06$ & $35.4 \pm 0.2$ \\
\hline & & & 100 & $24.2 \pm 0.24$ & $54.5 \pm 0.16$ \\
\hline & & 75 & 40 & $11.4 \pm 0.12$ & $13.4 \pm 0.23$ \\
\hline & & & 50 & $18.9 \pm 0.12$ & $23.4 \pm 0.02$ \\
\hline & & & 60 & $25.7 \pm 0.04$ & $30.9 \pm 0.11$ \\
\hline & & & 70 & $26.3 \pm 0.11$ & $46.3 \pm 0.05$ \\
\hline & & & 100 & $69.7 \pm 0.06$ & $81.2 \pm 1.39$ \\
\hline & & 100 & 40 & $50.3 \pm 0.14$ & $62.8 \pm 0.12$ \\
\hline & & & 50 & $48 \pm 0.12$ & $58.5 \pm 0.21$ \\
\hline & & & 60 & $40.1 \pm 0.01$ & $70.2 \pm 0.31$ \\
\hline & & & 70 & $59.7 \pm 0.05$ & $74.5 \pm 0.04$ \\
\hline & & & 100 & $64.3 \pm 0.12$ & $71.1 \pm 0.07$ \\
\hline
\end{tabular}

TLC plates were used for an initial assessment of the number of major compounds in the non-polar sub-fractions with highest inhibition. Finally, the 20:1 and 9:1 hexane:ethyl acetate fractions from the silica column of Fao100-100 were analysed by LC-MS/MS and NMR. Although TLC did not reveal the purity of the obtained sub- 
fraction, LC-MS revealed the presence of at least 3 major components. On the basis of TLC and LC-MS analysis, the sub-fraction was shown to be free of DEHP.

The LC-MS/MS analysis of the fraction showed it contained at least three major compounds. This was consistent with the NMR screening, which shows the fraction to be a complex mixture of compounds that could not be identified from proton, carbon, or COSY and HSQC spectra. LC-MS/MS analysis of the extract was carried out in order to provide spectral data that might give preliminary identification of the extract composition using the GNPS database (See Section 1.3.3).

Using the auto MS/MS mode, the main molecular ions observed from the LC-MS/MS analysis had $\mathrm{m} / \mathrm{z}$ values of 287.12, 329.22, and 415.21 which eluted from the C18 column at 5.547, 6.091 and 8.215 min respectively. Targeted LC-MS/MS data was obtained for each of the significant masses from the auto MS/MS and used as input for the GNPS database. The compound with mass $[\mathrm{M}+\mathrm{H}]^{+}$of 415.21 gave a match with cosine value of 0.89 , MassDiff $=0.001$, to the library compound $6-[3-[(3,4-$ dimethoxyphenyl)methyl]-4-methoxy-2-(methoxymethyl)butyl]-4-methoxy-1,3benzodioxole, also known as niranthin with structure shown in Figure 26.

The match came from a Gold class entry in the GNPS natural products library, matching 25 peaks in the daughter ion spectra between the submitted and library spectra. An additional match to the same compound was obtained from a user-contributed GNPS entry from the Jadhav/Dorrestein lab. This shared 28 peaks with the same cosine value of 0.89 and suggesting the real mass of compound to be $432.215 \mathrm{~m} / \mathrm{z}$ due to the loss of $\mathrm{H}_{2} \mathrm{O}$ from the mass spectrum as shown in the GNPS file. LC-MS/MS methods and experimental details are in Section 3.7.1. 


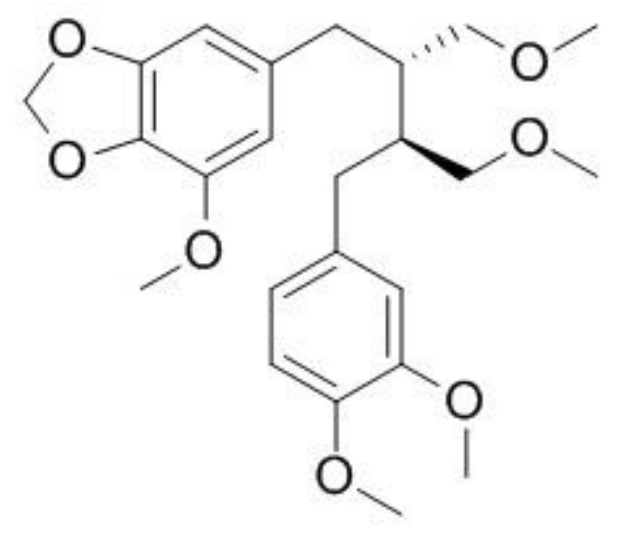

Figure 26: Niranthin chemical structure

The spectra of compounds with $\mathrm{m} / \mathrm{z}$ values of 287.12 and 329.22 were similarly submitted to GNPS, giving matches to three different structural fragment hits with masses $122.10 \mathrm{~m} / \mathrm{z}, 132.08 \mathrm{~m} / \mathrm{z}$ and $411.20 \mathrm{~m} / \mathrm{z}$. The lower molecular weight matches might reflect fragments of the higher mass ions identified from LC-MS/MS, whereas the match to a database compound of mass 411.20 from extract $\mathrm{m} / \mathrm{z}$ values of 329.22 or below may reflect either that the $\mathrm{m} / \mathrm{z}$ values of 287.12, 329.22 arise from fragments of a larger molecule in the extract or that there are shared structural motifs between the $411.20 \mathrm{~m} / \mathrm{z}$ library hit and the species with $\mathrm{m} / \mathrm{z}$ values of 287.12, 329.22 from the active fraction.

The structure of $122.10 \mathrm{~m} / \mathrm{z}$ GNPS library hit (2,4,6-trimethylpyridine, shown in Appendix ) was observed in the spectra of both the components with $\mathrm{m} / \mathrm{z}$ of 287.12 and 329.22 with cosines of 0.96 and 0.95 respectively. However, the compound $132.08 \mathrm{~m} / \mathrm{z}$, 2-methylindole, with a high cosine value of 0.98 was only present in $287.12 \mathrm{~m} / \mathrm{z}$ fragment, suggesting that the two spectra are from daughter ions of different parent molecules.

Further analysis using the GNPS de-replication tool for each of the mass spectra gave the same compounds as shown above for the best match from the spectral libraries available in GNPS. There were other compound hits from the de-replication workflow but only with very low quality match statistics. The de-replication workflow was also applied to the already identified compound with $\mathrm{m} / \mathrm{z}$ of 415.21 . Given the quality of the 
match from the initial search, it is not surprising that no alternative matches were found with acceptable statistics.

Taken together, the LC-MS/MS paired with GNPS analysis revealed that the fraction of Neisosperma oppositifolia that was active against AG contained at least 3 compounds. One of these was identified with high confidence as the known plant natural product niranthin. The remaining two compounds have not been identified, however there were GNPS fragment matches to 2,4,6-trimethylpyridine in both molecules and 2methylindole in the lower $\mathrm{m} / \mathrm{z}$ ion. These identified fragments make it likely that these additional compounds present in the fraction are alkaloids. As shown in previous studies (Ahmad K. , 2009; Ahmad, et al., 2010), Neisosperma oppositifolia is rich in alkaloids, and even its bark has shown to possess novel alkaloid compounds.

The 50\% inhibition concentration of compound mixture from Fao75-100 was calculated from a range of different extract concentrations in the bioassay analysis against AG shown in Figure 27 . The $50 \%$ inhibition was estimated at $\sim 0.03 \mathrm{mg} / \mathrm{mL}$.

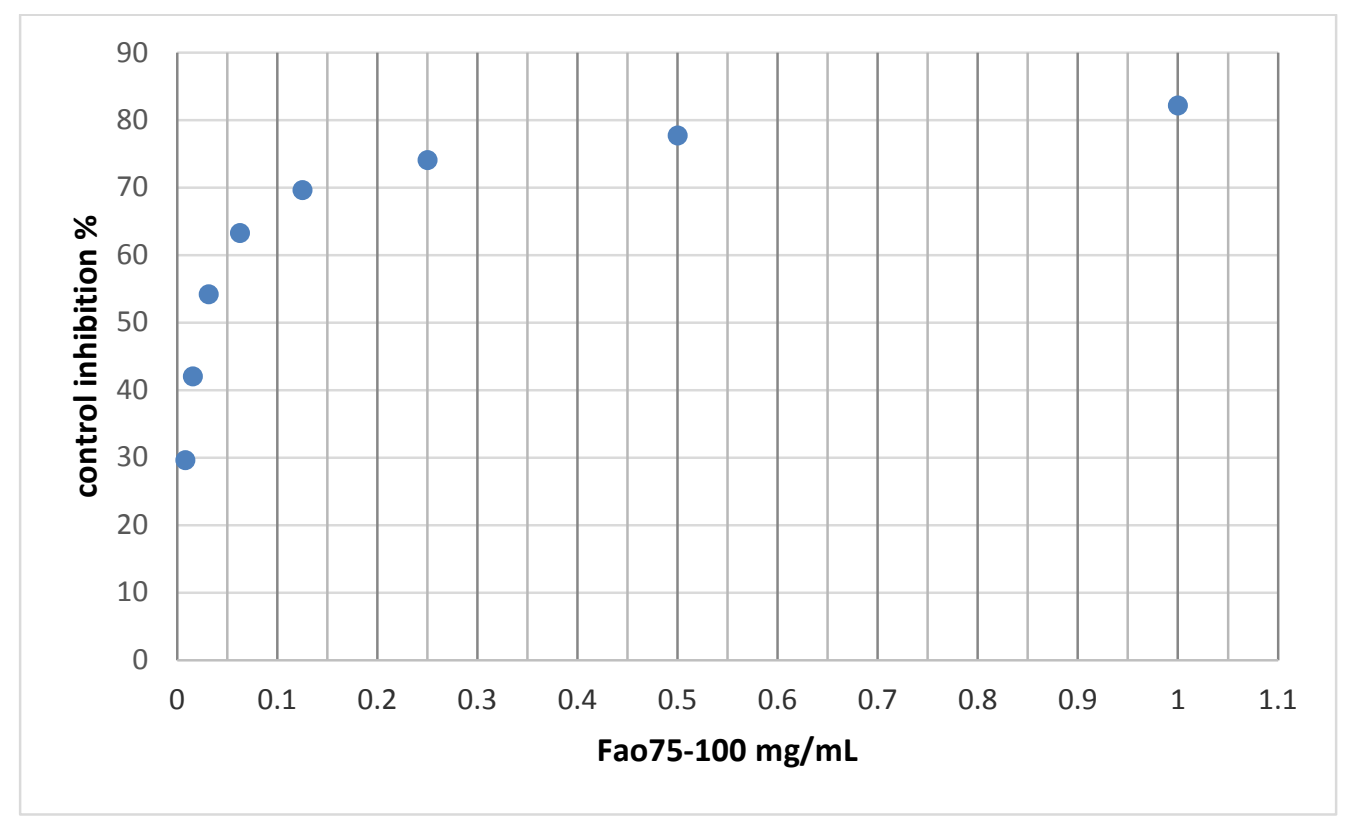

Figure 27: Fao75-100 AG inhibition, plotted as \% activity of untreated control.

The MTT assay to test for the toxicity of F75-100 using HL 60 cells appears to be more toxic than the purified threo-dihydroguaiaretic acid isolated from Myristica fatua in this 
study. The $50 \%$ cell viability obtained was $0.005 \pm 0.0018 \mathrm{mg} / \mathrm{mL}$ concentrations shown in Figure 28.

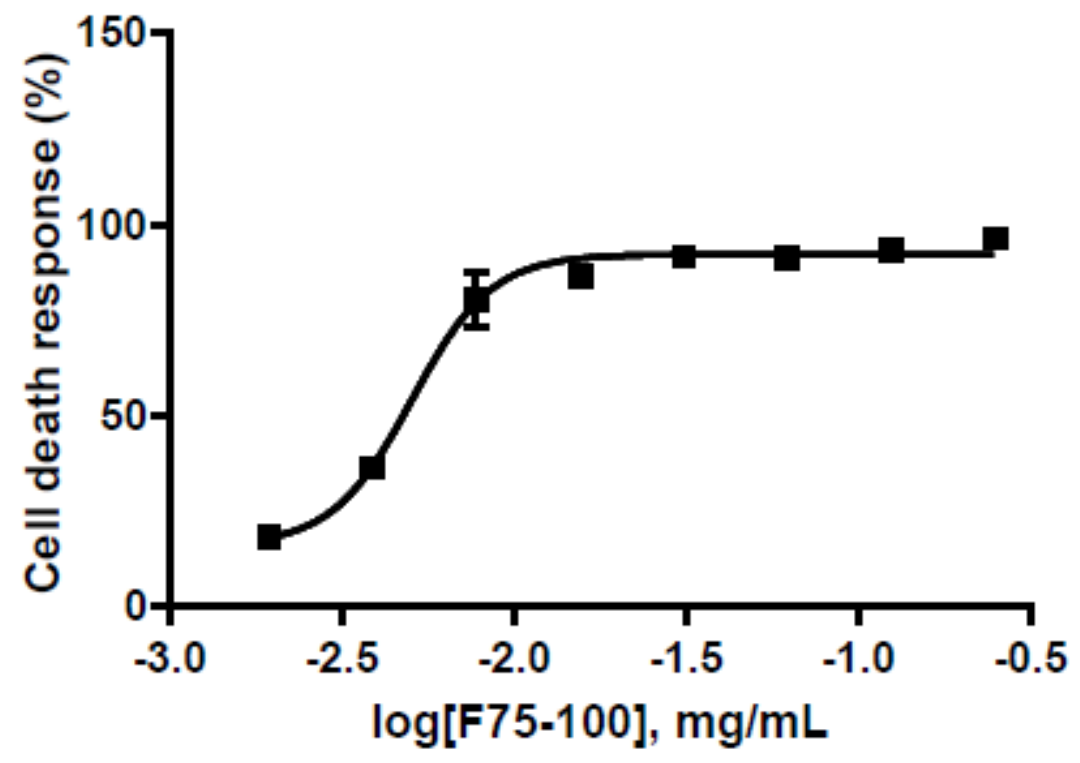

Figure 28: Fao100-100 cytotoxicity assay plot

The type of inhibition of Fao100-100 on $\alpha$-glucosidase action was determined by increasing substrate PNPG concentration. The product of 4-nitrophenol for each concentration was determined by plotting concentrations of 4-nitrophenol as explained in the experimental Section 2.3. The Lineweaver-Burk plot (Figure 29) shows the Fao100-100 to be a competitive inhibitor of the AG enzyme. 


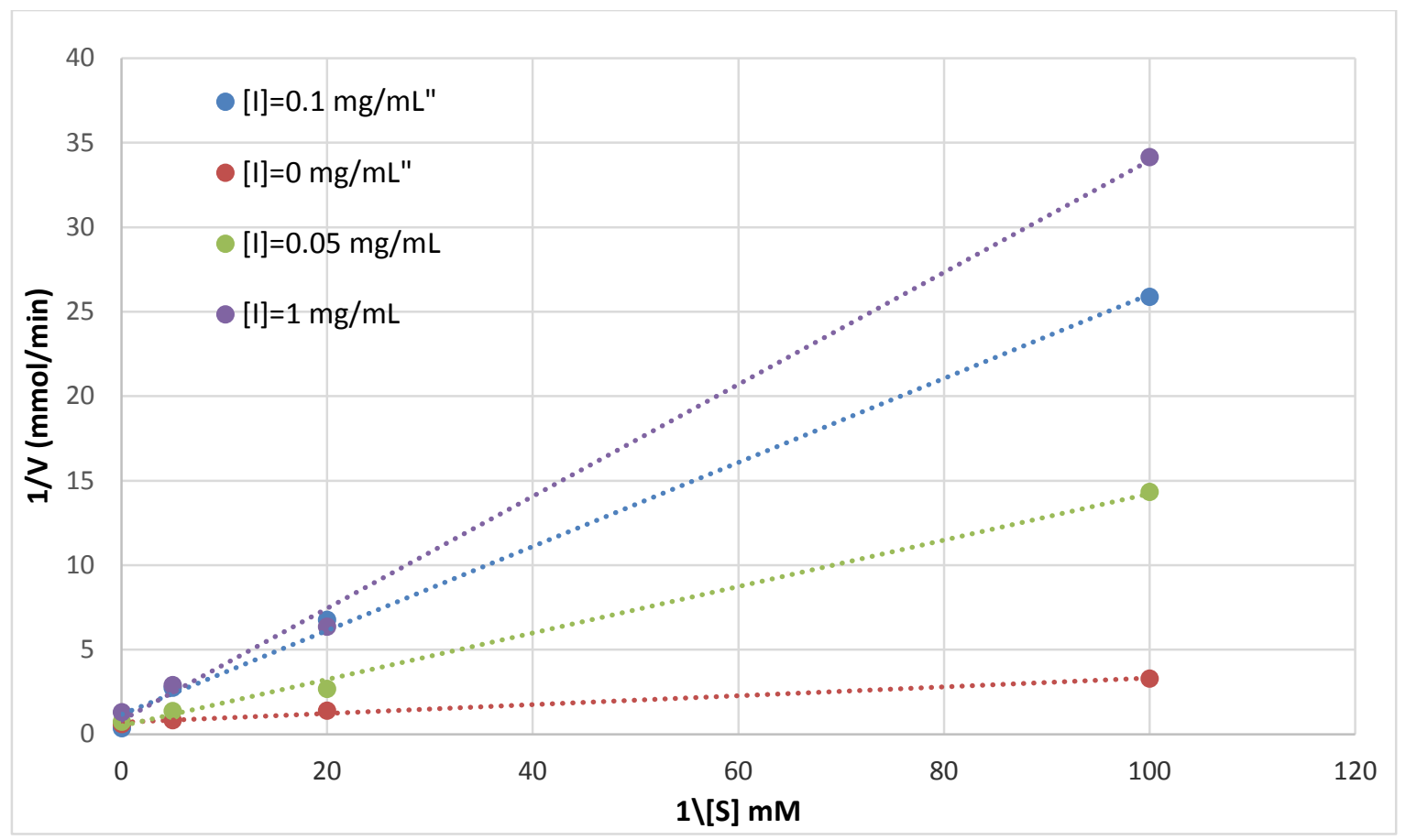

Figure 29: Fao100-100 Lineweaver-Burk plot

Plant extracts with concentrations of $1.0 \mathrm{mg} / \mathrm{mL}, 0.1 \mathrm{mg} / \mathrm{mL}$ and $0.05 \mathrm{mg} / \mathrm{mL}$ were incubated with enzyme prior to the addition of the 4-nitrophenyl- $\alpha$-D-glycoside (PNPG) substrate at concentrations of $0.02 \mathrm{mM}, 0.05 \mathrm{mM}, 0.2 \mathrm{mM}$ and $20 \mathrm{mM}$ were used to determine. Kinetic parameters were obtained from the Lineweaver Burk plot Figure 20: Ki was calculated at $0.0928 \mathrm{mg} / \mathrm{mL}$. The Fao100-100 extract did not inhibit PPL, thereby suggesting that it is not a non-selective enzyme inhibitor. It is notable that the Ki for AG inhibition $(0.0928 \mathrm{mg} / \mathrm{mL})$ is roughly 20 -fold higher than the $\mathrm{IC}_{50}$ observed for the MTT assay $(0.005 \pm 0.0018 \mathrm{mg} / \mathrm{mL})$.

\subsection{DISCUSSION OF ALPHA-GLUCOSIDASE}

A study previously investigating an extract of Phyllanthus amarus isolated niranthin as one of its major compounds and the extract was reported to be have antimalarial activity (Nbgolua, et al., 2015). Niranthin was also isolated from Phyllanthus niruri having antihepatitis B virus activity as reported by Sheng and peers (2014) using in vivo and in vitro models. Thus, although there is limited information on the application of niranthin 
as an anti-diabetic treatment, it is encouraging that it has been considered as a possible treatment for other conditions.

Alkaloids from plants have previously been identified as potent antidiabetics and others have identified their activity against AG. The study presented by Tiong and colleagues (2013) isolated and identified four alkaloids from leaf extract of Catharanthus roseus having high inhibition against tyrosine phosphatase-1B, indicating potential as type 2 diabetic treatment. Their findings also supported antioxidant activity of the alkaloids being isolated from this species (Tiong, et al., 2013).

A total of 37 alkaloids from the leaves of Adhatoda vasica were tested against AG activity by Yinet and colleagues (2014). Two of these compounds shown in (Figure 30) were shown to inhibit AG competitively. Other strong AG inhibitors mentioned in this paper such as deoxynojirimycin and (2R,3R,4R,5R)2,5-bis(hydroxymethyl)-3,4dihydroxypyrrolidine have antiviral biological activities (Yinet, al., 2014)
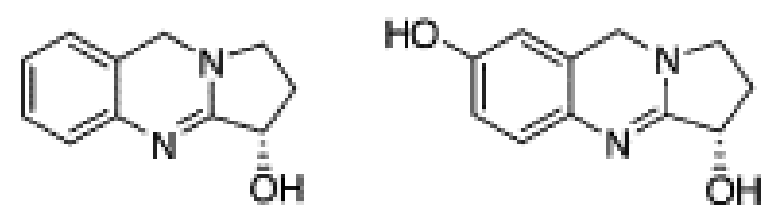

\section{Figure 30: (-)Vasicine \& (+) Vasicinol}

A Malaysian anti-diabetic study (Ahmad K. , 2009) of the stem bark of Neisosperma oppositifolia showed several bioactive compounds. Their approach to utilise MS and NMR techniques is similar to our approach. Although the preliminary study presented here was unable to identify specific compounds in the time available, Ahmad and coworkers were able to isolate two new natural products from their work: Oppositinines A and $\mathrm{B}$.

The inhibition of AG by ethanolic extract of stem bark Acacia nilotica carried out by Natasha and colleagues (2012) also having competitive inhibition recorded a much lower IC $_{50}$ value of $\sim 8 \mu \mathrm{g} / \mathrm{mL}$ (Jaiswal, et al., 2012) which compares favourably with the $0.03 \mathrm{mg} / \mathrm{mL} \mathrm{IC}_{50}$ found for the Fao100-100 sub-fraction. However, the activity from our studies was within the range observed from inhibition by extracts of Aegle 
marmelos and Citrullus colocynthis against AG at $72.23 \pm 0.30 \%$ and $85.9 \pm 0.10 \%$ respectively at $1 \mathrm{mg} / \mathrm{mL}$ (Gurudeeban, et al., 2012).

The results here partially support earlier reports of the use of Neisosperma oppositifolia for antidiabetic treatment in Malaysia (Kartini, 2009). However, the work presented here is very preliminary, and further work needs to be done in order to identify the unknown compounds in the extract by further purification and NMR analysis of those that have the highest activity. Due to the much higher level of inhibition of cell metabolism, revealed by the MTT assay, compared to AG inhibition as well as the difficulty in further separation, this additional work was de-prioritised in the study presented here, and needs to be carefully considered when evaluating the potential of this extract of the Fao for AG inhibition. However, the fraction is a mixture, and the active component for AG inhibition may not be the same one that was responsible for the cytotoxic or cytostatic effects.

\subsection{CONCLUSION}

In following the motivation from Whistler, the aim of this project was to identify Samoan plants that have bioactive compounds with potential to inhibit specific target enzymes for treatment of diabetes and obesity: $\alpha$-glucosidase and lipase. These enzymes were used for in vitro screening of carefully selected plants. A preliminary screening narrowed the plant selection to five Samoan plants: Annona muricata, Barringtonia samoensis, Barringtonia asiatica, Myristica fatua, and Neisosperma oppositifolia used in this study.

Bioactivities of the selected plants were determined using optimised bioassays of the enzymes. A range of conditions were tested and carefully evaluated in order to produce reliable results for specific fractionation of each extract. Where possible, compounds in the extract fractions of plant samples that were most active in the in vitro screening were identified using reverse-column chromatography linked to mass spectrometry, and also by NMR spectroscopy.

An active fraction of the extract of Neisosperma oppositifolia was identified as a competitive inhibitor of AG. This extract contained at least three major compounds. 
Mass spectrometry and a search through the GNPS database identified the presence of nirathin and other unknown alkaloids. Further investigation of this particular plant species was not carried out in this study as there were concerns over potential toxicity: the $\mathrm{IC}_{50}$ found for inhibition of cellular metabolism as found through the MTT assay was almost 20-fold lower than the Ki found for AG inhibition. However, use in Malaysia of extracts of this plant to control diabetes suggests that there may be an avenue for future work. It is possible that the toxicity and AG inhibition result from different compounds in the mixture. Therefore it will be necessary to purify specific compounds that lead to AG inhibition and evaluate them independently for toxicity.

Although the presence of the plasticiser DEHP inhibiting PPL was found in the extracts, a second batch of fractions were obtained from Samoa which were prepared without the use of plasticware. There were carefully tested to ensure there was no further contamination. The known compound threo-dihydroguaiaretic acid was identified and isolated from Atone showing high PPL inhibition obtained at $80.4 \pm 0.04 \%$ (1 mg/mL). Although the compound is known, this activity has not been reported previously. Kinetic modelling showed it exhibits a mixed inhibition in the enzyme reaction, with a Ki value of $0.0196 \mathrm{mg} / \mathrm{mL}(59.3 \mu \mathrm{M})$. This compound was approximately 20-fold less toxic than the AG inhibitory extract of Neisosperma oppositifolia according to the MTT assay. The $\mathrm{IC}_{50}$ for the MTT assay was 2-fold than the $\mathrm{IC}_{50}$ for PPL inhibition for threo-dihydroguaiaretic acid, and the literature record of an $\mathrm{LD}_{50}$ of $75 \mathrm{mg} / \mathrm{kg}$ following IP administration in mice does indicate the need to carefully evaluate the dose that would be required for therapeutic use of either threo-dihydroguaiaretic acid or an extract of the Atone in control diabetes and obesity. 
Appendix A: GNPS analysis

F75-100:

6-[3-[(3,4-dimethoxyphenyl)methyl]-4-methoxy-2-

(methoxymethyl)butyl]-4-methoxy-1,3-benzodioxole
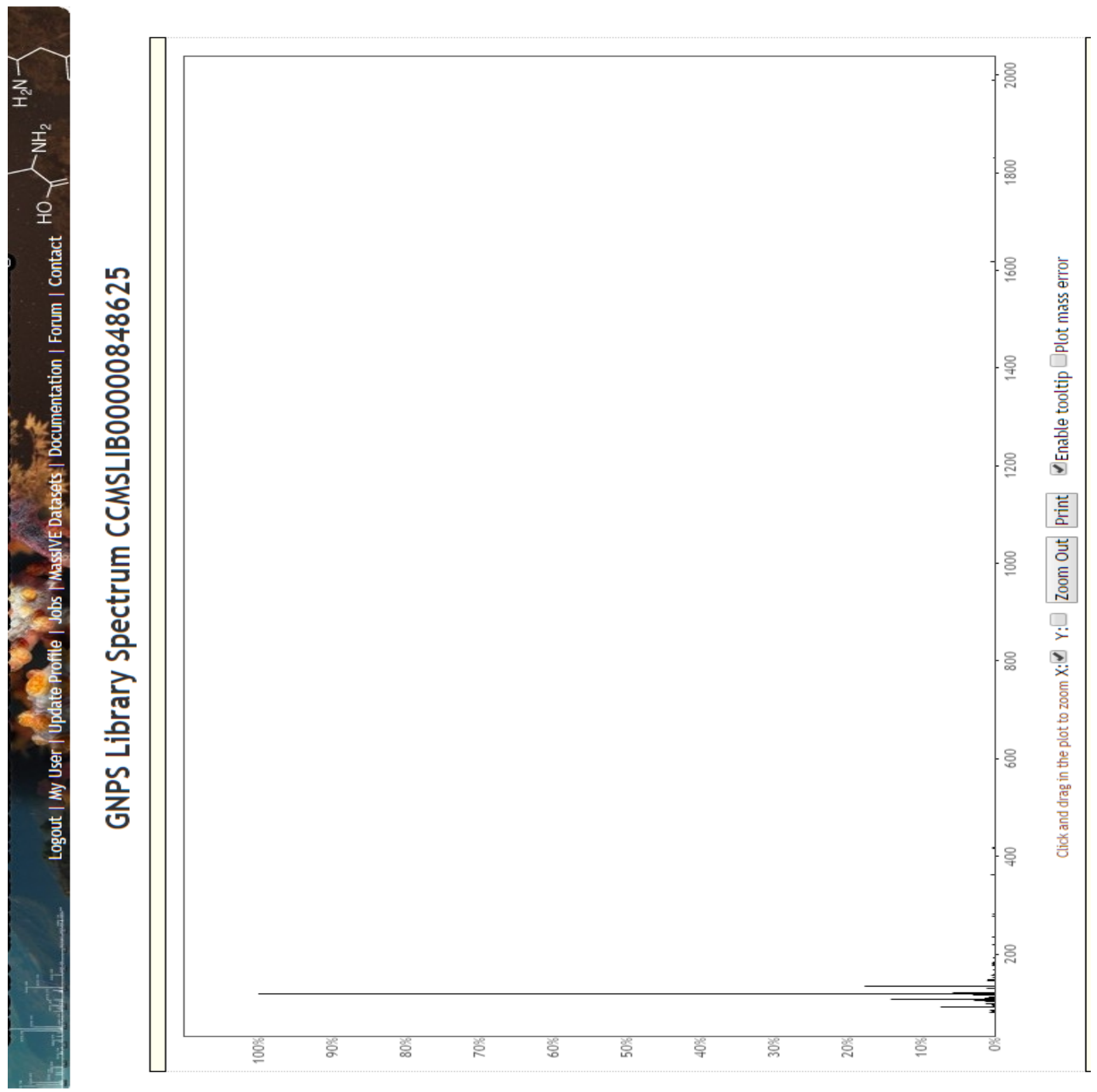

Spectral Raw Data-file from library compound LC-MSMS of 6-[3-[(3,4dimethoxyphenyl)methyl]-4-methoxy-2-(methoxymethyl)butyl]-4-methoxy-1,3benzodioxole. 


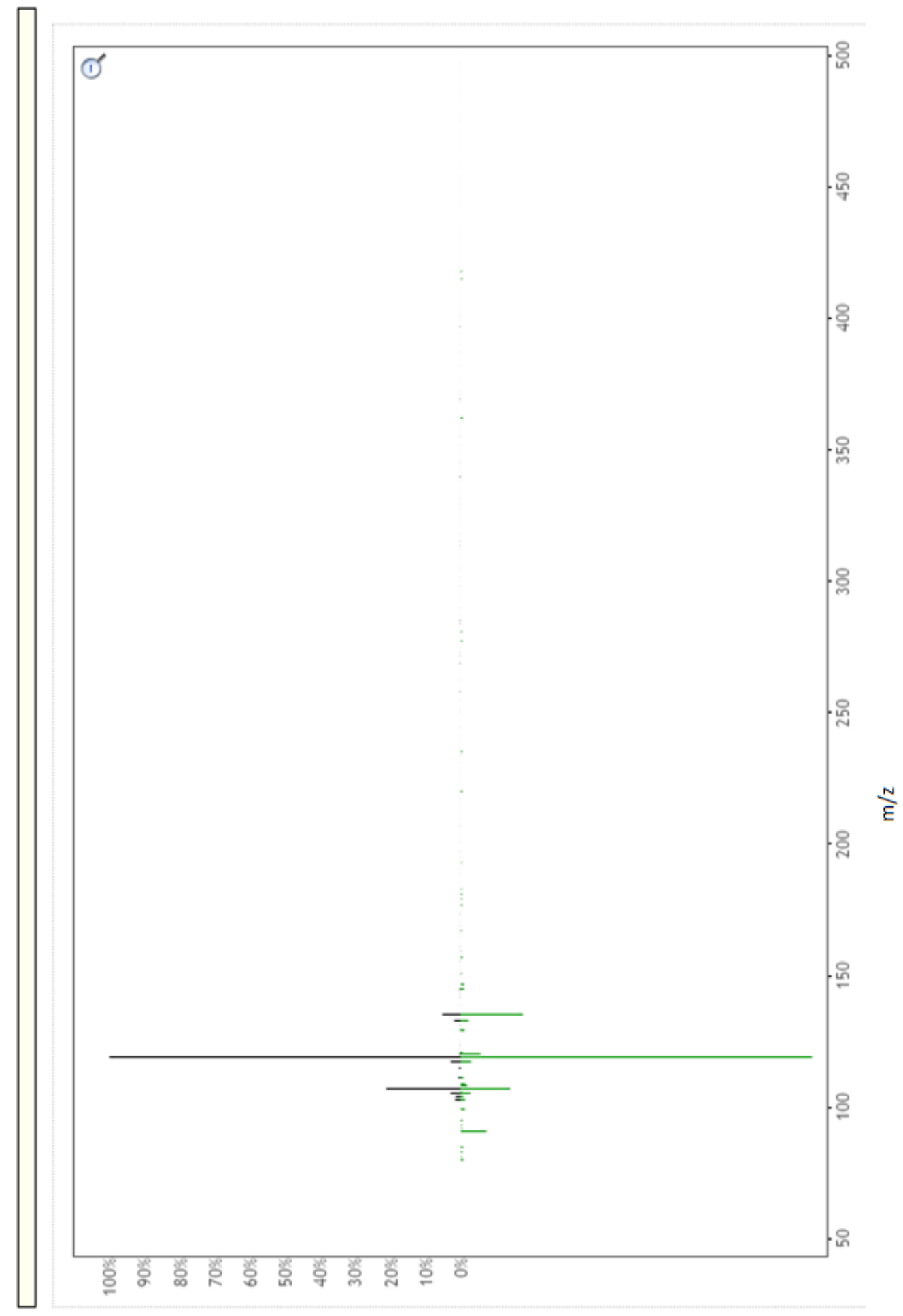

Raw Spectral data from the extract in this study (black) vs Library Spectral data (green) of $\quad 6-[3-[(3,4-d i m e t h o x y p h e n y l) m e t h y l]-4-m e t h o x y-2-(m e t h o x y m e t h y l) b u t y l]-4-$ methoxy-1,3-benzodioxole. A mirror image output from GNPS comparing the sample spectral data to the matching compound in its database. 


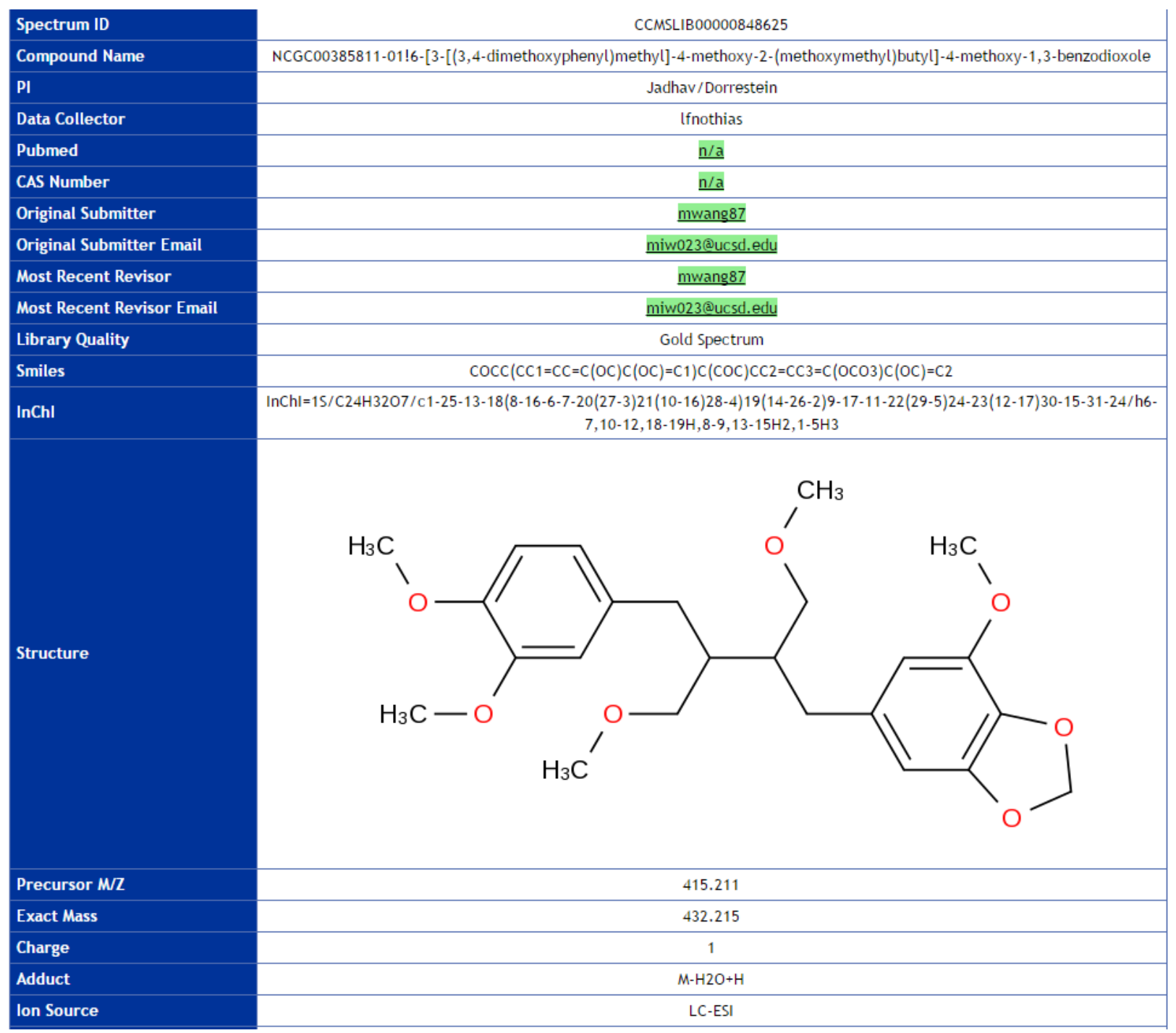

GNPS user library information on compound 6-[3-[(3,4-dimethoxyphenyl)methyl]-4methoxy-2-(methoxymethyl)butyl]-4-methoxy-1,3-benzodioxole.

The GNPS library database is able to provide information on the recorded natural product, source of its first discovery, its structure, and the ion source used from its submitter and precursor and exact masses. Expected $\mathrm{m} / \mathrm{z}$ observed in mass spectrum $415.211 \mathrm{~m} / \mathrm{z}$ whereas its exact mass is $432.214 \mathrm{~m} / \mathrm{z}$ due to loss of a water molecule and proton. 
Appendix B F75-100 fragment 1 identification

$\underline{F 75-100}[\mathrm{M}+\mathrm{H}] 287.12 \mathrm{~m} / \mathrm{z}$
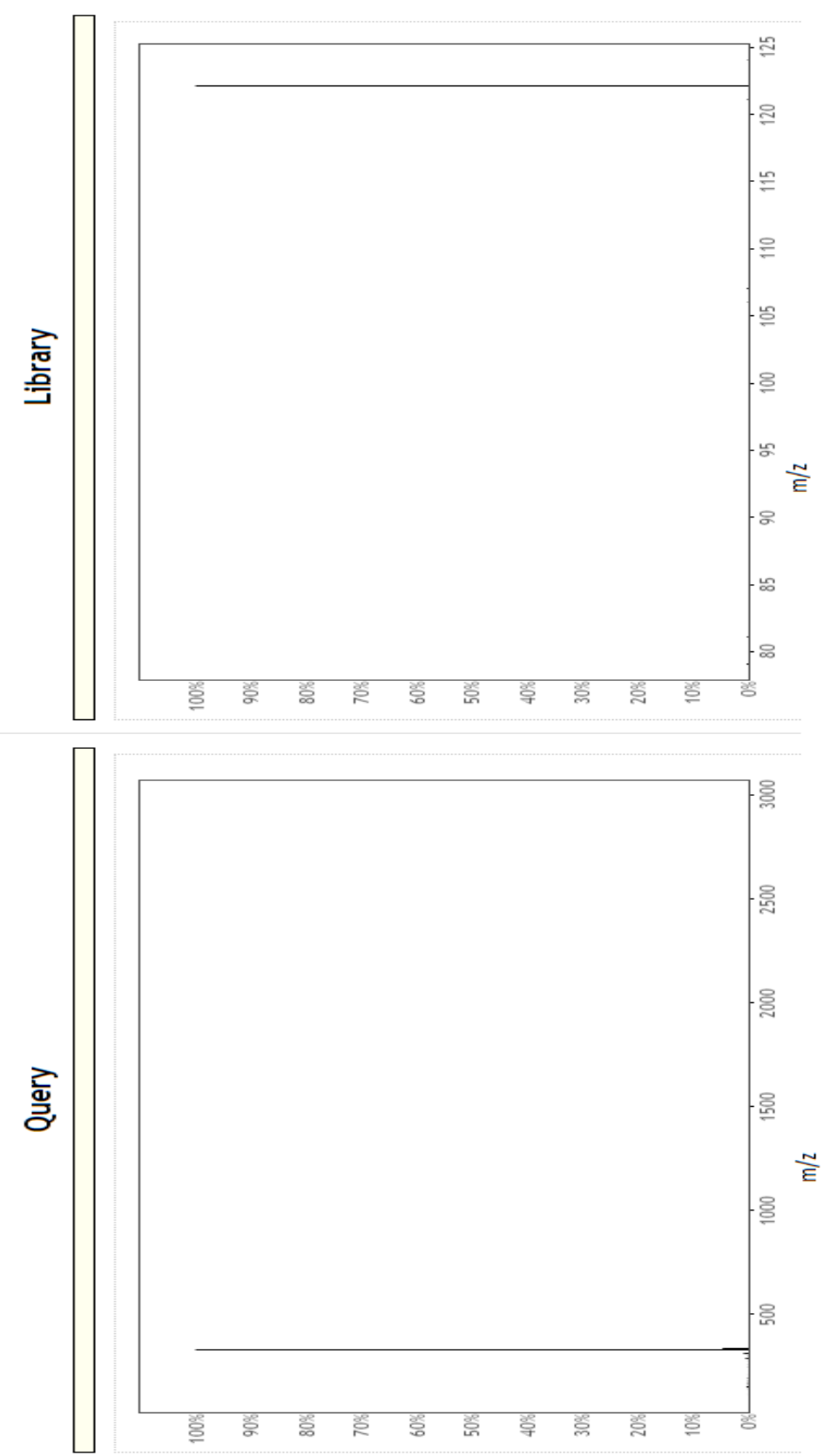

Raw spectral data (Query) observed in mass [M $+\mathrm{H}] 287.12 \mathrm{~m} / \mathrm{z}$ and GNPS spectra of 2,4,6-Trimethylpyridine. The mass spectra cluster match from the target LC-MS of F75100 matching the library cluster mass spectra resulting in the output match of 2,4,6Trimethylpyridine from GNPS. 
Appendix C F75-100 fragment 2 identification

\section{$\underline{F 75-100 ~ a t ~}[\mathrm{M}+\mathrm{H}] 392.22 \mathrm{~m} / \mathrm{z}$}
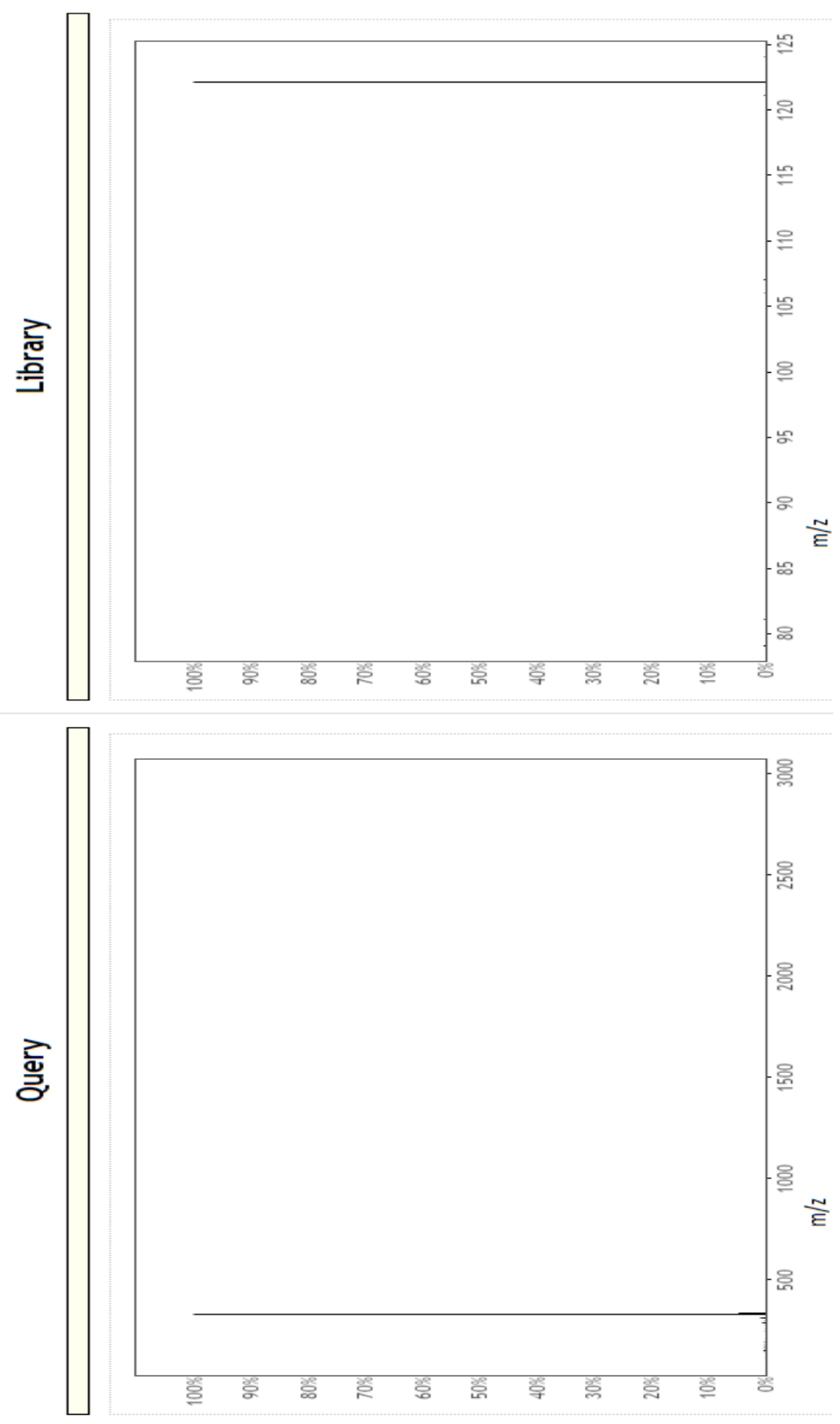

Raw spectral data observed at [M + H] $392.22 \mathrm{~m} / \mathrm{z}$ and GNPS spectra of 2,4,6Trimethylpyridine

Similarly, for another major compound in F75-100 it contains the same cluster of daughter ions which GNPS was able to match to 2,4,6-Trimethylpyridine. 


\begin{tabular}{|c|c|}
\hline Compound Name & MassbankEU:SM806602 2.4,6-Trimethylpyridine 2,4,6-trimethylpyridin \\
\hline PI & Masbank EU \\
\hline Data Collector & Massbank \\
\hline CAS Number & $108-75-8$ \\
\hline Original Submitter & mwang87 \\
\hline Original Submitter Email & miw023@ucsd.edu \\
\hline Most Recent Revisor & mwang87 \\
\hline Most Recent Revisor Email & miw023@ucsd.edu \\
\hline Library Quality & Bronze Spectrum \\
\hline Smiles & $C C 1=C C(C)=N C(C)=C 1$ \\
\hline InChl & $1 \mathrm{~S} / \mathrm{C} 8 \mathrm{H} 11 \mathrm{~N} / \mathrm{C1}-6-4-7(2) 9-8(3) 5-6 / \mathrm{h} 4-5 \mathrm{H}, 1-3 \mathrm{H} 3$ \\
\hline Structure & \\
\hline Precursor M/Z & 122.096 \\
\hline Exact Mass & 0.0 \\
\hline Charge & 1 \\
\hline Adduct & {$[M+H]^{+}$} \\
\hline lon Source & ESI \\
\hline
\end{tabular}

GNPS user library information on compound 2,4,6-Trimethylpyridine

The precursor mass $122.096 \mathrm{~m} / \mathrm{z}$ observed using a positive ion mode (where exact mass will be $121.096 \mathrm{~m} / \mathrm{z}$ ) is the same as the exact mass of the compound recorded. Hence, the zero mass value in the library database of GNPS. 
Appendix D $\alpha$-Glucosidase inhibitory fraction

\section{NMR Spectra of F100 sub-fraction}

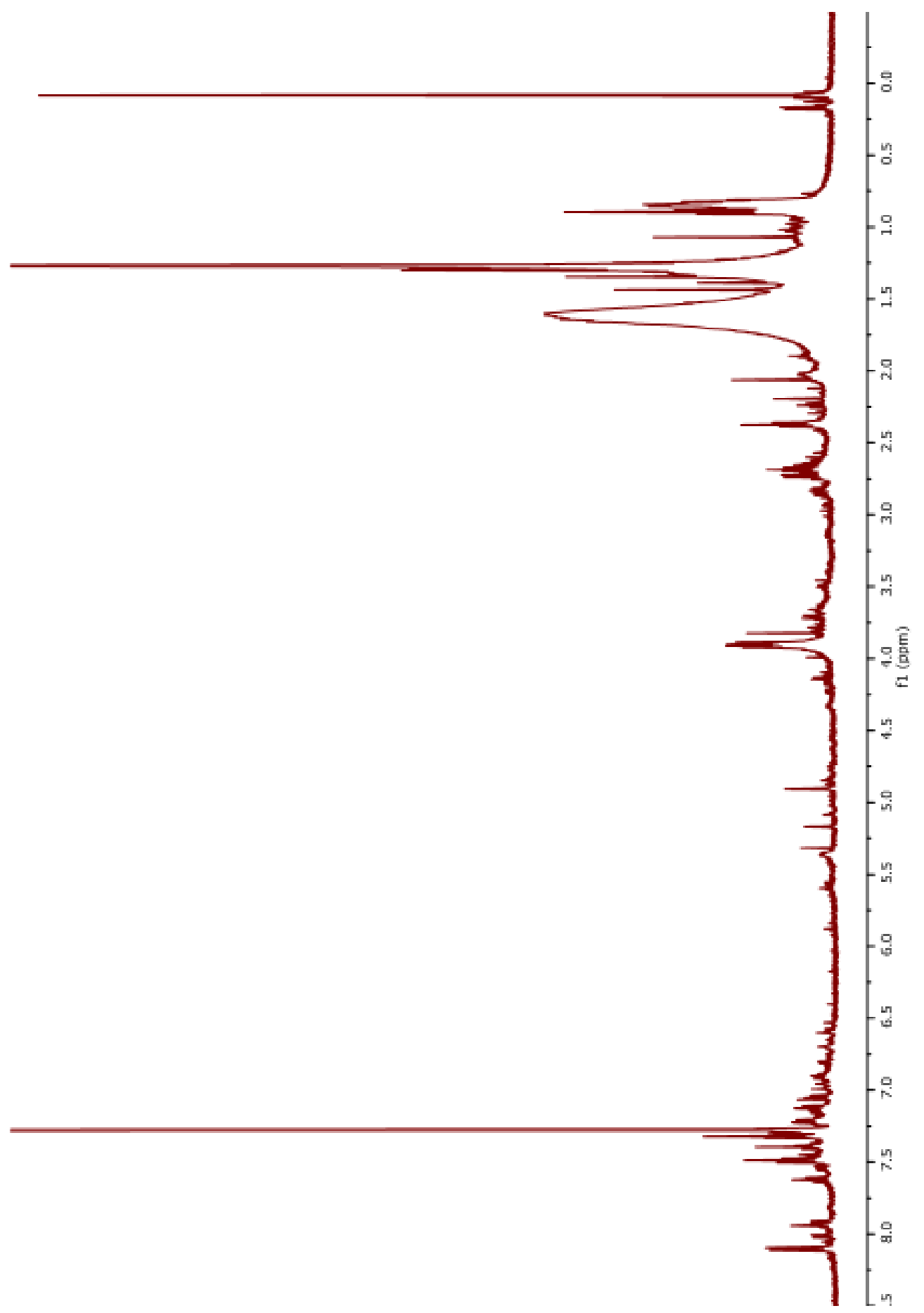

${ }^{1} \mathrm{H}$ NMR Spectrum of F100 sub-fraction mixture 
Appendix E: DEHP NMR data

NMR Spectra of DEHP

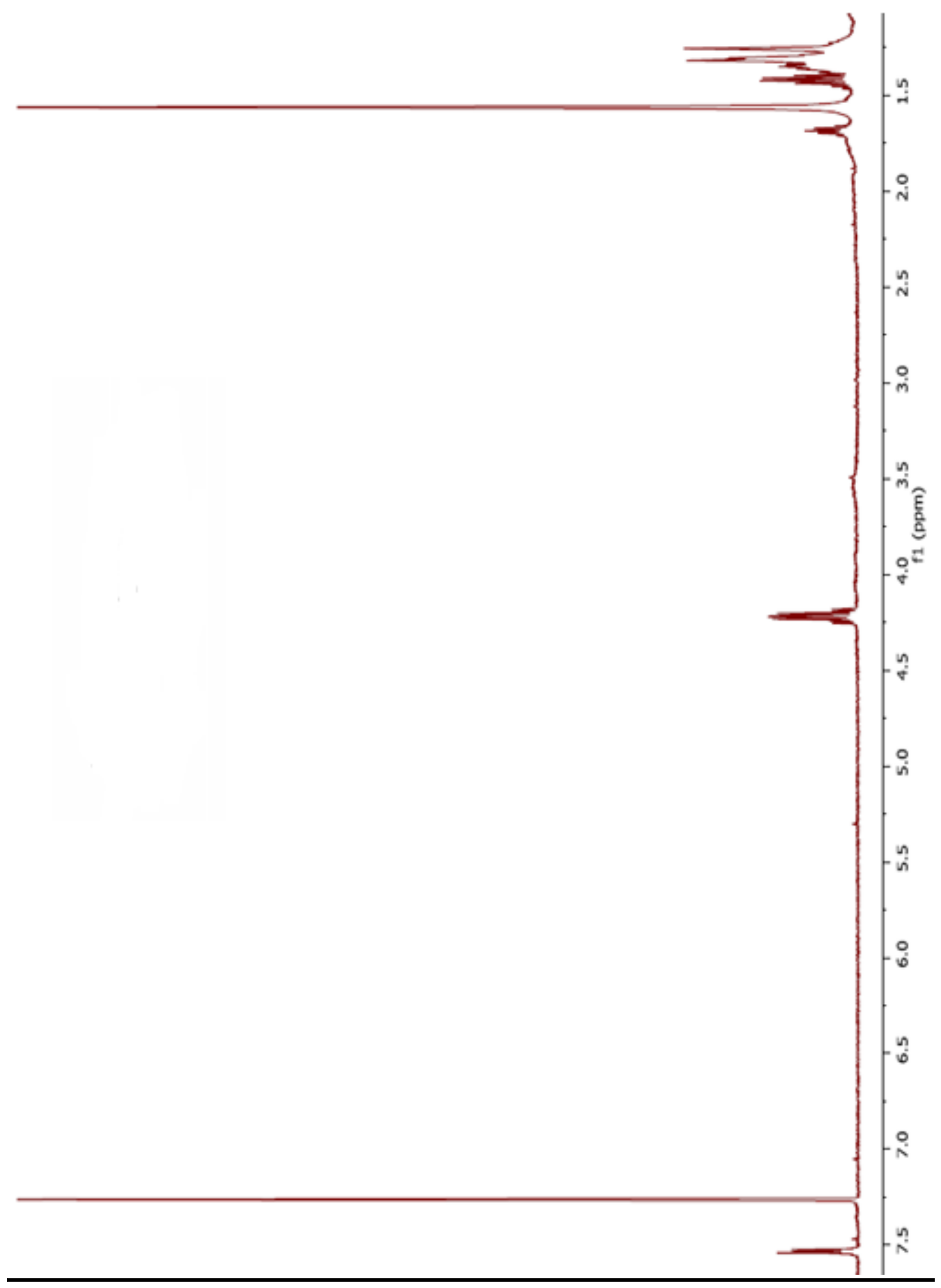

${ }^{1} \mathrm{H}$ spectrum of DEHP (F13) (500 MHz, CDCl3) 
${ }^{13} \mathrm{C} \underline{\text { NMR Spectrum of DEHP (Fao30-100) }}$

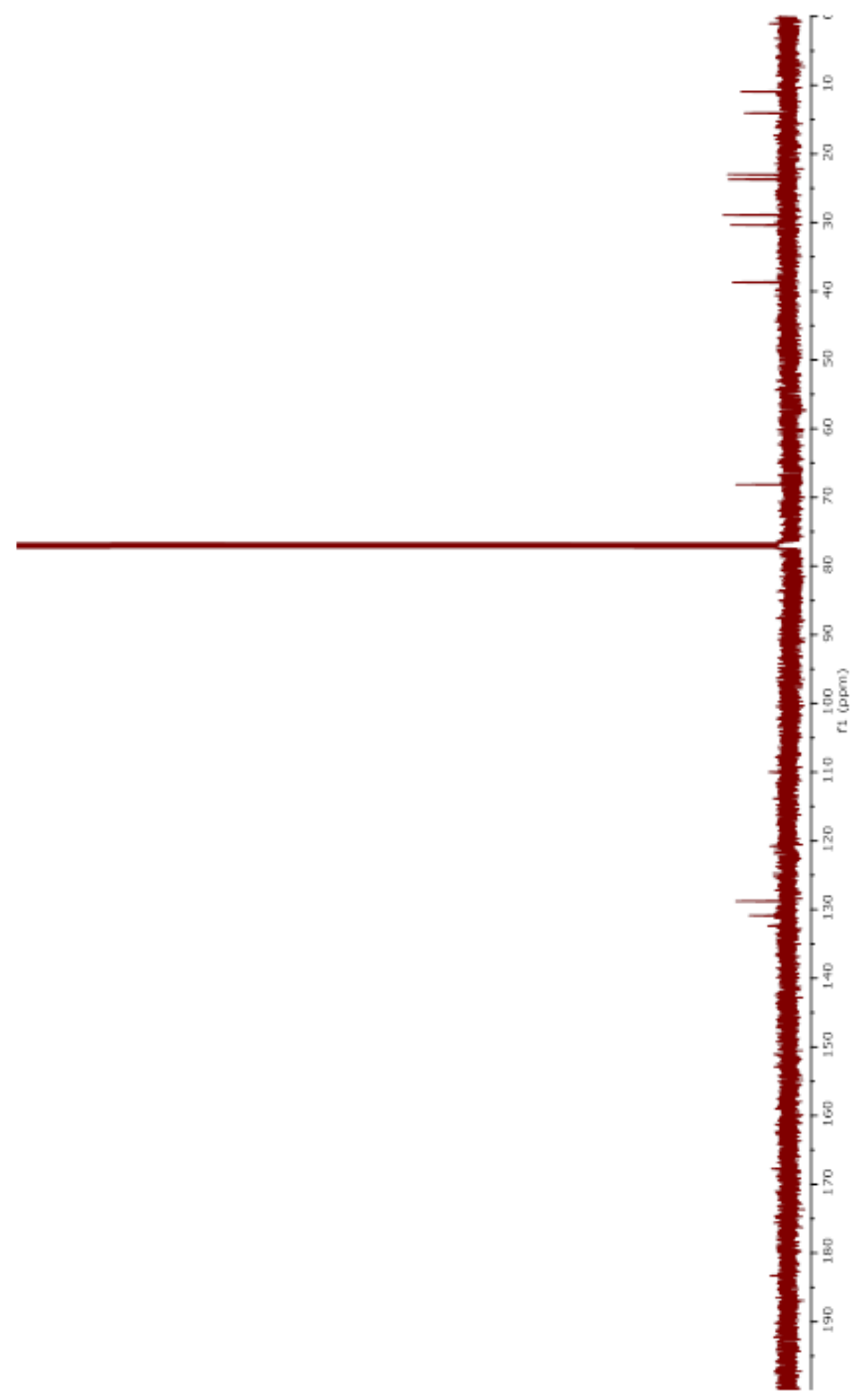

${ }^{13} \mathrm{C}$ NMR Spectrum of DEHP 


\section{$\underline{\text { Fao30-100 - COSY }}$}

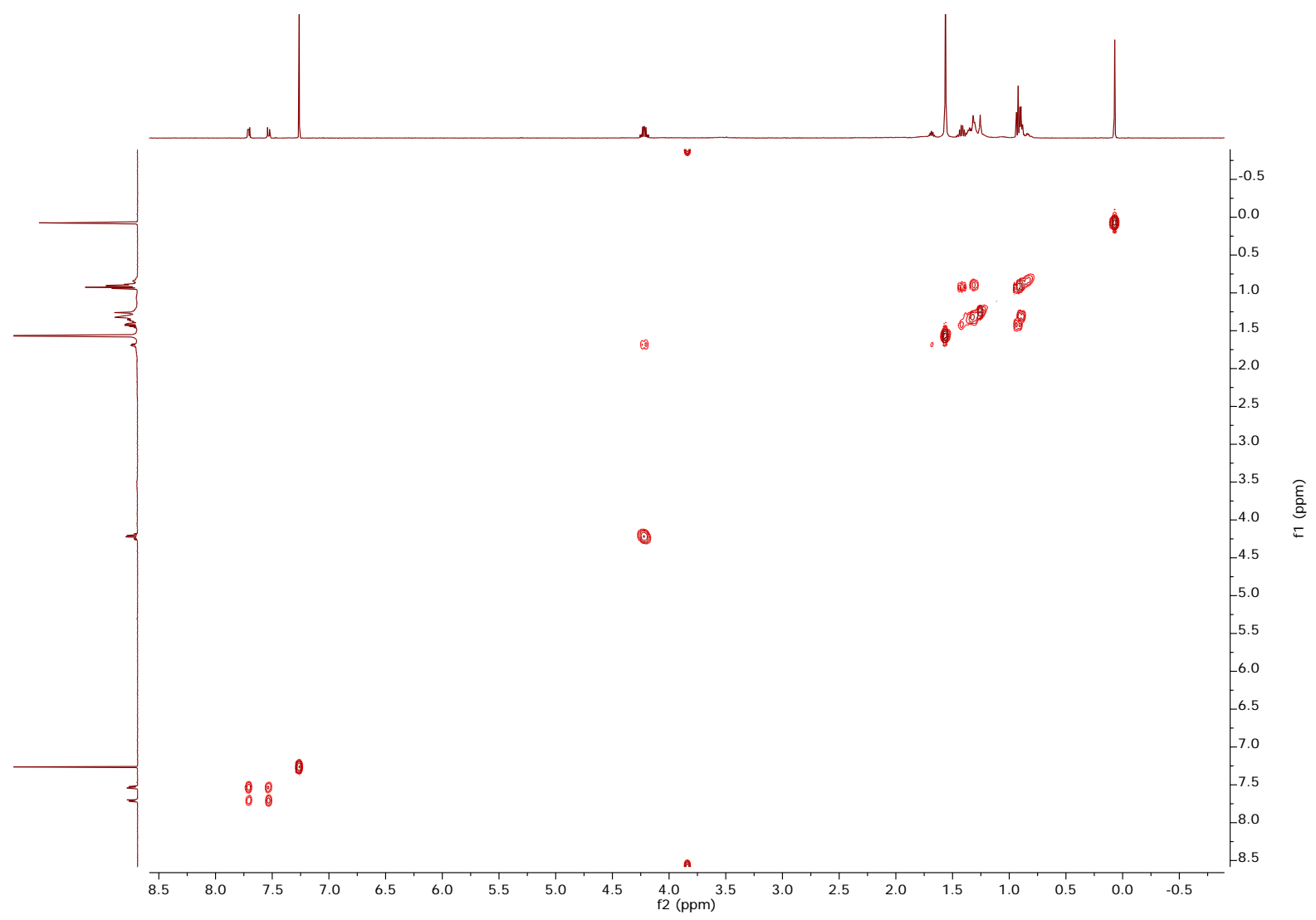




\section{F30-100 - HSQC}

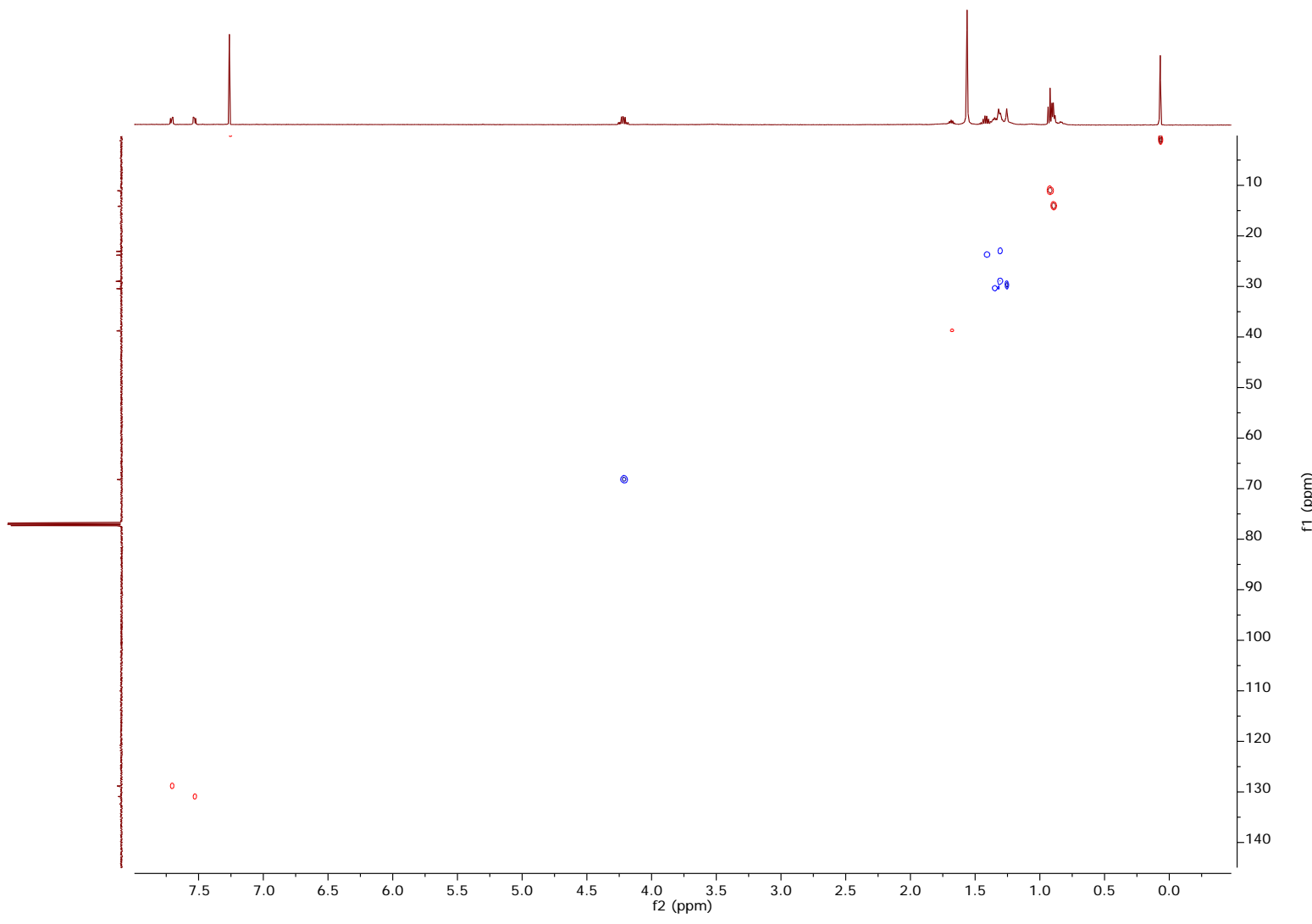




\section{Fao30-100 - HMBC}

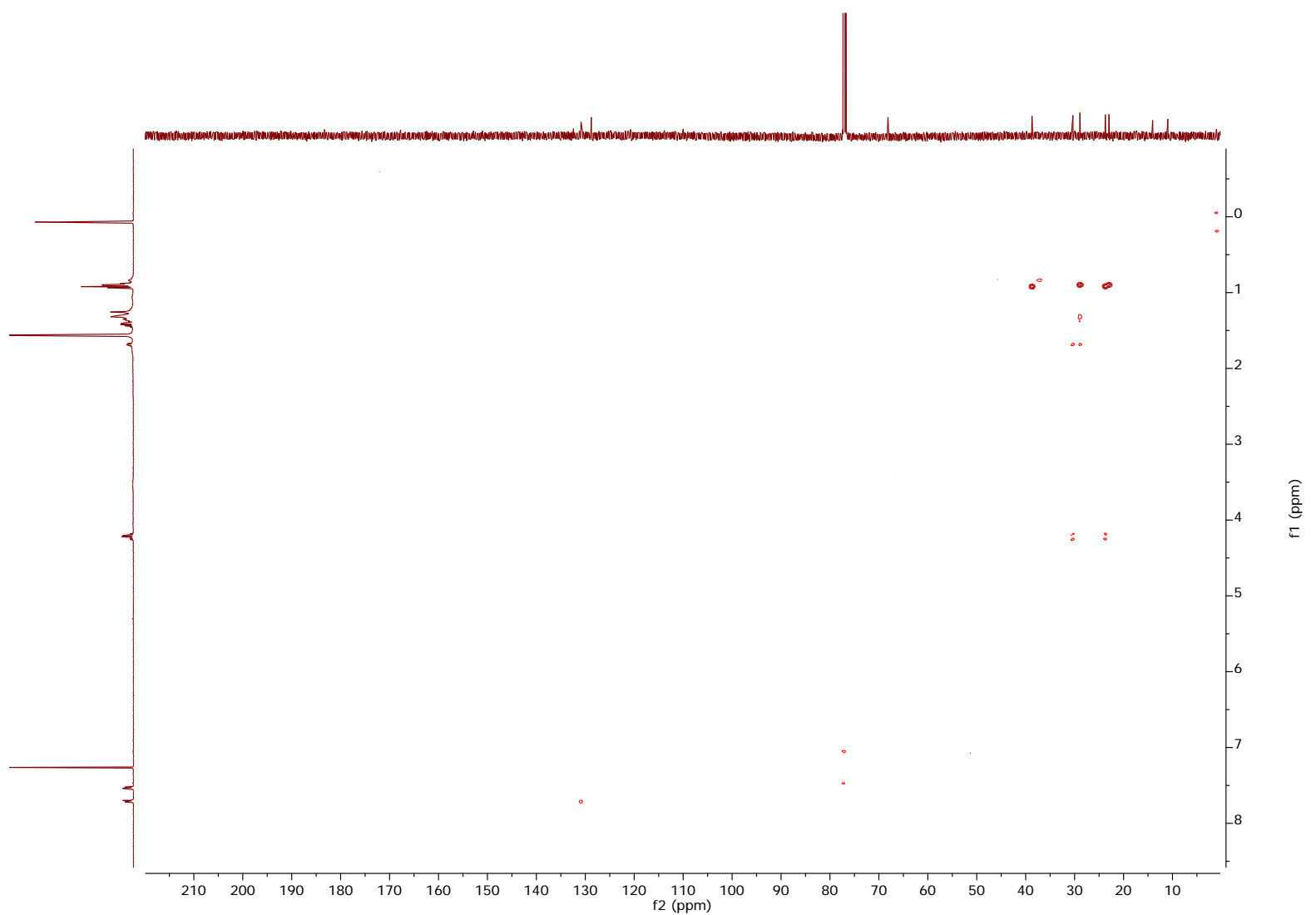


Appendix G NMR spectrum of isolated threo-dihydroguaiaretic acid

NMR Spectrum of threo-dihydroguaiaretic acid (Atone100-100)

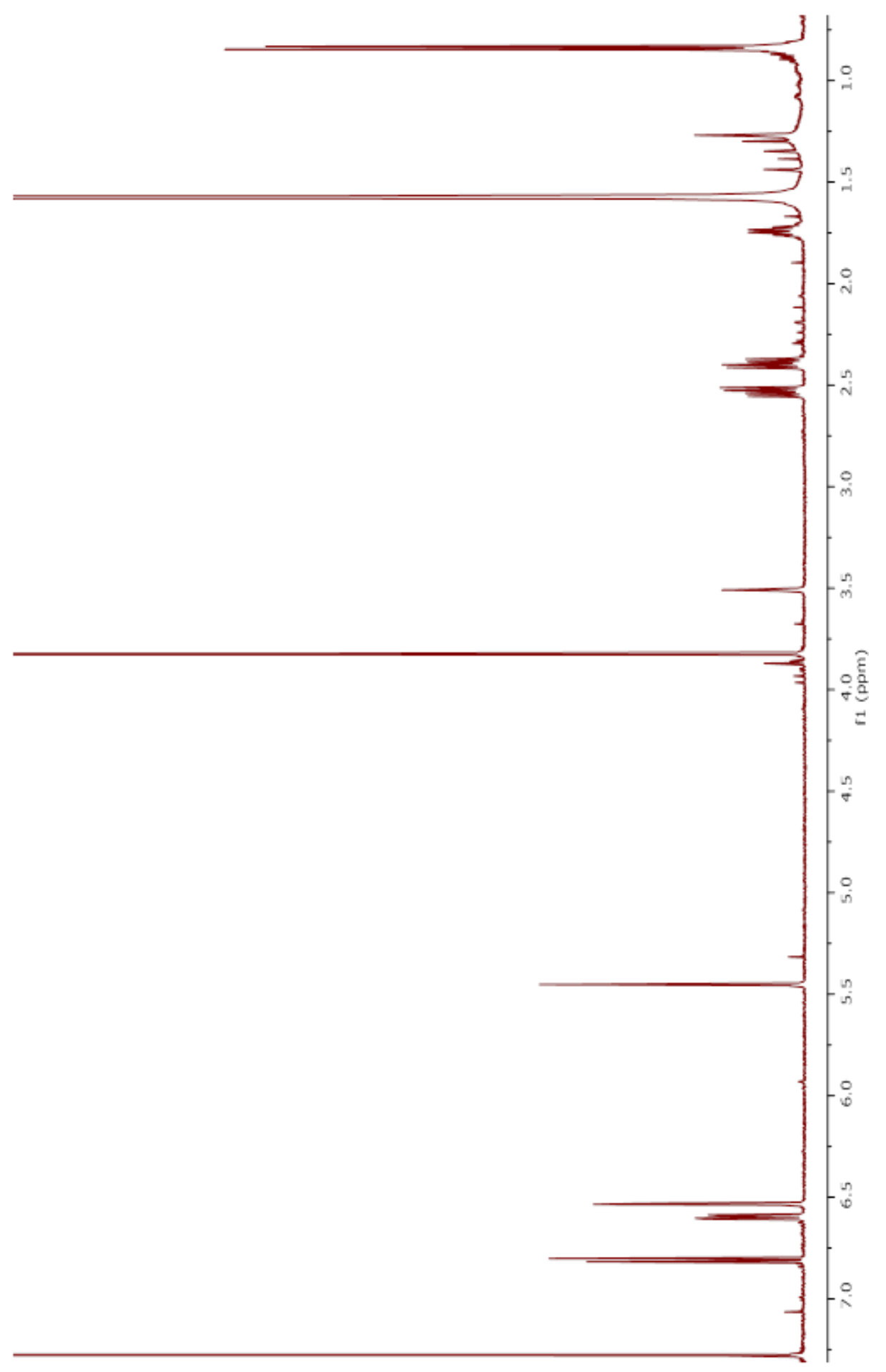




\section{References}

Abdollahi, M., Ranjbar, A., Shadnia, S., Nikfar, S., \& Rezaie, A. (2004). Pesticides and oxidative stress: a review. Medicinal Science Monit, 144-147.

Abel-Mawla, A., Mohamed, M., \& Mostafa, A. (2011). Induction of Biologically Active Flavonoids in Cell Cultures of Morus nigra and Testing their Hypoglycemic Efficacy. Sciencia Pharmaceutica, 951-961.

Abraham, E., Chain, E., \& Fletcher, C. (1941, August 16). Further observations on penicillin. Lancet, 177-189.

Abudula, R., Jeppesen, P., Rolfsen, S., Xiao, J., \& Hermansen, K. (2004). Rebaudioside a potently stimulates insulin secretion from isolated mouse islets: studies on the dose-, glucose-, and calcium-dependency. Metabolism, 1378-1381.

Abudula, R., Matchkov, V., Jeppesen, P., Nilsson, H., Aalkjaer, C., \& Hermansen, K. (2008). Rebaudioside A directly stimulates insulin secretion from pancreatic beta cells: a glucose-dependent action via inhibition of ATP-sensitive $\mathrm{K}+$-channels. Diabetes Obesity Metabolism, 1074-1085.

Adisakwattana, S., Intrawangso, J., Hemrid, A., Chanathong, B., \& Makynen, K. (2012). Extracts of edible plants inhibit pancreatic lipase, cholesterol esterase and cholesterol micellization, and bind bile acids. Food Technology and Biotechnology, 11-16.

Adisakwattana, S., Jeerasuk, M., Supatra, S., Chuliporn, C., Hathaichanok, T., Benjanut, C., . . . Suwimol, S. (2010). Lipid-Lowering mechanisms of grape seed extract (Vitis vinifera L) and its antihyperlidemic activity. Journal of Medicinal Plants Research , 2113-2120.

Ado, M., Abas, F., Mohammed, A., \& Ghazali, H. (2013). Anti- and pro-lipase activity of selected medicinal, herbal and aquatic plants, and structure elucidation of an anti-lipase compound. Molecules, 14651-14669. 
Affourtit, C., \& Brand, M. (2006). Stronger control of ATP/ADP by proton leak in pancreatic beta-cells than skeletal muscle mitochondria. Biochemical Journal, 151159.

Agbo, A., \& Ngogang, Y. (2005). Toxicity of herbal preparations. Cameroon Journal of Ethnobotanical, 23-28.

Aguilar, M.-I. (2004). Reversed-Phase High Performance Liquid Chromatography. In M.-I. Aguilar, Methods in Molecular Biology (pp. 9-22). Totowa: Humana Press.

Ahmad, K. (2009). Indole Alkaloids from Neisosperma oppositifolia and Kopsia Singapurensis; Acetamidostilbene radical cation oxidative cyclization approaches to unusual indolostilbene hybrids. Kuala Lumpur: University of Malaya .

Ahmad, K., Thomas, N., Hadi, H., Mukhtar, M., Mohamad, K., Nafiah, M., . . . Awang, K. (2010). Oppositinines A and B: New Vasorelaxant beta- Carboline Alkaloids from Neisosperma oppositifolia. Chemical Pharmaceutical Bulletin, 1085-1087.

Amaranthus, M., \& Simpson, L. (2011). A Plant Evolution Revolution. ACRES, The Voice of Eco-Agriculture, 1-4.

American Diabetes Association. (2008). Diagnosis and Classification of Diabetes Mellitus. Diabetes Care , 62-68.

Aniszewki, T. (2007). Alkaloids-Secrets of Life: Alkaloid Chemistry. Elsevier .

Asgarpanah, J., \& Kazemivash, N. (2012). Phytochemistry and pharmacologic properties of Myristica fragrans (Hoyutt).: A review. African Journal of Biotechnology, 12787-12793.

Ashcroft, F., \& Rorsman, P. (2004). Molecular defects in insulin secretion in type-2 diabetes. Review of Endocronology Metabolic Disorders, 135-142.

Attele, A., Wu, J., \& Yuan, C. (1999). Multiple constituents and multiple actions. Biochemical Pharmacology, 1685-1693.

Azwanida, N. N. (2015). A Review on the Extraction Methods Use in Medicinal Plants, Principle, Strength and Limitation. Medicinal \& Aromatic Plants, 1-6. 
Babre, N., Debnath, S., Manjunath, Y., Parameshwar, P., Wankhede, S., \& Hariprasath, K. (2010). Antioxidant Potential Of Hydoralcoholic extract of Barringtonia acutangula . International Journal of Pharmacy and Pharmaceutical Sciences, 201-203.

Baell, J., \& Holloway, G. (2010). New Substructure Filters for Removal of Pan Assays Interference Compounds (PAINS) from Screening Libraries and for Their Exclusion in Bioassays. Journal of Medicinal CHemistry, 2719-2740.

Balick, M., \& Cox, P. (1997). Plants, People, and Culture: the Science of Ethnobotany. New York: Scientific American Library.

Ballinger, S. (2005). Mitochondrial dysfunction in cardiovascular disease. Free Radical Biological Medicine, 1278-1295.

Balunas, M., \& Kinghorn, D. (2005). Drug Discovery from Medicinal Plants. Science Direct, 431-441.

Ban, J., Cho, S., Kim, J., Bang, K., Seong, N., Song, K., . . . Seong, Y. (2004). Protection of NMDA induced neuronal cell damage by methanol extracts of Myristica fragrans seeds in cultured rat cerebellar granule cells. Natural Products Sciences, 289-295.

Bataille, D. (2002). Molecular mechanisms of insulin secretion. Diabetes Metabolism, 4-13.

Bedekar, A., Shah, K., \& Koffas, M. (2010). Natural products for type II diabetes treatment. Advanced Applied Microbiology, 21-73.

Benhaddou-Andaloussi, A., Marineou, L., Spoor, D., Vuong, T., Leduc, C., Joly, E., . . . Haddad, P. (2008). Antidiabetic activity of Nigella sativa seed extract in cultured pancreatic $\beta$-cells, skeletal muscle cells, and adipocytes. Pharmacal Biology, 96-104.

Benkestock, K. (2008). Electrospray Ionization Mass Spectrometry for Determination of Noncovalent Interactions in Drug Discovery. Stockholm: US-AB.

Berger, E. (2001). The Canada Health Monitor Surveys of Health Issues in Canada. Ottawa: Health Canada. 
Beutler, J. A. (2010). Natural Products as a Foundation for Drug Discovery. Curr Protoc Phamacol, 1-9.

Bouslimani, A., Sanchez, S., Garg, N., \& Dorrestein, P. (2014). Mass spectrometry of Natral Products: Current, Emerging and Future Technologies. Natural Products Rep, 718-729.

Braun, C., Brayer, G., \& Withers, S. (1995). Mechanism-based Inhibition of Yeast $\alpha$-Glucosidase and Human Pancreatic $\alpha$-Amylase by a New Class of Inhibitors. Journal of Biological Chemistry, 26788-26781.

Brian, L. F. (2007). Miglitol. xPharm: The Comprehensive Pharmacology Reference, 1-4.

Bross-Walch, N., Kuhn, T., Moskau, D., \& Zerbe, O. (2005 ). Strategies and Tools for Structure Determination of Natural Products Using Modern Methods of NMR Spectroscopy. Chemistry \& Biodiversity, 147-178.

Burger, A., \& Fiebig, H. (2014). Preclinical Screening for New Anticancer Agents. In A. Burger, H. Fiebig, \& M. Rydek (Ed.), Handbook of Anticancer Pharmacokinetics and Pharmacodynamics (pp. 23-40). New York: Springer Science.

Buss, A., \& Waigh, R. (1995). Natural products as leads for new pharmaceuticals. (M. Wolff, Ed.) New York: John Wiley \& Sons, Inc.

Byung-Wook, Y., Zejun, Y., Rabia, A., Sunmi, H., \& Young-Woo, J. (2013). Plant natural products: history, limitations and the potential of cambial meristematic cells. Biotechnology and Genetic Engineering Reviews, 47-60.

Carter, G. (2011). Natural products and pharma 2011: strategic chages spur new opportunities. Natural Products Rep, 1783-1789.

Chan, C., De-Leo, D., Joseph, J., McQuaid, T., Ha, X., Xu, F., . . . Wheeler, M. (2001). Increased uncoupling protein-2 levels in beta-cells are associated with impared glucose-stimulated insulin secretion: mechanism of action. Diabetes, 13011310. 
Chawla, R., Thakur, P., Chowdhry, A., Jaiswal, S., Sharma, A., Goel, R., . . . Arora, R. (2013). Evidence based herbal drug standardization approach in coping with challenges of holistic management of diabetes: a dreadful lifestyle disorder of 21st century. Journal of Diabetes Metabolic Disorder, 35.

Chen, X., Zheng, Y., \& Shen, Y. (2006). Voglibose (Basen, AO-128), one of the most important $\alpha$-glucosidase inhibitors. Current Medicimal Chemistry, 109-116.

Cheng-Dong, Z., Ya-Qing, D., Jin-Ming, G., \& Zhi-Gang, R. (2010). Screening for Anti-Lipase Properties of 37 Traditional Chinese Medicinal Herbs. Chin Med Assoc, 319-324.

Christensen, R., Kristensen, P., Bartels, E., Bliddal, H., \& Astrup, A. (2007). Efficacy and safety of the weight-loss drug rimonabant: a meta-analysis of randomised trials. The Lancet, 1706-1713.

Clark, A. G. (2004). Multimedia in Biochemistry and Molecular Biology Education. Biochemistry and Molecular Biology Education, 201-206.

Clarke, E. (1970). The Forensic Chemistry of Alkaloids, in the Alkaloids. New York: Academic Press.

Clearinghouse, N. D. (2014, June). Causes of Diabetes.

Colditz, G., \& Willett, W. (1990). Weight as a risk factor for clinical diabetes in women. American Journal of Epidemiology, 501-513.

Colegate, S., \& Molyneux, R. (2008). Bioactive Natural Products. New York: Taylor \& Francis Group.

Cragg, G., \& Newman, D. (2013). Natural products: a continuing source of novel drug leads. Biochemistry Biophysicis Acta, 3670-3695.

Cribb, P. \&. (1996). The orchids of Samoa. London: Kew Gardens.

Cuong, T. D., Hung, T. M., Han, H. Y., Roh, H. S., Seok, J. H., Lee, J. K., . . Min, B. S. (2014). Potent acetylcholinesterase inhibitory compounds from Myristica fragrans. Natural Products Community , 499-502. 
David, H., \& Jean-Francois, B. (2011). A reassessment of Marquesan Ochrosia and Rauvolfia (Apocynaceae) with two new combinations. PhytoKeys, 95-107.

Dechakhamphu, A., \& Wongchum, N. (2015). Screening for anti-pancreatic lipase properties of 28 traditional Thai medicinal herbs. Asian Pacific Journal of Tropical Biomedicine, 1042-1045.

Dewick, P. (2002). Medicinal natural products: a biosynthetic approach. Chichester: Wiley.

Dhanani, T., Shah, S., Gajbhiye, N. A., \& Kumar, S. (2017). Effect of extraction methods on yield, phytochemical constituents and antioxidant activity of Withania somnifera. Arabian Journal of Chemistry, 1193-1199.

Dias, A., Urban, S., \& Roessner, U. (2012). A Historical Overview of Natural Products in Drug Discovery. Metabolites, 303-336.

Dixit, P., Devasagayam, T., \& Ghaskadbi, S. (2008). Formuulated antidiabetic preparation Syndrex has a strong antioxidant activity. Eurology Journal of Pharmacology, 216-225.

Drew, B. S., Dixon, A. F., \& Dixon, J. B. (2007). Obesity management: Update on orlistat. Vascular Health and Risk Management, 817-821.

Drug Discovery. (2007, October 20). Clinical Trials. pp. 880-889.

Durackova, X. (2008). Oxidants, antioxidants and oxidative stress. In G. A. (eds), Mitochondrial Medicine: Mitochondrial Metabolism, Diseases, DIagnosis and Therapy (pp. 19-49). Amsterdam: Springer.

Dutra, L., de-Melo, T., Chelucci, R., Chin, C., \& dos-Santos, J. (2016). The Paradigma of the Interference in Assays for Natural Products. Biochemistry \& Pharmacology, 1-2.

Dwek, R., Butters, T., Platt, F., \& Zitzmann, N. (2002). Targeting glycosylation as a therapeutic approach. Nature Reviews Drug Discovery, 65-75. 
Ekwall, B., Silano, V., Paganuzzi-Stammati, A., \& Zucco, F. (1990). Toxicity Tests with Mammalian Cell Cultures. In P. Bourdeau, Short-Term Toxicity Tests for Nongenotoxic Effects (pp. 75-99). John Wiley \& Sons Ltd.

Elekofehinti, O. O. (2015). Saponins: Anti-diabetic principles from medicinal plants - A review. Pathophysiology, 95-103.

Ellen, D., Ellen, L., Danny, G., \& Guy, S. (2007). Novel Advances with Plant Saponins as Natural Insecticides to Control Pest Insects. Global Sciences Book, 97105.

Faulkner, D. (1993). Academic chemistry and the discovery of bioactive marine natural products. In D. Faulkner, D. Attaway, \& O. Zaborsky (Eds.), Marine Biotechnology: Pharmaceutical and Bioactive Natural Products (Vol. 1, p. 500). New York: Plenum Press.

Florence, N., Benoit, M., Jonas, K., Alexandra, T., Désiré, D., Pierre, K., \& Théophile, D. (2014). Antidiabetic and antioxidant effects of Annona muricata (Annonaceae), aqueous extract on streptozotocin-induced diabetic rats. Journal of Ethnopharmacology, 784-790.

Foliaki, S., \& Pearce, N. (2003). Prevalence and Causes of Diabetes in Pacific people. Pacific Health Dialogue, 1-9.

Ford, E., Williamson, D., \& Liu, S. (1997). Weight change and diabetes incidence: findings from a national cohort of U.S. adults. American Journal Epidemiology, 146:214-22.

Frederic, P., V, A. F., \& John, M. (2009). Culture of Samoa. Beau Bassin: Alphascript Publishing.

Gabriel, A., Agbor, D., \& Julius, E. (2007). Medicinal plants can be good sources of antioxidants: case study in Cameroon. Pakistan Journal of Biological Sciences, 537544.

Ganewatta, M., Chen, Y., Wang, J., Zhou, J., Ebalunode, J., Nagarkatti, M., . . . Tang, C. (2014). Bio-inspired resin acid-derived materials as anti-bacterial resistance agents with unexpected activities. Chemical Science, 2011-2016. 
Giweli, A. A., Džamić, A. M., Soković, M., \& Ristić, M. (2013). The Chemical Composition, Antimicrobial and Antioxidant Activities of the Essential Oil of Salvia frticosa Growing Wild in Libya. Archives of Biological Sciences, 321-329.

Glazer, G. (2001). Long-term pharmacotherapy of obesity 2000: a review of efficacy and safety. Archives of Internal Medicine, 1814-1824.

Gopiesh-khanna, V., \& Kannabiran, K. (2008). Antimicrobial activity of saponin fractions of the leaves of Gymnema sylvestre and Eclipta prostrata. World Journal of Microbiology and Biotechnology, 2737-2740.

Gorre, T., Bhikku, A., Nagulu, M., \& Rani, G. (1984). Anti-epileptic activity of Barringtonia Asiatica (L.). International Journal of Pharmacological Screening Methods, 20-24.

Gueritte, F., \& Fahy, J. (2005). The vinca alkaloids. Boca Raton, FL: Taylor and Francis.

Gurudeeban, S., Kaliyamurthi, S., \& Thirugnanasambandam, R. (2012). Alpha glucosidase inhibitory effect and enzyme kinetics of coastal medicinal plants. Bangladesh J Pharmacol, 186-191.

Gwynn, J., \& Hylands, P. (2000). Plants a source of new medicine. Drug Discovery, 54-57.

Haberkorn, G. (2008). Pacific Islands' Population and Development. Wellington: Population Association of New Zealand.

Halpern, A., \& Mancini, M. (2003). Treatment of obesity: an update on antiobesity medications. Obesity Review, 25-42.

Hamden, K., Jaouadi, B., Salami, T., Carreau, S., Bejar, S., \& Elfeki, A. (2010). Modulatory Effect of Fenugreek Saponins on the Activities of Intestinal and Hepatic Disaccharidase and Glycogen and Liver Function of Diabetic Rats. Biotechnology Bioprocess Engineering, 745-753.

Hamden, K., Keskes, H., Belhaj, S., Mnafgui, K., Feki, A., \& Allouche, N. (2011). Inhibitory potential of omega-3 fatty and fenugreek essential oil on key enzymes of 
carbohydrate-digestion and hypertension in diabetes rats. Lipids in Health and Disease, 226.

Handa, S. S. (2008). An Overview of Extraction Techniques for Medicinal and Aromatic Plants. In S. S. Handa, Extraction Tecnologies for Medicinal and Aromatic Plants (p. 11). Italy: ICIS UNIDO.

Hannan, J., Marenah, L., Ali, L., Rokeya, B., Flatt, P., \& Abdel-Wahab, Y. (2006). Ocimum sanctum leaf extracts stimulate insulin secretioin from perfused pancreas, isolated islets and clonal pancreatic beta-cells. Journal of Endocrinology, 127-136.

Hannan, J., Marenah, L., Ali, L., Rokeya, B., Flatt, P., \& Abdel-Wahab, Y. (2007). Insulin secretory actions of extracts of Asparagus racemosus root in perfused pancreas, isolated islets and clonal pancreatic beta-cells. Journal of Endocrinology, 159-168.

Harborne, J., \& Baxter, H. (1999). The handbook of natural flavonoids. Winchester: Wiley.

Harvey, A. (2008). Natural products in drug discovery. Drug Discovery Today, 894901.

Harvey, A. L. (2015). The re-emergence of natural products for drug discovery in the genomics era. Nature Reviews Drug Discovery, 111-129.

Health, T. (1840, October 03). The Navigator's or Samoa Islands: medicine and surgery. The Polynesian 1, p. 17.

Heng, L., Vincken, J., van-Koningsveld, G., Legger, L., Gruppen, H., van-Boekel, M., . . . Voragen, A. (2006). Bitterness of saponins and their content in dry peas. Journal of Food Agriculture, 1225-1231.

Henkel, T., Brunne, R., Muller, H., \& Reichel, F. (1999). Statistical investigation of structural complementarity of natural products and synthetic compounds. Angew. Che. Int., 643-647.

Herrmann, K. (1995). The Shikimate Pathway: Early Steps in the Biosynthesis of Aromatic Compounds. The Plant Cell, 907-919. 
Ho, C., Lam, C., Chan, M., Cheung, R., Law, L., Lit, L.,Tai, H. (2003). Electrospray Ionisation Mass Spectrometry: Principles and Clinical Applications. The Clinical Biochemist Reviews, 3-12.

Hosseinzadeh, S., Jafarikukhdan, A., Hosseini, A., \& Armand, R. (2015). The Application of Medicinal Plants in Traditional and Modern Medicine: A Review of Thymus vulgaris. International Journal of Clinical Medicine, 635-642.

Hu, F., Mansone, J., \& Stampfer, M. (2001). Diet, lifestyle, and the risk of type 2 diabetes mellitus in women. English Journal of Medicine, 790-797.

Hua, J., Qi, J., \& Yu, B. (2013). Iridoid and phenylpropanoid glycosides from Schrophularia ninpoensis HemsI. and their $\alpha$-Glucosidase inhibitory activities. Fitoterapia, 67-73.

Huth, J., Mendoza, R., Olejniczak, E., Johnson, R., Cothron, D., Liu, Y., Hajduk, P. (2005). Alarm NMR: a rapid and robus experimental method to detect reactive false positives in biocheimcal screens. Journal of the American Chemical Society, 217224.

International Conservation. (2011). The Rare Plants of Samoa. Apia: Critical Ecosystem Partnership Fund (CEPF) and Conservational International Pacific Islands Program (CI-Pacific).

Iyer, R. (2007). In vitro Propagation of Nutmeg, Myristica Fragrans. In S. Jain, \& H. Haggman, Protocols for Micropropagation of Woody Trees and Fruits (pp. 335344). Chennai: Springer.

Jaiswal, N., Srivastava, S. P., Bhatia, V., Mishra, A., Sonkar, A. K., Narender, T., . . . Tamrakar, A. K. (2012). Inhibition of Alpha-Glucosidase by Acacia nilotica Prevents Hyperglycemia along with Improvement of Diabetic Complications via Aldose Reductase Inhibition. Journal of Diabetes and Metabolism, 1-7.

James, D. M., Sylesh, K. V., \& John, T. H. (2007). Plant natural products: Back to the future or into extinction? Elsevier, 2015-2022.

Je'quier, E. (2002). Pathways to obesity. International Journal of Obesity, 12-17. 
Jose, L., Flavio, F., \& Guillermo, R. (2015). Natural Products for the Treatment of Type 2 Diabetes Mellitus. Plant Medical, 975-993.

Kabera, J., Semana, E., Mussa, A., \& He, X. (2014). Plant Secondary Metabolites: Biosynthesis, Classification, Function and Pharmacological Properties. Journal of Pharmacy and Pharmacology, 377-392.

Kang, J. (2012). Principles and Applications of LC-MS/MS for the Quantitative Bioanalysis of Analytes in Various Biological Samples. In J. Prasain, Tandem Mass Spectrometry (pp. 441-492). Shanghai, China: InTechChina. Retrieved from American Society for Mass Spectrometry.

Kang, J., \& Park, C. (2012). Anti-obesity drugs: a review about their effects and safety. Diabetes \& Metabolism, 13-25.

Kanti, B., \& Syed, I. (2009). Plant polyphenols as dietary antioxidants in human health and disease. Oxidative Medicine and Cellular Longevity, 270-278.

Kapoor, L. (1990). Crc handbook of ayurvedic medicinal plants. Boca Raton, FL: CRC Press.

Kartini, A. (2009). INDOLE ALKALOIDS FROM NEISOSPERMA OPPOSITIFOLIA AND KOPSIA . Kuala Lumpar: University of Malay.

Kathirvel, A., \& Sujatha, V. (2012). Phytochemical analysis and antioxidant activity of Barringtonia acutangula (L) Gaertn, leaves. International Journal of Pharmacal Pharmaceutical Science, 277-281.

Katiyar, C., Gupta, A., Kanjilal, S., \& Katiyar, S. (2012). Drug discovery from plant sources: An integrated approach. An Inernational Quarterly Journal of Research in Ayurveda, 10-19.

Kendall, M. \&. (2011). A Biogeographic Assessment of the Samoan Archipelago. Silver Spring: NOAA Technical Memorandum NOS NCCOS 132.

Kennett, S., \& Dan, S. A.-K. (2007). Targeted Natural Product Isolation Guided by HPLC-SPE-NMR: Constituents of Hubertia Species. Journal of Natural Products, $1472-1477$. 
Khatib, N., \& Patil, P. (2011). Evaluation of hypoglycemic activity of Barringtonia acutangula fruit extracts in streptozotocin induced Hyperglyceic wistar rats. Journal of cell and tissue research, 2573-2578.

Kim, E., Kwon, K., Han, M., Song, M., Lee, J., Lv, N., . . Park, B. (2007). Coptidis rhizoma extract protects against cytokine-induced death of pancreatic $\beta$-cells through suppression of NK-KB activation. Experimental Molecular Medicine, 149159.

Kim, K., \& Kim, H. (2008). Korean red ginseng stimulates insulin release from isolated rat pancreatic islets. Journal of Ethnopharmacology, 190-195.

Kim, Y., Jeong, Y., Wang, M., Lee, W., \& Rhee, H. (2005). Inhibitory effect of pine extract on $\alpha$-glucosidase activity and postprandial hyperglycemia. Nutrition, 756761.

Kitagawa, I. (2002). Licorice root. A natural sweetener and an important ingredient in Chinese medicine. Pure Application of Chemistry, 1189-1198.

Knott, A., \& Bossy-Wetzel, E. (2009). Nitric oxide in health and disease of the nervous sytem. Antioxidant Redox Signal, 541-553.

Kong, J. M., Goh, N. K., Chia, L. S., \& Chia, T. F. (2003). Recent advantages in traditional plant drugs and orchids. Acta Pharmacologica Sinica, 24, 7-21.

Lahlou, M. (2013). The Success of Natural Products in Drug Discovery. Pharcology \& Pharmacy, 17-31.

Lambert, J. D., Zhao, D., Meyers, R. O., Kuester, R. K., Timmermann, B. N., \& Dorr R.T. (2002). Nordihydroguaiaretic acid: hepatotoxicity and detoxification in the mouse. Toxicon, 1701-8

Lee, J., Lee, S., Seo, J., Yoo, M., Kwon, J., Choi, S., . . Ryu, S. (2006). Inhibitory effects of the seed extract of Myristicae semen on the proliferation of human tumor cell lines (II). Korean Journal of Pharmacognosy, 240-244.

Leu, Y., Chen, Y., Yang, C., Huang, C., Lin, G., Tsai, K., . . Liu, S. (2009). Extract isolated from Angelica hirsutiflora with insulin secretagogue activity. Journal of Ethnopharmacology, 208-212. 
Li, Y., Zhou, F., Gao, F., Bian, F., \& Shan, F. (2009). Comparative evaluation of quercetin, isoquercetin and rutin as ihibitors of alpha-glucosidase. Agric Food Chem 57, 11463-11468.

Lin, E., Wang, Y., Mehendale, S., Sun, S., Wang, C., Xie, J., . . Y Yuan, C. (2008). Antioxidant protection by American Ginseng in pancreatic $\beta$ - cells. American Journal of Chinese Medicine, 981-988.

Lin, S., Naseri, T., Linhart, C., Morrell, S., Taylor, R., McGarvey, S. T., Magliano, D. J., \& Zimmet P. (2016). Trends in diabetes and obesity in Samoa over 35 years, 1978-2013. Diabetic Medicine, 654-661.

Liu, L., Yu, Y., Liu, C., Want, X., Liu, X., \& Xie, L. (2011). Insulin deficiency induces abnormal increase in intestinal disaccharidase activities and expression under diabetic states, evidences from in vivo and in vitro study. Biochemical Pharmacology, 1963-1970.

Liu, X., Wei, J., Tan, F., Zhou, S., Wiirthwein, G., \& Rohdewald, P. (2004). Antidiabetic effect of Pycnogenol French maritime pine bark extract in patients with diabetes type II. Life Science, 2505-2513.

Liu, X., Wei, J., Tan, F., Zhou, S., Wurthwein, G., \& Rohdewald, P. (2004). Pycnogenol, French maritime pine bark extract, improves endothelial function of hypertensive patients. Life Science, 855-862.

Love, K., \& Paull, R. E. (2011). Soursop. Manoa: University of Hawai'i.

Lowe, M. (2002). The triglyceride lipases of the pancreas. Journal of Lipid Research, 2007-2016.

Lv, N., Song, M., Kim, E., Park, J., Kwon, K., \& Park, B. (2008). Guggulsterone, a plant sterol, inhibits NF-KB activation and protects pancreatic cells from cytokine toxicity. Molecular Cellular Endocrinology, 49-59.

Maechler, P. (2003). Novel regulation of insulin secretion; the role of mitochondria. Current Opinion Investigating of Drugs, 1166-1172.

Mahady, G., Pendland, S., Stoia, A., Hamill, F., Fabricant, D., Dietz, B., \& Chadwick, L. (2005). In vitro susceptibility of Helicobacter pylori to botanical 
extracts used traditionally for the treatment of gastrointestinal disorders. Physiotherapy Research, 988-991.

Manisha, M., Priyanjali, D., Jayant, L., Saroj, G., \& Thomas, P. (2007). Indian Herbs and Herbal Drugs Used for the Treatment of Diabetes. Journal of Clinical Biochemistry and Nutrition, 163-173.

Mann, J. (1994). Murder, Magic, and Medicine. New York: Oxford University Press.

Macías-Villamizar, V., Cuca-Suárez, L., González Adelantado, F. V., Rodríguez Pastor, S. (2016). Lignoids Isolated from Nectandra turbacensis (Kunth) Nees (Lauraceae). Records of Natural Products, 654-658.

Martins, F., Noso, T., Porto, V., Curiel, A., Gambero, A., \& Bastos, D. (2009). Maté tea inhibits in vitro pancreatic lipase activity and has hypolipidemic effect on highfat diet-induced obese mice. Integrative Physiology, 42-47.

Matsui, T., Ueda, T., Oki, T., Sugita, K., Terahara, N., \& Matsumoto, K. (2001). $\alpha-$ Glucosidase inhibitory action of natural acylated anthocyanins. 1. Survey of natural pigments with potent inhibitory activity. Journal of Agricultural Food Chemistry, 1948-1951.

Matsuo, T., Odaka, H., \& Ikeda, H. (1992). Effect of an intestinal disaccharidase inhibitor (AO-128) on obesity and diabetes. American Journal of Clinical Nutrition, 314S-317S.

Meghana, K., Sanjeev, G., \& Ramesh, B. (2007). Curcumin prevents streptozotocininduced islet damage by scavenging free radicals: A prophylactic and protective role. Eurology Journal of Pharmacology, 183-191.

Min, B., Cuong, T., Hung, T., Min, B., Shin, B., \& Woo, M. (2011). Inhibitory Effect of Lignans from Myristica fragrans on LPS-induced NO Production in RAW264.7 Cells. . Bulletin of Korean Chemical Society, 40-59.

Mishra, B., \& Tiwari, V. (2011). Natural products: an evolving role in future drug discovery. European Journal of Medicinal Chemistry, 4769-4807.

Moore, R. (1982). Pure Application. Chemistry, 54. 
Moreno, D., Ilic, N., Poulev, A., Brasaemle, D., Fried, S., \& Raskin, I. (2003). Inhibitory Effects of Grape Seed Extract on Lipases. Basic Nutritional Investigation, 876-879.

Morita, T., Jinno, K., Kawagishi, H., Arimoto, Y., Suganuma, H., Inakuma, T., \& Sugiyama, K. (2003). Hepatoprotective effects of myristicin from nutmeg (Myristica fragrans) on lipopolysaccharide/d-galactosamine induced liver injurty. Journal of Agricultural Food Chemistry, 1560-1565.

Morrison, J. (1935). The journal of James Morrison. Great Britain: Golden Cockerel Press.

Morton, J. F. (1987). Soursop. In J. F. Morton, Fruits of warm climates (pp. 75-80). Miami, Florida: Creative Resources Systems, Inc.

Muchova, J. (1999). Diabetes mellitus antioxidants. In Z. Durackova, L. Bergendi, J. Carsky, \& (eds), Free Radicals and Antioxidants in Medicine (II) (pp. 203-232). Bratislava: SAP.

Muchova, J., Liptakova, A., Orszaghova, Z., Garaiová, I., Tison, P., Cársky, J., \& Duracková, Z. (1999). Antioxidant systems in polymorphonuclear leukocytes of type 2 diabetes mellitus. Diabetic Medicine, 74-78.

Must, A., Spanadno, J., Coakley, E., Field, A., Colditz, G., \& Dietz, W. (1999). The disease burden associated with overweight and obesity . JAMA, 1523-1529.

Natasha, J., Swayam, S., Vikram, B., Akansa, M., Amit, S., Tadigoppula, N., . . . \& Akhilesh, K. T. (2012). Inhibition of Alpha-Glucosidase by Acacia nilotica Prevents Hyperglycemia along with Improvement of Diabetic Complications via Aldose Reductase Inhibition. Diabetes \& Metabolism, 1-7.

Nawwar, M., Ayoub, N., Hussein, S., Hashim, A., El-Sharawy, R., Wende, K., . . . Lindequist, U. (2012). Flavonol triglycoside and investigatio of the antioxidant and cell stimulating activities of Annona muricata linn. Archives of Pharmacal Research, 761-767. 
Nbgolua, K., Mudogo, V., Mpiana, P. T., Ashande, M. C., Ndege, C. S., Tshibangu, D. S., \& Tshilands, D. D. (2015). Bioactivity validation of Phyllanthus amarus using cell lines as model system. Discovery Phytomedicine, 23-28.

Nelson-Dooley, C., Della-Fera, M., Hamrick, M., \& Baile, C. (2005). Novel treatments for obesity and osteoporosis: targeting apoptotic pathways in adipocytes. Current Medicinal Chemistry, 2215-2225.

Newman, D. J., \& Cragg, G. M. (2012). Natural products as sources of new drugs over the 30 years from 1981 to 2010. Journal of Natural Products, 311-335.

Newman, D. J., \& Cragg, G. M. (2016). Natural Products as Sources of New Drugs from 1981 to 2014. Journal of Natural Products, 629-661.

Newman, D., Cragg, G., \& Snader, K. (2003). Natural Products as Sources of New Drugs over the Period 1981-2002. Natural Products, 1022-1037.

Oda, K., Matsuda, H., Murakami, T., Katayama, S., Ohgitani, T., \& Yoshikawa, M. (2000). Adjuvant and haemolytic activities of 47 saponins derived from medicinal and food plants. Biological Chemistry, 67-74.

Odey, M. O., Iwara, I. A., Udiba, U. U., Johnson, J. T., Inekwe, U. V., Asenye, M. E., \& Victor, O. (2012). Preparation of Plant Extracts from Indigenous Medicinal Plants. International Journal of Science and Technology, 688-692.

Osadebe, P. O., Omeje, E. O., Nworu, S. C., Esimone, C. O., Uzor, P. F., David, E. K., \& Uzoma, J. U. (2010). Antidiabetic principles of Loranthus micranthus Linn. parasitic on Persea americana. Asian Pacific Journal of Tropical Medicine, 619-623.

Ouyang, L., Luo, Y., Tian, M., Zhang, S., Lu, R., Wang, J., . . \& \& Li, X. (2014). Plant natural products: from traditional compounds to new emerging drugs in cancer therapy. Cell Proliferation in Basic and Clinical Sciences, 506-515.

Pamela, S., \& Douglas, E. (2004). The Origina and Diversification of Angiosperms. American Journal of Botany, 1614-1626.

Patel, S. B., Santani, D., Shah, M. B., \& Patel, V. S. (2012). Anti-hyperglycemic and Anti-hyperlipidemic Effects of Bryonia Laciniosa Seed Extract and its Saponin 
Fraction in Streptozocin-induced Diabetes in Rats. Journal of Young Pharmacists, 171-176.

Perla, V., \& Jayanty, S. (2013). Biguanide related compounds in traditional antidiabetic functional foods. Food Chemistry, 1574-1580.

Petit, P., Sauvaire, Y., Hillaire-Buys, D., Leconte, O., Baissac, Y., Posin, G., \& Ribes, G. (1995). Steroid saponins from fenugreek seeds: extraction, purification, and pharmacological investigation on feeding behaviour and plasma cholesterol. Steroids, 674-680.

Petrovska, B. B. (2012). Historical review of Medicinal Plants' Usage. Pharmacognosy Review, 1-5.

Prance, G. (2012). A Revision of Barringtonia (Lecythidaceae). Allertonia, 1-161.

Price, K., Johnson, I., \& Fenwick, G. (1987). The chemistry and biological significance of saponins in foods and feedstuffs. Critical Reviews in Food Science and Nutrition, 27-135.

Puls, W., Keup, U., Krause, H., Thomas, G., \& Hoffmeister, F. (1977). Glucoidase inhibitation. A new approach to the treatment of diabetes, obesity and hyperlipoproteinaemia. Naturwissenschaften, 536-537.

Rahimi, R., Nikfar, S., Larijani, B., \& Abdollahi, M. (2005). A review on the rold of antioxidants in the management of diabetes and its complications. Biomedical Pharmacother, 365-373.

Ramawat, K., \& Merillon, J. (2008). Bioactive Molecules and Medicinal Plants. Berlin: Springer-Verlag.

Rangel-Grimaldo, M., Rivero-Cruz, I., Madariaga-Mazon, A., Figueroa, M., \& Mata, R. (2017). $\alpha$-Glucosidase Inhibitors from Preussia minimoides. Journal of Natural Products, 582-587.

Renu, P., Rohit, M., Mohammad, H., Sanjeev, K., Jayanta, S., Rameshkumar, K., \& Brijesh, K. (2016). Rapid screening and quantitative determination of bioactive compounds. Food Chemistry, 483-493. 
Robert, H. (1980). Classification of Plant Communities. London: The Hague.

Roh, C., \& Jung, U. (2012). Screening of crude plant extract with anti-obesity activity. International Journal of Molecular Science, 1710-1719.

Roussi, F., Gueritte, F., \& Fahy, J. (2012). The vinca alkaloids . Boca Raton, FL: Taylor and Francis.

Royal Botanic Gardens Kew. (2016). State of the World's Plants. Royal Botanic Gardens, Kew.

Rubinson, K. (2000). Contemporary instrumental analysis. New Jersey: PrenticeHall Inc.

Sarker, D., Latif, Z., \& Gray, A. (2006). Natural Products Isolation. New Jersey: Humana Press Inc.

Sasidharan, S., Chen, Y., Saravanan, D., Sundram, K., \& Latha, Y. (2011). Extraction, Isolation and Characterization of Bioactive Compounds from Plants Extracts. African Journal of Traditional, Complementary and Alternative Medicines: AJTCAM, 1-10.

Savithramma, N., Linga-Rao, M., \& Suhrulatha, D. (2011). Screening of Medicinal Plants for Secondary Metabolites. Middle-East Journal of Scientific Research, 579584.

Schafer, A., \& Hogger, P. (2007). Oligomeric procyanidins of French maritime pine bark extract (Pycnogenol) effectively inhibit $\alpha$-glucosidase. Diabetes Resistance Clinical Practise, 41-46.

Selvaraj G., K. S. (2012). Alpha glucosidase inhibitory effect and enzyme kinetics of coastal medicinal plants. A Journal of the Bangladesh Pharmacological Society, 186-191.

Seo, E., Curtis-Long, M., Lee, B., Kim, H., Ryu, Y., Jeong, T., . . . Park, K. (2007). Xanthones from Cudrania tricuspidata displaying potent alpha-glucosidase inhibition. Bioorg Med Chem Lett , 6421-6424. 
Seyedan, A., Alshawsh, M., Alshagga, M., Koosha, S., \& Mohamed, Z. (2015). Medicinal Plants and Their Inhibitory Activities against Pancreatic Lipase: A Review. Cairo, Egypt : Hindawi Publishing Corporation.

Shakya, A. (2016). Medicine Plants: Future source for new drugs. International Journal of Herbal Medicine, 59-64.

Shannon, L., Grove, K. A., Yennawar, N. H., \& Lambert, J. D. (2017). Inhibition of pancreatic lipase by black tea theaflavins: Comparative enzymology and in silico modeling studies. Food Chemistry, 296-300.

Sharma, R. (2012). Enzyme Inhibition and Bioapplications. Rijeka: InTechEurope.

Shaw, D. (1998). Risks or remedies? Safety aspects of herbal remedies in the UK. Journal of the Royal Society of Medicine, 294-296.

Sheikha, A. (2017). Biotechnology and Production of Anti-Cancer Compounds. St. West, Hamilton, Canada: Springer International Publishing AG.

Siewe-Ling, O., Suguna, P., How-Yee, L., \& Nalamolu, R. (2014). In Vitro Lipase Inhibitory Effect of Thirty Two Selected Plants in Malaysia. Asian Journal of Pharmaceutical and Clinical Research, 20-23.

Sikaris, B. (2004). The Clinical Biochemistry of Obesity. The Clinical Biochemist Review, 165-181.

Sirichai, A., Julnaryn, I., Araya, H., Benjanut, C., \& \& Kittana, M. (2012). Extracts of Plants Inhibit Pancreatic Lipase, Cholesterol Esterase and Cholesterol Micellization, and Bind Bile Acids. Food Technology, 11-16.

Sirichai, A., Pariwat, J., Pornsawan, P., Benjanut, C., Suwimol, S., \& Tipayanate, A. (2010). Evaluation of Alpha- glucosidase alpha-amylase and protein glycation inhibitory activities of edible plants. International Journal of Food Sciences and Nutrition, 295-305.

Sissi, W.-G., \& Iris, F. F. (2011). Herbal Medicine: A Growing Field with a Long Tradition. In W.-G. Sissi, \& F. B. Iris, Herbal Medicine (pp. 1-5). London: CRC Press/Taylor \& Francis. 
Smirin, P., Taler, D., Abitol, G., Brutman-Barazani, T., Kerem, Z., Sampson, S., \& Rosenweig, T. (2010). Sacropoteriumspinosum extract as an antidiabetic agent: in vitro and in vivo study. Journal of Ethnopharmacology, 10-17.

Soumya, D., \& Srilatha, B. (2011). Late Stage Complications of Diabetes and Insulin Resistance. Diabetes \& Metabolism, 1-7.

Sparg, S., Light, M., \& Van-Staden, J. (2004). Biological activities and distribution of plant saponins. Journal of Ethnopharmacology, 219-243.

Springob, K., \& Kutchan, T. (2009). Introduction to the Different of Natural Products. St. Louis, USA: Springer Science Business Media.

Stanley, D. (1999). South Pacific Organizer. Retrieved November 17, 2016, from Flora and Fauna of the South Pacific: http://www.southpacific.org/pacific/florafauna.html

Staunton, J., \& Weissman, K. (2001). Polyketide biosynthesis: a millenium review. Cambridge, UK: Natural Products Rep.

Strömstedt, A., Felth, J., \& Bohlin, L. (2014). Bioassays in natural product research - strategies and methods in the search for anti-inflammatory and antimicrobial activity. Phytochemical Analysis, 13-28.

Sukhde, S., Suman, P., Gennaro, L., \& Dev, D. (2008). Extraction Technologies for Medicinal and Aromatic Plants. Trieste: United Nations Industrial Development Organization and the International Centre.

Tabatabaei-Malazy, O., Larijani, B., \& Abdollahi, M. (2012). A Systematic Review of in vitro Studies Conducted on Effect of Herbal Products on Secretion of Insulin from Langerhans Islets. Journal of Pharmaceutical Science, 447-466.

Tan, S. Y., \& Tasumura, Y. (2015). Alexander Fleming (1881-1955): Discoverer of penicillin. Singapore Medical Journal, 366-367.

The Angiosperm Phylogeny Group. (2016). An update of the Angiosperm Phylogeny Group classification of orders and families of flowering plants. Botanical Journal of the Linnean Society, 1-20. 
The Plant List. (2010). Retrieved March 02, 2017, from Ochrosia: http://www.theplantlist.org/browse/A/Apocynaceae/Ochrosia/

Tiong, S. H., Looi, C. Y., Hazni, H., Arya, A., Paydar, M., Wong, W. F., . . . Awang, K. (2013). Antidiabetic and Antioxidant Properties of Alkaloids from Catharanthus roseus (L.) G. Don. Molecules, 9770-9784.

Tomohiro, I., Maria, D., \& Jun, K. (2011). Alpha- Glucosidase inhibitors from the bulb of Eleutherine americana. Food Chemistry, 308-311.

Tousch, D., Lajoix, A., Hosy, E., Azay-Milhau, J., Ferrare, K., Jahannault, C., . . . Petit, P. (2008). Chicoric acid, a new compound able to enhance insulin release and glucose uptake. Biochemical Biophysics Research Community, 131-135.

Tyler, V. E. (1999). Phytomedicines: Back to the Future. Journal of Natural Products, 1589-1592.

Uematsu, Y., Hirata, K., \& Saito, K. (2000). Spectrophotometric determination of saponin in Yucca extract used as food additive. Journal of AOAC International, $1451-1454$.

United States Department of Agriculture. (2010). Pacific Islands Area and Vegetative Guide. Washington: The U.S Department of Agriculture.

Urgan, S., \& Roessner, U. (2012). A historical overview of natural products in drug discovery. Metabolites, 303-333.

Van-Gils, C., \& Cox, P. (1994). Ethnobotany of nutmeg in the Spice Islands. Journal of Ethnopharmacology, 117-124.

Von Kruzeshtern, I. (1968). Voyage around the world in the years 1803, 1804, 1805, and 1806. Ridgewood: Gregg Press.

Wachsmuth, C., Vogl, F., \& Oefner, P. (2013). Modern Chemical Techniques. In T. Hyötyläinen, Chromatographi Methods in Metabolomics (pp. 87-113). London: Royal Society of Chemistry.

Wagenaar, M. M. (2008). Pre-fractionated microbial samples - the second generation natural products library at Wyeth. Molecules, 1406-1426. 
Walker, J. M. (2006). Natural Products Isolation. New Jersey: Humana Press Inc.

Wang, M., Carver, J. J., Phelan, V. V., Sanchez, L. M., Garg, N., Peng, Y., . . . Esquenazi, E. (2016). Sharing and community curation of mass spectrometry data with Global Natural Products Social Molecular Networking. Nature Biotechnology, 828-837.

Watson, J., \& Sparkman, O. (2007). Introduction of Mass Spectrometry: Instrumentation, Applications and Strategies for Data Interpretation. West Sussex, England: John Wiley \& Sons.

Wealth of India Division. (2000). The Wealth of India - A Dictionary for Information Resources on Plants, Animals and Minerals. New Delhi: National Institute of Science Communication and Information Resource (NISCAIR).

Wehmeier, U. (2003). The biosynthesis and metabolism of acarbose in Actinoplanes. Biocatalyss Biotransformation, 279-284.

Wehmeier, U., \& Piepersberg, W. (2004). Biotechnology and molecular biology of the $\alpha$-glucosidase inhibitor acarbose. Applied Microbiology Biotechnology, 613-625.

Whistler, A. (1984). Vegetation and Flora of the Aleipata Islands, Western Samoa. Pacific Science, 227-249.

Whistler, A. (1992). Flowers of the Pacific Island Seashore. Honolulu: Isle Botanica.

Whistler, A. (1992). Polynesian Herbal Medicine. Lawai, Hawaii: Everbest Printing Co., Ltd., Hong Kong.

Whistler, A. (1996). Samoan Herbal Medicine. Honolulu: Isle Botanica.

Whistler, A. (1998). A Study of the Rare Plants of American Samoa. Honolulu: The U.S. Fish and Wildlife Service.

Whistler, A. (2000). Plants in Samoan Culture. Honolulu: Isle Botanica.

Whistler, A. (2004). Rainforest Trees of Samoa. Honolulu: Isle Botanica. 
Whistler, A. (2011). The Rare Plants of Samoa. Honolulu: Conservation International.

WHO. (1985). Energy and protein requirements. Geneva: World Health Organisation Press.

WHO. (2014). Essential medicines and health products. Retrieved 11 22, 2016, from World Health Organisation: http://who.int/medicines/areas/traditional/en/

WHO. (2016). Global Report on Diabetes. France: World Health Organization Press.

Willis, K., \& McElwain, J. (2014). The Evolution of Plants. New York: Oxford University Press.

World Health Organisation . (1998). Medicinal Plants in the South Pacific. Manila: World Health Organisation.

World Health Organisation. (2010, July). Bulletin of the World Health Organisation. Retrieved August 23, 2015, from World Halth Organisation: http://www.who.int/bulletin/volumes/88/7/10-010710/en/

World Health Organisation. (2016). Global Health Observatory data. Retrieved September 09, 2016, from World Health Organisation: http://www.who.int/gho/ncd/risk_factors/obesity_text/en/

Xing, J., Xie, C., \& Lou, H. (2007). Recent applications of liquid chromatographymass spectrometry in natural products bioanalysis. Journal of Pharmaceutical and Biomedical Analysis, 368-378.

Xiong, F., Sun, X., Gan, L., Yang, X., \& Xu, H. (2006). Puerarin protects rat pancreatic islets from damage by hydrogen peroxide. Eurology Journal of Pharmacology, 1-7.

Yang, Y., Yu, L., Komaki, H., Oky, N., \& Igarashi, Y. (2016). Absolute configuration of NFAT-133, an aromatic polyketide with immunosuppressive and antidiabetic activity from actinomycetes. The Journal of Antibiotics, 69-71. 
Yibchok-anun, S., Adisakwattana, S., Yao, C., Sangvanich, P., Roengsumran, S., \& Hsu, W. (2006). Slow acting protein extract from fruit pulp of Momordicacharantia with insulin secretagogue and insulinomimetic activities. Biological Pharmacal Bulletin, 1126-1131.

Zhang, C., Parton, L., Ye, C., Krauss, S., Shen, R., Lin, C., . . L Lowell, B. (2006). Genipin inhibits UCP2-mediated proton leak and acutely reverses obesity- and high glucose-induced b cell dysfunction in isolated pancreatic islets. Cellular Metabolism, 417-427.

Zhang, J., Zhao, S., Yin, P., Yan, L., Han, J., Shi, L., . . . Ma, C. (2014). Alphaglucosidase Inhibitory Activity of Polyphenols from the Burs of Castanea mollissima Blume. Molecules, 8373-8386.

Zheng, C., Duan, Y., Gao, J., \& Ruan, Z. (2010). Screening for anti-lipase properties of 37 traditional Chinese medicinal herbs. Journal of Chinese Medicine Association, 319-333. 